\title{
Supported Gold Nanoparticles as Catalysts for the Oxidation of Alcohols and Alkanes
}

\author{
Sónia A. C. Carabineiro* \\ Centro de Química Estrutural, Instituto Superior Técnico, Universidade de Lisboa, Lisbon, Portugal
}

Supporting gold nanoparticles have shown to be extremely active for many industrially important reactions, including oxidations. Two representative examples are the oxidation of alcohols and alkanes, that are substrates of industrial interest, but whose oxidation is still challenging. This review deals with these reactions, giving an insight of the first studies performed by gold based catalysts in these reactions and the most recent developments in the field.

Keywords: gold, nanoparticles, carbon supports, metal oxides, alcohol, oxidation

\section{INTRODUCTION}

OPEN ACCESS

Edited by:

Jochen Lauterbach, University of South Carolina,

United States

Reviewed by:

Tomoo Mizugaki,

Osaka University, Japan

Andrea Gualandi,

University of Bologna, Italy

*Correspondence:

Sónia A. C. Carabineiro sonia.carabineiro@tecnico.ulisboa.pt

Specialty section: This article was submitted to Catalysis and Photocatalysis,

a section of the journal

Frontiers in Chemistry

Received: 24 June 2019 Accepted: 08 October 2019 Published: 05 November 2019

Citation:

Carabineiro SAC (2019) Supported Gold Nanoparticles as Catalysts for the Oxidation of Alcohols and Alkanes.

Front. Chem. 7:702.

doi: 10.3389/fchem.2019.00702
Heterogeneous catalysis by gold nanoparticles is now a "hot topic," as it can have applications in several industrially and environmentally important oxidation reactions (Thompson, 1998, 1999, 2006; Bond and Thompson, 1999, 2000; Sanchez et al., 1999; Haruta and Daté, 2001; Bond, 2002; Haruta, 2002, 2003, 2004, 2005; Ma et al., 2003; Corti et al., 2005; Bond et al., 2006; Hashmi and Hutchings, 2006; Carabineiro and Thompson, 2007, 2010; Corma and Garcia, 2008; Della Pina et al., 2008a, 2012; Hashmi and Rudolph, 2008; Song et al., 2010; Della Pina and Falletta, 2011; Pradal et al., 2011; Tsukuda et al., 2011; Mallat and Baiker, 2012; Rudolph and Hashmi, 2012; Takei et al., 2012; Liu X. Y. et al., 2013; Zhang and Ding, 2013; Majdalawieh et al., 2014; Takale et al., 2014; Alex and Tiwari, 2015; Biener et al., 2015; Freakley et al., 2015; Ishida et al., 2016; Pflasterer and Hashmi, 2016; Fang et al., 2017; Scurrell, 2017; Shahzad et al., 2017; Kim, 2018; Saldan et al., 2018; Zhao and Jin, 2018). Catalytic oxidations can be classified into two types (Sokolovskii, 1990): complete (or total) oxidation, used for catalytic destruction of various toxic compounds, and selective oxidation, used for organic compounds in fine chemistry, aiming at the synthesis of desired chemical products. Gold catalysts proved to be efficient for both types of oxidations (as shown on references cited above), including oxidation of CO, hydrogen production by water-gas shift (WGS), hydrogen purification by selective oxidation of $\mathrm{CO}$ in the presence of $\mathrm{H}_{2}$ (preferential oxidation, PROX), oxidative decomposition of volatile organic compounds (VOCs), selective oxidation of alcohols, hydrocarbons and sugars, among many others.

Gold nanoparticles also showed to be very good catalysts for the synthesis of fine chemicals, especially in selective oxidation (Biella et al., 2002a,b; Carrettin et al., 2002; Abad et al., 2005; Della Pina et al., 2008b, 2012; Hereijgers and Weckhuysen, 2009; Choudhary and Dumbre, 2011; Wu et al., 2011a,b,c; Biradar and Asefa, 2012; Xie et al., 2012; Wang H. et al., 2013; Sharma et al., 2016; Giorgi et al., 2017). This increasing interest is linked to environmental issues related with the need of more efficient processes and with new methods for synthesis of nanoparticles. As widely known in catalysis by gold, the need of small sized nanoparticles is mandatory (see references cited in the first paragraph). Gold can be a quite efficient catalyst, allowing high activities and selectivities, in some cases in solvent-free conditions, and without the use for harsh conditions 
(powerful oxidants, high temperatures and pressures), allowing mild conditions to be used (Biella et al., 2002a, 2003c; Pattrick et al., 2004; Moreno et al., 2013; Liu et al., 2014a; Villa et al., 2015b; Giorgi et al., 2017; Zhao and Jin, 2018).

Selective oxidation processes are used to activate raw materials and transform them into useful products and chemical intermediates (Carabineiro and Thompson, 2007, 2010). Some examples of such raw materials are alkanes and alcohols, which are of industrial interest, but are often characterized by low conversions and the formation of unwanted by-products. This review paper refers to the oxidations of those substrates, referring the first studies performed with gold based catalysts and the latest developments achieved so far, and it also includes a brief introduction about the main methods used for the preparation of this kind of catalysts.

\section{GOLD CATALYST PREPARATION METHODS}

There are several techniques described in the literature to obtain well-dispersed gold nanoparticles on several supports. The most common, leading to efficient catalysts, are referred below.

\section{Sol-Immobilization (COL)}

Colloidal Au can be synthesized in solution in the presence of an excess of stabilizing (capping) agents/ligands or surfactants (which can be as thiols, amines, polymers, phosphines, etc). This provides control of the size and shape of the formed nanoparticles, preventing them from agglomerating. Colloids prepared by reduction of chloroauric acid by citric acid, $\mathrm{NaBH}_{4}$, or other reducing agents, can be used to prepare gold on carbon or oxide supports, by deposition from the colloid, to give good dispersions of gold (Carabineiro and Thompson, 2010). The 1\% $\mathrm{Au} /$ carbon prepared by this method by Rossi's group (Bianchi et al., 2000, 2003; Porta et al., 2000, 2002; Biella et al., 2002a,b, 2003a,b; Porta and Rossi, 2003; Comotti et al., 2004, 2005; Beltrame et al., 2006; Della Pina et al., 2007, 2008a,b, 2012; Chen et al., 2008) was distributed by the World Gold Council as a reference catalyst for the scientific community (World-GoldCouncil, 2003). Other authors, including Carabineiro and coauthors, also successfully used this method to prepare active $\mathrm{Au} /$ carbon materials (Onal et al., 2004; Demirel-Gulen et al., 2005; Demirel et al., 2007b,c; Li B. D. et al., 2009; Zhu et al., 2010; Rodrigues et al., 2011, 2012a,b; Carabineiro et al., 2013; Ribeiro et al., 2017a,b; Tofighi et al., 2017).

Usually, a stabilizing agent is used in excess in order to effectively stabilize the nanoparticles. Then the colloids are deposited on the surface of the support to synthesize a heterogeneous catalyst. Thus, the stabilizing agent present in the colloidal solution might also form bonds with the support, and that can be detrimental as it might (partially) block the active metal sites (Donoeva and De Jongh, 2018). Also, the presence of stabilizing agents on the surface makes it more complicated to interpret catalytic results, since one does not know the effects they might have on the reaction ( Niu and $\mathrm{Li}$, 2014). Polyvinylpyrrolidone (PVP) is one of the most commonly used stabilizing agents (Onal et al., 2004; Demirel-Gulen et al., 2005; Demirel et al., 2007b,c; Shi et al., 2010; Wu J. et al., 2010; Zhu et al., 2010; Rodrigues et al., 2011, 2012b; Behera and Ram, 2012; Prati and Villa, 2012; Carabineiro et al., 2013; Koczkur et al., 2015; Du et al., 2016; Louie et al., 2017; Ribeiro et al., 2017a,b; Tofighi et al., 2017). Thus, the, removal of these compounds, used in the preparation, is of crucial importance. Usually, they are removed by decomposition at $\sim 300^{\circ} \mathrm{C}$ (Onal et al., 2004; Demirel-Gulen et al., 2005; Demirel et al., 2007b,c; Zhu et al., 2010; Rodrigues et al., 2011, 2012b; Carabineiro et al., 2013; Ribeiro et al., 2017a,b; Tofighi et al., 2017). However, UV light, ozone and solvothermal treatments can also be used (Niu and Li, 2014). The progresses on this method have been recently reviewed (Prati and Villa, 2014).

\section{Impregnation (IMP) and Double Impregnation (DIM)}

Impregnation (IMP) is the classical method used to prepare supported metal catalysts and consists of simply impregnating a support with a solution of a metal salt. This usually involves suspending the support in a larger volume of solution, from which the solvent is then removed. An alternative variation is the so-called incipient wetness (IW) technique, in which the pores of the support are filled with the solution.

Common gold precursors like chloroauric acid $\left(\mathrm{HAuCl}_{4}\right)$ or auric chloride $\left(\mathrm{AuCl}_{3}\right.$ or $\left.\mathrm{Au}_{2} \mathrm{Cl}_{6}\right)$ are usually used but complex salts, such as potassium aurocyanide $\left(\mathrm{KAu}(\mathrm{CN})_{2}\right)$ and the ethylenediamine complex $\left[\mathrm{Au}(\mathrm{en})_{2}\right] \mathrm{Cl}_{3}$, are also alternatives. Traditional supports are silica, alumina and magnesia, but titania, alumina, boehmite $(\mathrm{AlO}(\mathrm{OH}))$, ferric oxide $\left(\alpha-\mathrm{Fe}_{2} \mathrm{O}_{3}\right)$ and magnesium hydroxide can also be used (Bond and Thompson, 1999). After drying, the precursor needs calcination at temperatures as high as $800^{\circ} \mathrm{C}$. Reduction by hydrogen at $250^{\circ} \mathrm{C}$, aqueous oxalic acid at $40^{\circ} \mathrm{C}$ or aqueous magnesium citrate (Bond and Thompson, 1999) is also needed.

Conventional impregnation techniques are not so adequate for gold catalysts as they result in large gold particles, which are more likely to be inactive (Bamwenda et al., 1997; Bond and Thompson, 1999; Lee and Gavriilidis, 2002; Carabineiro and Thompson, 2007, 2010; Carabineiro et al., 2010g; Santos et al., 2010). Moreover, it is difficult to obtain high dispersions of gold. Also, during calcination, the gold particles experience severe agglomeration as $\mathrm{HAuCl}_{4}$ interacts only weakly with the support (Haruta, 1997; Lee and Gavriilidis, 2002; Meyer et al., 2004; Carabineiro and Thompson, 2007). An example is displayed in Figure 1a. A transmission electron microscopy (TEM) image shows a $400 \mathrm{~nm}$ particle of $\mathrm{Au}$ on a ceria support.

The presence of chloride is detrimental, since it increases the mobility of $\mathrm{Au}$ on the support, leading to the sintering of gold particles (Oh et al., 2002; Kung et al., 2003; Bond et al., 2006; Carabineiro and Thompson, 2007, 2010; Carabineiro et al., 2010g). Gold and chloride ions combine to form bridges, favoring the growth of the particles upon heating (Hargittai et al., 2001; Schulz and Hargittai, 2001). The early use of classical impregnation techniques was the main reason why Au was 

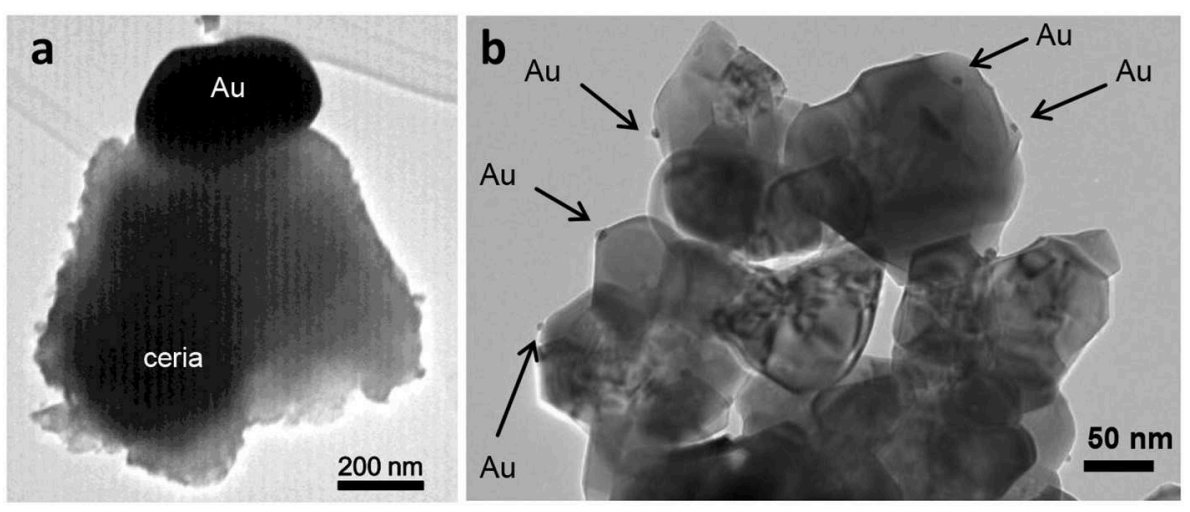

FIGURE 1 | TEM images of $\mathrm{Au} / \mathrm{CeO}_{2}$ prepared by traditional impregnation (a) and double impregnation (b). Adapted from Carabineiro et al. (2010e,g), Copyright (2010), with permission from Elsevier.

thought for so long to be inactive for catalysts, in comparison with other noble metals, like Pt and Pd.

However, Datye and co-workers reported an alternative impregnation method for supporting gold on alumina using $\mathrm{HAuCl}_{4}$ (Xu et al., 2003). Since impregnation under acidic conditions leads to poor dispersion of $\mathrm{Au}$ and the resulting catalysts are not very active, a two-step procedure has been developed: In the first step, gold chloride was adsorbed on alumina from an acidified solution. After washing off the excess gold precursor, the solid was treated with strong base to convert the chloride to an adsorbed hydroxide. Drying and calcining at $400^{\circ} \mathrm{C}$ yielded a catalyst with gold particles having an average diameter of $2.4 \mathrm{~nm}$, with good activity, and stability to hydrothermal sintering. This new method is a successful impregnation preparative route for gold catalysts, allowing them to have durability at least until $600^{\circ} \mathrm{C}$, since no chloride is present.

Also Bowker et al. refer the use of a double impregnation method (DIM) that removes chloride (Soares et al., 2006; Bowker et al., 2007). Briefly, this method consists in impregnating the support with an aqueous solution of the gold precursor $\left(\mathrm{HAuCl}_{4}\right)$ and then with a solution of $\mathrm{Na}_{2} \mathrm{CO}_{3}$, under constant ultrasonic stirring, followed by washing with water and drying in an oven overnight at $120^{\circ} \mathrm{C}$. These authors used this method to prepare $\mathrm{Au} / \mathrm{TiO}_{2}$ materials, and state that it represents an environmentally and economically favorable route to the production of highly active gold catalysts. This method has been used with great success for other supports, such as metal oxides and carbon materials by Carabineiro et al. (2010a,b,c,e,f, 2011a,b, 2012a,b, 2013, 2016), Bastos et al. (2012), Rodrigues et al. (2012b), Silva C. G. et al. (2014), Soria et al. (2014), Pérez et al. (2016). One example is shown in Figure 1b, where much smaller and better dispersed gold nanoparticles are seen on ceria. However, the sol immobilization method is better for carbon catalysts (Rodrigues et al., 2012b; Carabineiro et al., 2013), as stated above.

\section{Co-Precipitation (CP)}

This is one of the simplest ways to prepare gold catalysts and it was one of the first to be used (Haruta et al.,
1987; Bond et al., 2006; Carabineiro and Thompson, 2007). Its discovery was by serendipity in 1987: Haruta's group mixed $\mathrm{HAuCl}_{4}$, iron nitrate and sodium carbonate, and produced a $\mathrm{Au} / \mathrm{Fe}_{2} \mathrm{O}_{3}$ composite with low $\mathrm{Au}$ nanoparticle size (Haruta et al., 1987). Back then, classical impregnation was the method often used to prepare PGM catalysts, and it did not work when used for gold, as said above. Haruta's $\mathrm{Au} / \mathrm{Fe}_{2} \mathrm{O}_{3}$ material showed unprecedented catalytic activity for $\mathrm{CO}$ (and hydrogen) oxidation, being active at sub-ambient temperatures, a range of temperatures never reached before for this reaction (Haruta et al., 1987) [as gold exhibits low affinity for CO adsorption below $200^{\circ} \mathrm{C}$ (Vigneron and Caps, 2016)].

The method is still widely applied (Sreethawong et al., 2011; Liu R. et al., 2013; Tran Thi Minh et al., 2013; Wang H. et al., 2013; He et al., 2016; Ilieva et al., 2016; Liu et al., 2016; Mishra et al., 2016; Li et al., 2018; Patil et al., 2018). It consists on having an aqueous solution of $\mathrm{HAuCl}_{4}$ and water-soluble metal salts, such as a nitrate, being poured into an aqueous alkaline solution $\left(\mathrm{Na}_{2} \mathrm{CO}_{3}\right.$ and/or $\left.\mathrm{NH}_{4} \mathrm{OH}\right)$ and stirred for a few minutes. The two hydroxides (or hydrated oxides) are then precipitated simultaneously. After aging for about $1 \mathrm{~h}$, the precipitates are washed several times with water and filtered. The hydroxide and/or carbonate mixture is dried overnight and calcined to obtain powder catalysts (Lee et al., 2001; Seker and Gulari, 2002; Carabineiro and Thompson, 2007). Then a reduction step is necessary. It is possible that some catalysts prepared by this method contain a significant concentration of $\mathrm{Na}^{+}$and $\mathrm{Cl}^{-}$ ions, if a metal chloride is used as precursor. Both can act as a catalyst poison (Haruta, 1997; Bond and Thompson, 1999; Oh et al., 2002; Bond et al., 2006; Carabineiro and Thompson, 2007, 2010; Carabineiro et al., 2010g; Zhang et al., 2013). However, alkali have also been reported to enhance the activity of $\mathrm{Au}$ catalysts (Broqvist et al., 2004; Huang et al., 2011a,b; Li Y. et al., 2011; Nepak and Srinivas, 2015; Ribeiro et al., 2017a,b; Rodriguez et al., 2018). An understanding of the effect of residual $\mathrm{Na}$ would be an excellent way to advance gold research (Veith, 2016). The applicability of this technique is limited to metal hydroxides or carbonates that can be co-precipitated with $\mathrm{Au}(\mathrm{OH})_{3}$. 


\section{Deposition Precipitation (DP)}

This method is convenient and can be used for producing commercial gold supported catalysts (Haruta, 2003; Carabineiro and Thompson, 2007) and applied to the widest range of different support materials (Wolf and Schüth, 2002). It was discovered also by Haruta's group in 1991 (Tsubota et al., 1991) and is still widely used (Moreau et al., 2005; Sangeetha et al., 2009; Wei et al., 2010; Tran et al., 2011; Sanada et al., 2013; Soria et al., 2014; Zahoranova et al., 2015; Zamaro et al., 2015; Pérez et al., 2016; Priecel et al., 2016; Carabineiro et al., 2017; Chen B. B. et al., 2017; Kyriakou et al., 2017; Martins et al., 2017; Rodrigues et al., 2017a,b; Vourros et al., 2017; Yu et al., 2017; Jin et al., 2018). The precursor to the active species is brought out of solution in the presence of a suspension of the support, usually by raising the $\mathrm{pH}$ in order to precipitate a hydroxide. The surface of the support acts as nucleating agent, and most of the active precursor ends up being attached to the support. After the $\mathrm{pH}$ of an aqueous solution of $\mathrm{HAuCl}_{4}$ is adjusted with $\mathrm{NaOH}$, to a fixed point in the range of 6-10, a metal oxide support can be immersed in the solution. The partially hydrolysed species $\left[\mathrm{Au}(\mathrm{OH})_{\mathrm{n}} \mathrm{Cl}_{4-\mathrm{n}}\right]^{-}$ $(\mathrm{n}=1-3)$ then react with the surface of the support. Aging for about $1 \mathrm{~h}$ results in the deposition of $\mathrm{Au}(\mathrm{OH})_{3}$, exclusively on the surface of the metal oxide support, if the concentration and temperature are properly chosen (Haruta, 1997; Bond and Thompson, 1999; Carabineiro and Thompson, 2007).

The influence of the $\mathrm{pH}$ on the particle size of $\mathrm{Au}$ is remarkable, as above $\mathrm{pH}$ 6, the main species of $\mathrm{Au}$ in solution are transformed from $\mathrm{AuCl}_{4}^{-}$to $\left[\mathrm{Au}(\mathrm{OH})_{n} \mathrm{Cl}_{4-n}\right]^{-}(\mathrm{n}=1-3)$, and the mean particle diameters of $\mathrm{Au}$ in the calcined catalysts become smaller than $4 \mathrm{~nm}$ (Haruta, 1997). Several authors claim that a $\mathrm{pH}$ ranging from 7 to 8 is preferable depending on the oxide support (Wolf and Schüth, 2002; Kung et al., 2003; Wang et al., 2003; Zahoranova et al., 2015), since at this $\mathrm{pH}$, the value of $n$ is close to 3 , and at lower values of $\mathrm{pH}$, there is less hydrolysis of the $\mathrm{Au}-\mathrm{Cl}$ bond. However, Bond and coworkers (Moreau et al., 2005) showed that $\mathrm{pH} 9$ was the optimum value to be reached during deposition precipitation for $\mathrm{Au} / \mathrm{TiO}_{2}$ catalysts, and that value has been used by Carabineiro and coauthors to prepare different Au/oxide catalysts (Soria et al., 2014; Pérez et al., 2016; Carabineiro et al., 2017; Kyriakou et al., 2017; Martins et al., 2017; Rodrigues et al., 2017a,b; Vourros et al., 2017). Some examples of catalysts thus obtained are shown in Figure 2. At that $\mathrm{pH}$, the main species in solution are anionic $\mathrm{Au}$ complexes, with almost no chloride, while at lower values, the Au complexes contain chloride, Au particles are larger, and activities lower. However, the optimum $\mathrm{pH}$ range for precipitation that also assures an efficient metal utilization (>90\%) depends on the isoelectric point of the supporting material (Prati and Villa, 2012).

An alternative method for adjusting the $\mathrm{pH}$ is to use urea (Bond and Thompson, 1999; Dobrosz et al., 2005; Zanella et al., 2005; Gluhoi and Nieuwenhuys, 2007; Hugon et al., 2010). This consists in the slow decomposition of urea in the solution. Hydroxyl ions are generated slowly and uniformly throughout the liquid phase, and their concentration is always low because they are consumed almost as soon as they are formed. Louis and co-workers found that the use of urea yielded the same gold particle sizes as those obtained using $\mathrm{NaOH}(2-3 \mathrm{~nm})$, and no sodium poison was introduced (Zanella et al., 2005).

A constraint of the deposition-precipitation is that it is not very suitable for activated carbon (Prati and Martra, 1999; Haruta, 2003; Carabineiro and Thompson, 2007, 2010; Prati and Villa, 2012) or zeolites (Lin and Wan, 2003), due to their high isoelectric point [although some recent publications showed better results for these materials, especially after an acidic treatment (Cardenas-Lizana et al., 2015; Behravesh et al., 2017)]. Deposition-precipitation has the advantage over co-precipitation in that all of the active component remains on the surface of the support and none is buried within it (Bond and Thompson, 1999; Wang et al., 2003; Carabineiro and Thompson, 2007). Also, it gives narrower particle size distributions, but it is recommended that the support should have a surface area of at least $50 \mathrm{~m}^{2} / \mathrm{g}$ (Bond and Thompson, 1999; Carabineiro and Thompson, 2007).

\section{Liquid-Phase Reductive Deposition (LPRD)}

This method was first used by Sunagawa et al. and consists of mixing a solution of the gold precursor $\left(\mathrm{HAuCl}_{4}\right)$ with a solution of $\mathrm{NaOH}$ with stirring at room temperature (Sunagawa et al., 2008). The resulting solution is aged for $24 \mathrm{~h}$, in the dark, at room temperature, to complete the hydroxylation. Then, the appropriate amount of support is added to the solution and, after ultrasonic dispersion for $30 \mathrm{~min}$, the suspension is aged in the oven at $100^{\circ} \mathrm{C}$ overnight. The resulting solid is washed repeatedly with distilled water for chloride removal and dried in the oven at $100^{\circ} \mathrm{C}$, overnight.

The selective reductive deposition is performed by adsorption of the gold ions onto the surfaces where the reduction takes place. Thus, the initial adsorption is the key feature of this technique, and the key points are precise control of the metal complex by adjusting solute conditions, such as composition and structure of the metal complex; storing of the suspension until the equilibrium composition is attained, and aging the suspension at a controlled temperature. This method was later used by Carabineiro and co-authors to successfully prepare $\mathrm{Au}$ nanoparticles supported on various carriers (Carabineiro et al., 2010c,g, 2012b; Santos et al., 2010, 2014; Rodrigues et al., 2012b; Soria et al., 2014; Pérez et al., 2016).

\section{lon-Exchange}

In this method, ions on the surface of the support are replaced by gold ions. The procedure is especially effective with zeolites. But the introduction of catalytically active species into the cavities of these materials, as opposed to placing them on their external surface, presents certain difficulties, namely the lack of suitable cations or cationic complexes (Bond and Thompson, 1999). Nevertheless, different kinds of Au/zeolite systems have been prepared this way (Kang and Wan, 1995, 1997; Horvath et al., 2001; Chen et al., 2005; Magadzu et al., 2007; Tuzovskaya et al., 2007; Bogdanchikova et al., 2008; Sierraalta et al., 2008; Qi et al., 2012; Sanada et al., 2013; Zeng et al., 2014; Zamaro et al., 2015; Emayavaramban et al., 2016b; Chen B. B. et al., 2017).

Pitchon and co-workers have developed a novel method for preparing supported gold catalysts based on the direct anionic 


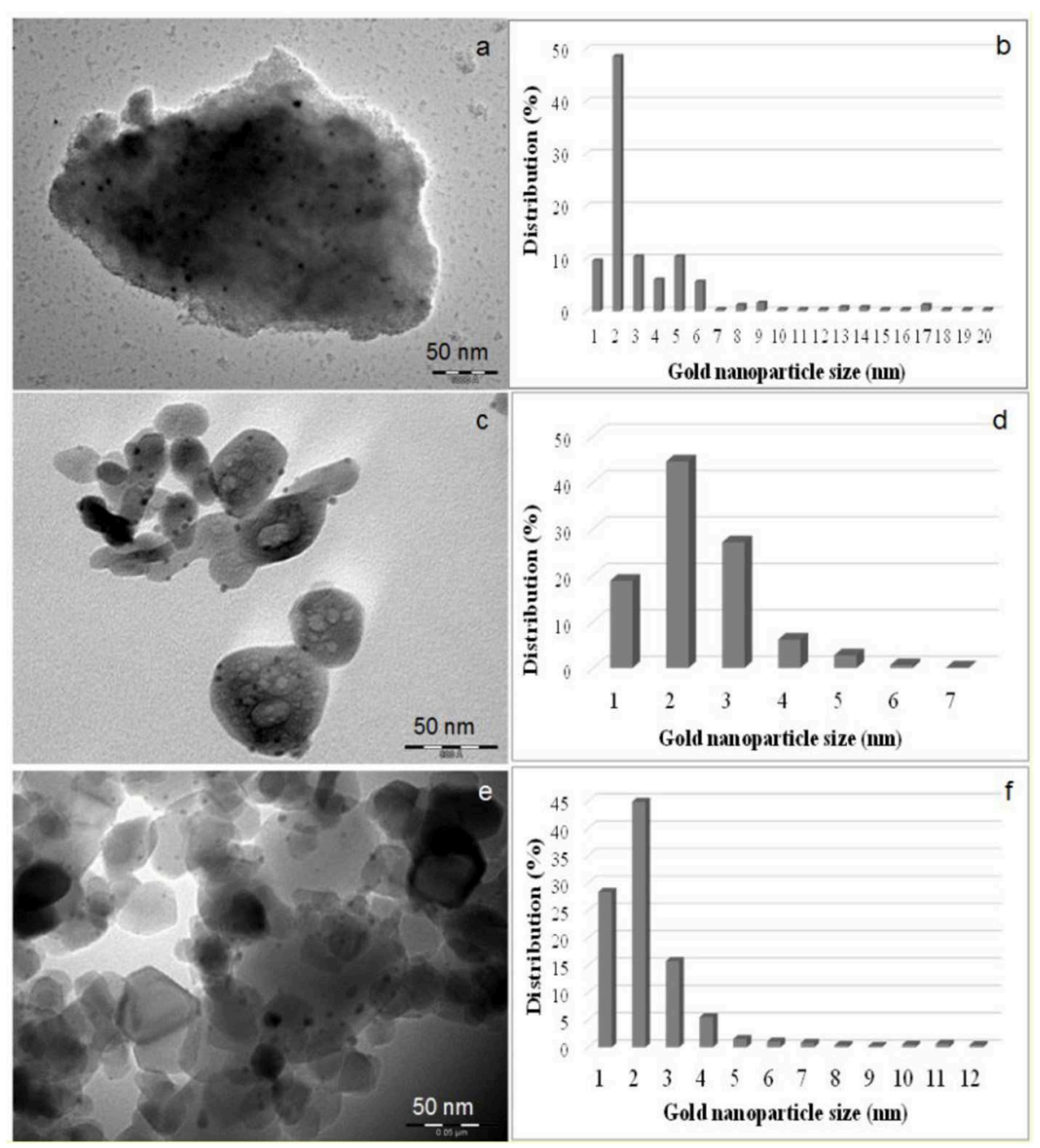

FIGURE 2 | TEM images of $\mathrm{Au} / \mathrm{Al}_{2} \mathrm{O}_{3}$ (a), $\mathrm{Au} / \mathrm{Fe}_{2} \mathrm{O}_{3}$ (c), and $\mathrm{Au} / \mathrm{TiO} \mathrm{O}_{2}$ (e) along with the corresponding size distribution histograms of gold nanoparticles (b,d,f). Used with permission from Martins et al. (2017). Copyright (2017) Wiley.

exchange (DAE) of the gold species with the hydroxyl groups of the support (Ivanova et al., 2004, 2006a,b; Dobrosz et al., 2005; Dobrosz-Gomez et al., 2009; Azizi et al., 2010; Liao et al., 2012). An aqueous solution of $\mathrm{HAuCl}_{4}$ is added to the support, heated to $70^{\circ} \mathrm{C}$ and aged for $1 \mathrm{~h}$. The slurry is then filtered, washed with warm water, dried in an oven at $120^{\circ} \mathrm{C}$, overnight, and calcined in air at $300^{\circ} \mathrm{C}$, for $4 \mathrm{~h}$. In order to completely remove the chloride ions, these authors take a fraction of the catalyst after drying and wash it with a concentrated solution of ammonia. However, this may be a dangerous procedure, since gold oxide and ammonia sometimes produce fulminating gold, which is explosive (Fisher, 2003; Bond et al., 2006; Carabineiro and Thompson, 2007, 2010; Steinhauser et al., 2008).

\section{Photochemical Deposition (PD)}

This method allows metal deposition over semiconductor materials, with simultaneous reduction of metal ions by the electrons of the conduction band (Carabineiro et al., 2010d). This process can be enhanced by addition of "sacrificial electron donors" (such as formaldehyde, methanol or 2-propanol) that can supply an almost unlimited amount of electrons. Photodeposition takes place at, or near, the photoexcited sites, leading to an enhanced dispersion. The gold precursor is usually dissolved in water and a sacrificial electron donor, mixed with the support, sonicated and photodeposited using a UV lamp.

This method has been used for preparation of gold catalysts, mostly on $\mathrm{TiO}_{2}$ (Wang et al., 1998, 2011; Chan and Barteau, 2005; He et al., 2006; Ruvarac-Bugarcic et al., 2008; Hidalgo et al., 2009, 2011; Sangeetha et al., 2009; Yang et al., 2009; Yogi et al., 2009; Carabineiro et al., 2010d; Kydd et al., 2010; Murcia-Mesa et al., 2010; Tanaka et al., 2012, 2014; Mei et al., 2013; Song et al., 2015; Negishi et al., 2017). Carabineiro et al. used it for the first time to deposit $\mathrm{Au}$ on $\mathrm{ZnO}$ supports (Carabineiro et al., 2010c,d). Other authors also prepared Au/ZnO (Naknam et al., 2009; Fernando et al., 2016; Wang X. W. et al., 2016; Andrade et al., 2017), and $\mathrm{Au}$ on other supports, such as $\mathrm{CeO}_{2}, \mathrm{C}_{3} \mathrm{~N}_{4}, \mathrm{CdS}, \mathrm{ZrO}_{2}, \mathrm{CuCrO}_{2}$, quartz, etc. (Boitsova et al., 1999; Kydd et al., 2010; Kominami 
et al., 2011; Chiu et al., 2014; Jiang et al., 2015; Singh and Pal, 2015; Xue et al., 2015).

\section{Ultrasonication (US)}

This method is similar to PD but without photodeposition; instead the sample is sonicated during $8 \mathrm{~h}$ (Carabineiro et al., 2010c). The procedure was a serendipitous discovery made by Carabineiro et al. when attempting to prepare gold on zinc oxide by $\mathrm{PD}$ [the $\mathrm{ZnO}$ support used was prepared by chemical vapor deposition, $\mathrm{ZnO}_{\mathrm{CVD}}$, according to a previously described procedure (Bacsa et al., 2009)]. The Au/ZnO sample was supposed to be sonicated for $30 \mathrm{~min}$ (then following the photodeposition step), but it was left in the fume hood and sonicated for $8 \mathrm{~h}$. After that time, the mixture showed a deep purple color, similar to the samples prepared by other methods. So, it was washed and dried normally. The obtained material $\left(\mathrm{Au} / \mathrm{ZnO}_{\mathrm{CVD}} \mathrm{US}\right)$ was tested for $\mathrm{CO}$ oxidation and turned out to be the most active catalyst of the study (Carabineiro et al., 2010c). A TEM image with the respective histogram of size distribution is shown in Figure 3. US was also used by the same authors to prepared $\mathrm{Au}$ on $\mathrm{Fe}_{2} \mathrm{O}_{3}$ (Carabineiro et al., 2012a), $\mathrm{MgO}$ (Carabineiro et al., 2011b), $\mathrm{CuO}, \mathrm{NiO}$, $\mathrm{La}_{2} \mathrm{O}_{3}$, and $\mathrm{Y}_{2} \mathrm{O}_{3}$ materials (Carabineiro et al., 2011a), however the results obtained were not as good as those on $\mathrm{Au} / \mathrm{ZnO}$ (Carabineiro et al., 2010c).

\section{Vapor-Phase Methods and Grafting}

These methods are similar, differing only if a solvent is present or not. In the vapor-phase method (Chemical Vapor Deposition), a stream of a volatile compound of gold is transported onto a high area support by an inert gas and it reacts chemically with the surface of the support to form a precursor to the active species (Haruta, 1997; Carabineiro and Thompson, 2007, 2010). The most widely used gold precursor is $\mathrm{AuCl}_{3}$ or $\mathrm{HAuCl}_{4}$, but other substances have also been used, mainly to prevent chloride contamination. Gold particles have successfully been incorporated into $\mathrm{TiO}_{2}, \mathrm{WO}_{3}$, and $\mathrm{MoO}_{3}$ thin films using a single step process by this technique (Manna et al., 2016). Recently, it was shown that chemical vapor deposition can be used to synthesize gold nanocrystals with various morphologies, such as prisms, icosahedrons, and 5-fold twinned decahedrons on silicon substrates (Manna et al., 2016). The advantage of this method is that high-quality anisotropic crystals of gold can be produced without the need for surfactants or templates.

In Physical Vapor Deposition, gold is vapourized from a target under vacuum and deposited on an oxide support or carbon under high vacuum conditions (Carabineiro and Thompson, 2010). The 3M company in Minnesota (USA) has found that very active gold nanocatalysts can be prepared this way on a wide range of supports, including some that are water soluble or not suitable for deposition-precipitation, like $\mathrm{SiO}_{2}$ (Brey et al., 2005; Brady et al., 2006). This method is low-cost, has great reproducibility, does not need washing and thermal treatment steps, as do those materials resulting from solution preparation methods, and has no toxicity hazards. Recently, gold nanoparticles with high thermal stability (up to $600^{\circ} \mathrm{C}$ ) were supported on $\mathrm{Al}_{2} \mathrm{O}_{3}$, using this technique (Smirnov et al., 2016).

In the grafting method, a gold complex in solution reacts with the surface of a support, forming species convertible to a catalytically active form. Thus, gold phosphine complexes have been grafted onto the surface for a number of freshly precipitated wet hydroxides (Yuan et al., 1997; Kozlova et al., 1998, 1999; Bond and Thompson, 1999; Kozlov et al., 1999, 2000; Olea and Iwasawa, 2004; Carabineiro and Thompson, 2007), since they have many surface $-\mathrm{OH}$ groups reactive to the $\mathrm{Au}$ compounds. Vacuum-drying at room temperature and temperature-programmed calcination in air follows, causing simultaneous transformation of both precursors to gold particles and oxides, respectively, under their chemical interactions by temperature-programmed calcination. $\mathrm{Au}$-phosphine complexes are choice candidates for metal precursors because they thermally decompose to Au metal in a temperature range similar to that used for the transformation of wet metal hydroxides to oxides. Moreover, the phosphine ligands are expected to retard the growth to large $\mathrm{Au}$ metallic particles. Gold can be deposited on $\mathrm{SiO}_{2}, \mathrm{MCM}-41, \mathrm{SiO}_{2}-\mathrm{Al}_{2} \mathrm{O}_{3}$, and activated carbon, as nanoparticles with high dispersion by the gas-phase grafting of an acetylacetonate complex of gold, while liquid-phase preparation methods are not that effective with these supports (Okumura et al., 2003).

\section{Bi- and Tri-Metallic Gold Catalysts}

Since gold is already established on its own, more advances are always expected when it is combined with other metals, in order to increase its activity/selectivity (Carabineiro and Thompson, 2007). Gold-based bimetallic catalysts showed great potential for many important chemical transformation reactions, owing to their good activity and high selectivity under relatively mild conditions, in reactions such as selective oxidation, selective hydrogenation, $\mathrm{C}-\mathrm{C}$ coupling and photocatalysis, as recently reviewed (Zhao and Jin, 2018). There are many cases in the literature of bimetallic gold catalysts prepared by several techniques, as shown in several recent reviews (Kharisov et al., 2009; Li B. D. et al., 2009; Shah et al., 2012; Zhao et al., 2013; Hutchings, 2014; Freakley et al., 2015; Villa et al., 2015c; Alshammari et al., 2016; Louis, 2016; Priecel et al., 2016; Zhang L. et al., 2016).

\section{Post-treatment and Storage}

After preparing the gold-based catalyst, a variety of posttreatment conditions can be used, including calcination or reduction (Tsubota et al., 1998; Kozlov et al., 1999; Boccuzzi et al., 2001; Fu et al., 2003; Moreau et al., 2005; Bond et al., 2006; Ivanova et al., 2006a; Carabineiro and Thompson, 2007, 2010; Huang et al., 2011b; Carabineiro et al., 2012b; Ayastuy et al., 2016, 2017). It is worth to note that many catalysts are used effectively without any need of such treatments. In fact, there are times when reduction or calcination is even detrimental (Bond and Thompson, 2000; Moreau et al., 2005). The size of the gold particles can also influenced by the thermal treatment (Bond et al., 2006; Carabineiro and Thompson, 2007, 2010). Nevertheless, samples prepared by the sol-method described 


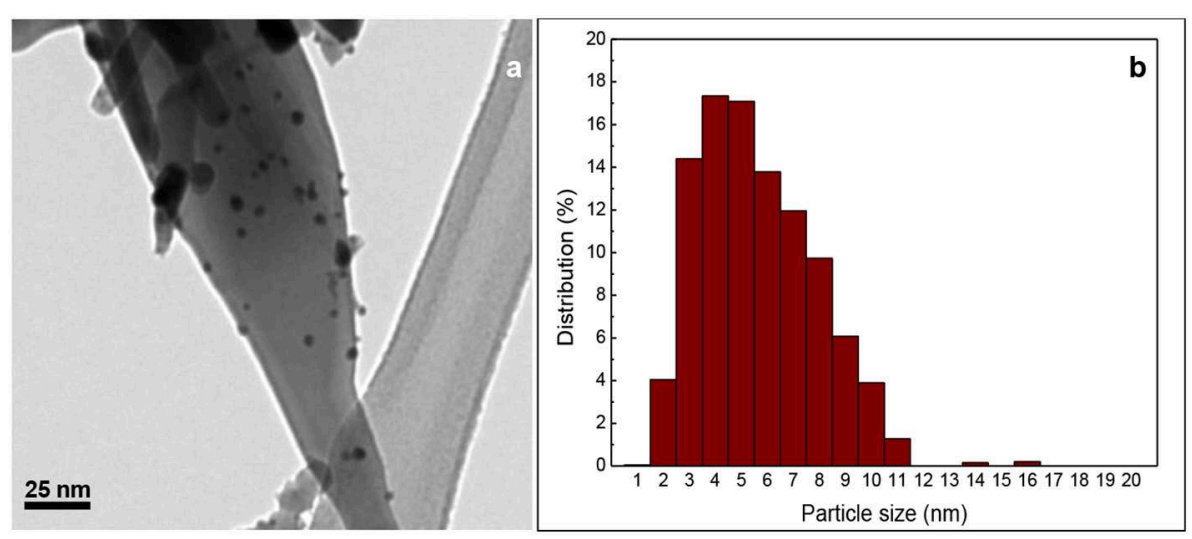

FIGURE 3 | (a) TEM image of $\mathrm{Au} / \mathrm{ZnO}_{\mathrm{CVD}}$ prepared by US (support prepared by chemical vapor deposition) and (b) Au nanoparticle size distribution. Reprinted from Carabineiro et al. (2010c), Copyright (2010), with permission from Elsevier.

above, are often heat treated to decompose the organic scaffold (Onal et al., 2004; Demirel-Gulen et al., 2005; Demirel et al., 2007b,c; Li B. D. et al., 2009; Zhu et al., 2010; Rodrigues et al., 2011, 2012b; Ribeiro et al., 2017a,b; Tofighi et al., 2017).

It is recommended that "as prepared" samples are stored in a refrigerator at $0^{\circ} \mathrm{C}$ and that calcined catalysts should also be kept cold, and that, after drying, samples are kept in a vacuum desiccator in the dark, with reduction being performed immediately before use (Zanella and Louis, 2005; Lee et al., 2007; Wu et al., 2008; Raphulu et al., 2009; Carabineiro and Thompson, 2010; Wei et al., 2010; Tran et al., 2011).

\section{SELECTIVE OXIDATION USING GOLD CATALYSTS}

Prati and Rossi's group studied the liquid phase oxidation of several organic substrates (alcohols, sugars, aldehydes, amines, imines, etc.), showing that $\mathrm{Au}$ /carbon was the preferred catalyst (Prati and Rossi, 1998; Prati and Martra, 1999; Bianchi et al., 2000, 2003, 2005; Porta et al., 2000, 2002; Biella et al., 2002a,b, 2003a,b,c; Porta and Rossi, 2003; Comotti et al., 2004, 2005; Porta and Prati, 2004; Prati and Porta, 2005; Beltrame et al., 2006; Della Pina et al., 2007, 2008a,b, 2012; Della Pina and Falletta, 2011; Prati and Villa, 2012, 2014; Prati et al., 2012, 2018; Wang D. et al., 2013; Villa et al., 2015b,c; Dimitratos et al., 2016; Jouve et al., 2018; Motta et al., 2018), compared to silica, alumina or titania (Porta et al., 2000, 2002). The method dealing with immobilization of colloidal particles (COL) was one of the best preparation procedures used (Prati and Martra, 1999; Villa et al., 2013b; Prati and Villa, 2014; Jouve et al., 2018), and narrow nanoparticle size distribution was obtained (around 3-6 nm). Carbon supports are naturally microporous thus providing a protection for the small Au nanoparticles, allowing to limit their diameter.

Gold catalysts also showed better resistance to deactivation and poisoning. These are limiting factors in liquid phase oxidation (Bond et al., 2006; Carabineiro and Thompson, 2007, 2010).

\section{ALCOHOL OXIDATION}

The liquid phase oxidation of alcohols is a good example of a selective oxidation reaction, important in both academia and industry, which is an interesting path for obtaining fine chemicals and intermediates (Besson and Gallezot, 2000; Sheldon and Van Bekkum, 2001; Mallat and Baiker, 2004; Enache et al., 2006; Dimitratos et al., 2012; Guo et al., 2014; Ranveer et al., 2015; Olenin et al., 2018; Torbina et al., 2018). It has been the subject of important research, due the need to use renewable biomass-derived feedstocks and replace toxic oxidants by more environmentally friendly ones. In the past, oxidation reactions were carried out with the use of strong oxidants, like $\mathrm{KMnO}_{4}$, Jones reagent (chromium trioxide in diluted sulfuric acid), pyridine dichromate and $\mathrm{RuO}_{4}$, which increased the costs and produced large amounts of toxic wastes (Zhao et al., 1998; Tojo and Fernández, 2006). A large decrease in the amounts of chemical waste and pollution can be obtained if those oxidants are replaced by "greener" ones (like molecular oxygen and $\mathrm{H}_{2} \mathrm{O}_{2}$ ) (Dimitratos et al., 2012).

Gold catalysts have successfully been used in the oxidation of alcohols, as shown by several reviews (Besson and Gallezot, 2000; Prati and Porta, 2005; Bond et al., 2006; Hashmi and Hutchings, 2006; Hutchings et al., 2006; Carabineiro and Thompson, 2007, 2010; Edwards et al., 2007; Ishida and Haruta, 2007; Fristrup et al., 2008; Della Pina and Falletta, 2011; Della Pina et al., 2012; Dimitratos et al., 2012; Takei et al., 2012; Hutchings, 2014; Freakley et al., 2015; Sharma et al., 2016). Gold based materials have also been successfully used in alcohol photooxidation (Nizova and Shulpin, 1992; Zhang et al., 2012; Yu et al., 2014; Luken et al., 2015; Chen et al., 2016; Chasse and Hallett-Tapley, 2018).

\section{Oxidation of Diols}

The first report on the use of gold nanoparticles on carbon and alumina was released in 1998 by Prati and Rossi, referring to alcohol oxidation (Prati and Rossi, 1998). The materials were prepared by IMP and DP. In that work, ethane-1,2-diol and 

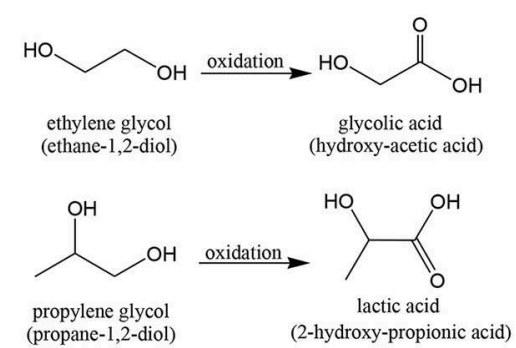

SCHEME 1 | Examples of diols used in selective oxidation reactions and respective products.

propane-1,2-diol were oxidized to the respective monoacids, in an alkaline (aqueous) solution, with high selectivity (Scheme 1). Gold was highly selective for the mono-oxidation of ethane1,2-diol to glycolate, compared to $\mathrm{Pt}$ and $\mathrm{Pd}$. For propane 1,2-diol, the gold catalyst allowed to obtain only lactate (total selectivity). Au catalysts also showed very good stability in recycling tests, higher than the $\mathrm{Pt}$ and $\mathrm{Pd}$ materials. These results are very important due to the industrial interest for glycolic acid and lactic acid. In fact, the usual chemical synthesis methods involves toxic and corrosive reagents, high-pressure equipment and alternative fermentation processes (used for lactic acid production), which show low productivity and complicated problems with purification (Bond et al., 2006; Carabineiro and Thompson, 2007).

Subsequent studies by the same group (Prati and Martra, 1999; Bianchi et al., 2000; Porta et al., 2000, 2002; Biella et al., 2003c; Porta and Rossi, 2003; Comotti et al., 2005) confirmed that $\mathrm{Au} /$ carbon was very active in the selective oxidation of 1,2-diols to $\alpha$-hydroxyacids, in mild conditions, much better than mono-, di-, and tri-metallic Pd-, Pt-, and Bi-based catalytic systems, as $\mathrm{Au}$ showed more selectivity and more resistance to poisoning. Nevertheless, it requires strong alkaline conditions, which also enhanced selectivity. Au/carbon was also the most stable in recycling tests, without deactivation or leaching being observed.

\section{Oxidation of Polyalcohols}

Mixed Au-PGM/C were also tested by the same group in the selective oxidation of the polyalcohol $d$-sorbitol (Scheme 2) to gluconic and gulonic acids (Dimitratos and Prati, 2005; Dimitratos et al., 2005b; Prati and Porta, 2005). Bimetallic catalysts showed a resistance to poisoning and improved selectivity compared to monometallic. The addition of $\mathrm{Au}$, after Pd or Pt being added and reduced, produced the best results (Dimitratos and Prati, 2005). Au and Au/Pt showed selectivities of $60 \%$ and $62 \%$, respectively, to gluconate/gulonate (Dimitratos and Prati, 2005; Dimitratos et al., 2005b; Prati and Porta, 2005).

The oxidation of glycerol is also a very important reaction. The glycerol molecule has many functionalizations, is obtainable from sustainable bio-sources, like sunflower crops and rapeseed, from which several products can be formed by oxidation (Scheme 3), and it is important that the process allows selectivity to distinct products aiming at making their use as chemical intermediates economically viable (Hutchings, 2005; Villa et al.,

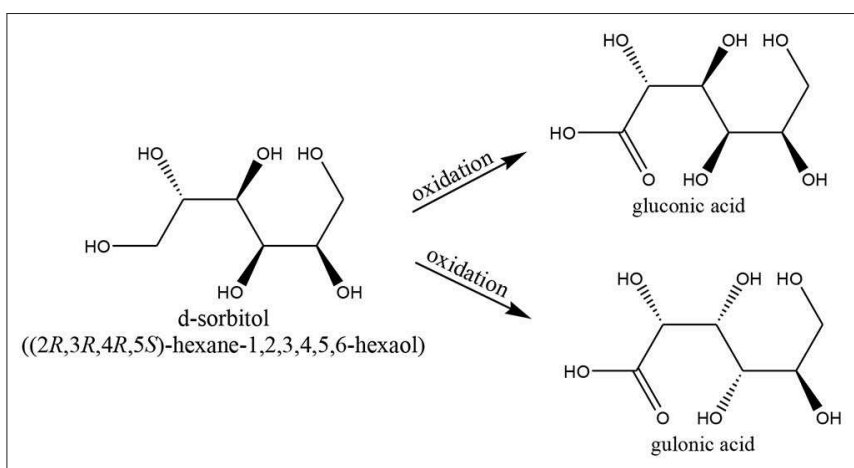

SCHEME 2 | d-Sorbitol oxidation reactions.

2015b; Prati and Villa, 2017). Glyceric acid and dihydroxyacetone (Scheme 3) can be used as chemical intermediates in the industry of fine chemistry, namely in pharmaceuticals (Zhou et al., 2008). To date, these molecules are commercially obtained using either expensive and polluting oxidation processes (like glyceraldehyde) or by microbial (incomplete) fermentation by Gluconobacter oxidans (like dihydroxyacetone) (Pagliaro et al., 2007, 2009; Zhou et al., 2008; Hu et al., 2010; Ciriminna et al., 2014). As glycerol has a high boiling point, its selective oxidation is often carried out using water as liquid medium and $\mathrm{O}_{2}$ as oxidant ((Porta and Prati, 2004); Carabineiro and Thompson, 2007).

Glyceraldehyde is the major product obtained from glycerol oxidation, using $\mathrm{Pt}$ or $\mathrm{Pd}$ catalysts on activated carbon, with a small amount of dihydroxyacetone (Garcia et al., 1995). The main disadvantage of catalysts that are based on these metals is that they tend to deactivate after some reaction time, due to poisoning by oxygen (Besson and Gallezot, 2000; Porta and Prati, 2004). Au catalysts are more resistant to oxygen poisoning compared to PGMs, permitting the use of high oxygen partial pressures (Prati and Rossi, 1998). However, they require the use of a basic medium to ensure a good conversion of glycerol (Carrettin et al., 2003; Hutchings et al., 2006; Zope et al., 2010; Villa et al., 2015b). Moreover, their activity (and selectivity) are also dependent of Au nanoparticle size which is also dependent on the method of preparation method and on the support.

Hutchings and co-workers published some studies dealing with glycerol oxidation in the liquid phase using $\mathrm{Au} /$ charcoal (Carrettin et al., 2002), Au/activated carbon (Carrettin et al., 2003) or Au/graphite (Carrettin et al., 2002, 2003, 2004). Before that, glyceraldehyde could be obtained with a selectivity of 70-80\% using Pt catalysts (Garcia et al., 1995). However, Hutchings and co-workers (Carrettin et al., 2002, 2003, 2004; Hutchings et al., 2006) showed that glycerol oxidation could yield glyceric acid (Scheme 3) with high conversion and total selectivity, for $1 \% \mathrm{Au} /$ charcoal or $1 \% \mathrm{Au} /$ graphite catalysts, in mild conditions $\left(60^{\circ} \mathrm{C}, 3 \mathrm{~h}\right.$, using water as solvent) (Carrettin et al., 2002). Without $\mathrm{NaOH}, \mathrm{Au} / \mathrm{C}$ was inactive and the formation of undesirable $\mathrm{C}-1$ products (like formic acid, Scheme 3) was eliminated when $\mathrm{NaOH}$ 


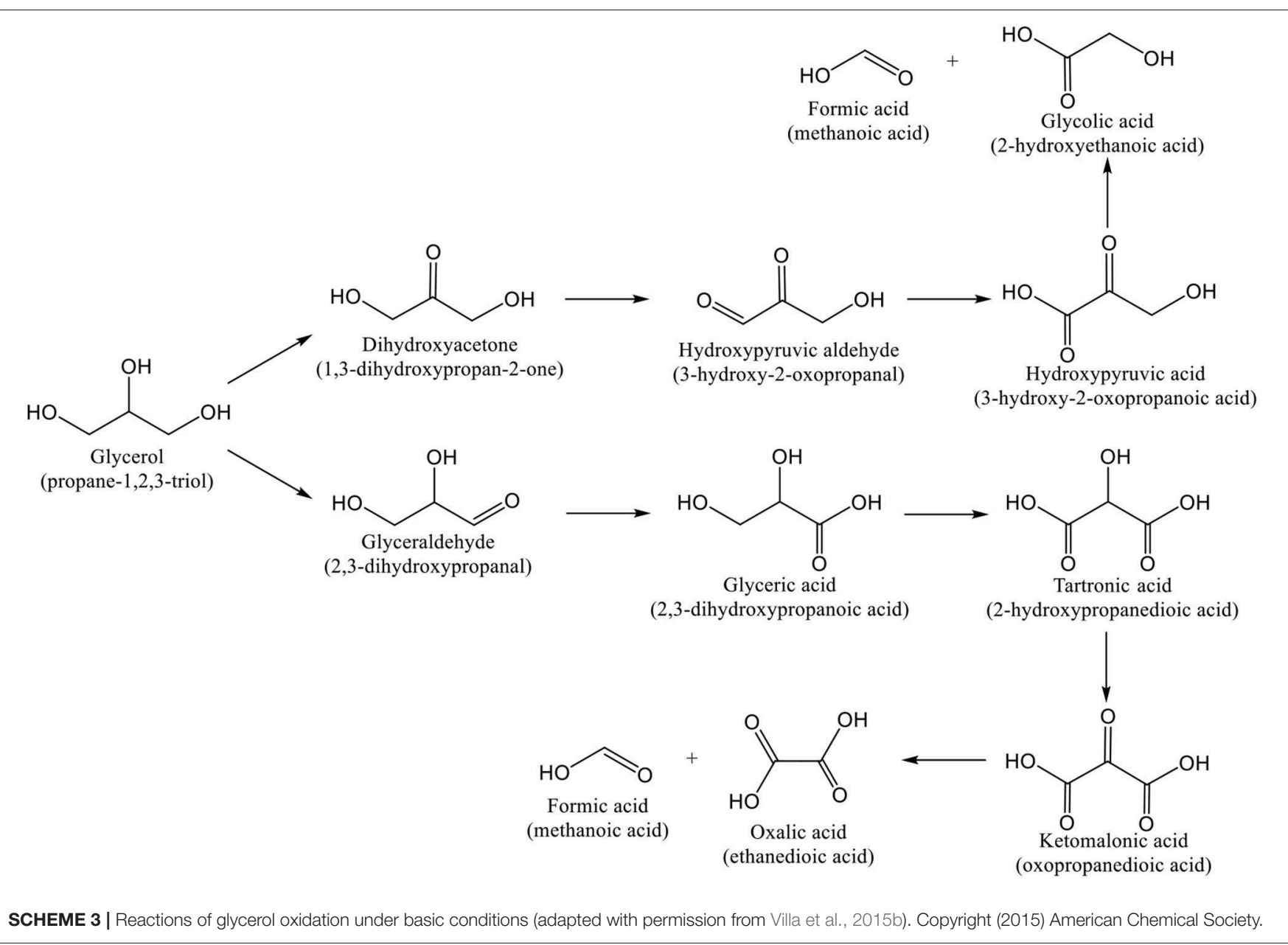

was added (Carrettin et al., 2003). It was proposed that the base aided the initial dehydrogenation by abstraction of the $\mathrm{H}$ of the primary $\mathrm{OH}$ group of glycerol and, thus, allowing to overcome the rate limiting step of the oxidation (Carrettin et al., 2003).

Claus's group also investigated this reaction using gold catalysts on carbon supports [carbon black (Demirel-Gulen et al., 2005; Demirel et al., 2007a,b,c), activated carbon (Demirel et al., 2007a,b) and graphite (Demirel-Gulen et al., 2005)] and oxides $\left[\mathrm{Al}_{2} \mathrm{O}_{3}\right.$ (Demirel-Gulen et al., 2005), MgO (DemirelGulen et al., 2005), $\mathrm{TiO}_{2}$ (Demirel-Gulen et al., 2005; Demirel et al., 2007a), and $\mathrm{CeO}_{2}$ (Demirel et al., 2007a)]. The oxide materials were prepared by DP using urea, while the carbon materials were prepared by COL. The carbon black gave better results than activated carbon or graphite (Demirel-Gulen et al., 2005; Demirel et al., 2007a,b,c). Results showed that the oxidation of glycerol is structure-sensitive reaction, as the selectivity to the glyceric acid product increased up to $75 \%$ with decreasing $\mathrm{Au}$ nanoparticle size (down to the best value of $3.7 \mathrm{~nm}$ ) on carbon black (Demirel-Gulen et al., 2005). The selectivity to glyceric acid product was $40 \%$ for smaller Au nanoparticles ( $2.7 \mathrm{~nm})$, but the glycolic acid selectivity increased from 15 to $36 \%$ (DemirelGulen et al., 2005). This showed that the nanoparticle particle size of the Au/carbon catalysts could play an important role in the reaction.

Porta and Prati studied these reactions on Au/carbon catalysts, namely activated carbon (Porta and Prati, 2004; Bianchi et al., 2005; Prati and Porta, 2005; Jouve et al., 2018) and graphite (Porta and Prati, 2004). Au on activated carbon was more active than $\mathrm{Au}$ on graphite. Well-dispersed nanoparticles on activated carbon of $6 \mathrm{~nm}$, were not able to maintain the preliminary selectivity up to full conversion, but larger $(>20 \mathrm{~nm})$ nanoparticles were able to maintain constant selectivity during the reaction time (Porta and Prati, 2004). This showed that gold nanoparticle size was not the only issue, but other factors, such as preparation method (with COL being better than IMP), and temperature (since an increase in the temperature promoted glyceric acid oxidation to tartronic acid, Scheme 3) could also play an important role. $92 \%$ of selectivity was found at full conversion (Porta and Prati, 2004).

The same group also used gold on (multi-walled) carbon nanotubes (CNTs) (Prati et al., 2011, 2016) and carbon nanofibers (CNFs) (Prati et al., 2011; Wang D. et al., 2013; Villa et al., 2016). It was shown that the basicity of CNFs led to an activity increase, but the selectivity was mostly linked to the nature of 
the surface groups, as the selectivity to C-3 products was best for surfaces with basic and hydrophobic nature, but surfaces more hydrophilic led to an increase of the products of $\mathrm{C}-\mathrm{C}$ bond cleavage (Prati et al., 2011).

$\mathrm{Au}$ nanoparticles were also supported on CNFs with different degrees of graphitization (Wang D. et al., 2013). The CNF surface containing a larger amount of ordered graphitic layers led to gold nanoparticles preferentially immobilized on the (111) plane, with more facet area. Higher C-3 product selectivity was found on the (111) surface, showing that larger Au nanoparticles were more selective toward C-3 products compared to the smaller ones.

Addition of nitrogen to CNFs also had positive results (Villa et al., 2016). Au nanoparticles trapped within N-functionalized CNFs were more efficient for glycerol oxidation and promoted selectivity for di-acid products, while Au nanoparticles trapped on the surface produce the molecule derived from $\mathrm{C}-\mathrm{C}$ cleavage as a major by-product.

Nitrogen doped CNTs were also used (Prati et al., 2016). The introduction of nitrogen functionalities was performed by high temperature treatment $\left(600^{\circ} \mathrm{C}\right)$ in the presence of $\mathrm{NH}_{3}$. The turnover frequency (TOF, moles of product per mol of $\mathrm{Au}$ catalyst per time) obtained for N-doped CNTs was $853 \mathrm{~h}^{-1}$, much higher than the 182 and $186 \mathrm{~h}^{-1}$ obtained for pristine and oxidized CNTs, respectively. The selectivity to glycerate was $68 \%$ for the $\mathrm{N}$-doped material and 55\% for the pristine sample (for 90\% conversion).

Carabineiro and co-authors compared several metals (Pt, Pd, $\mathrm{Ir}, \mathrm{Rh}$, and $\mathrm{Au}$ ) on activated carbon as catalysts for glycerol oxidation, showing, for the first time, that that $\mathrm{Rh}$ could be an active catalyst for this reaction, although having high sensitivity to oxygen poisoning, as other PGMs (Rodrigues et al., 2011). IMP and COL were used as preparation methods. Not surprisingly, IMP yielded an inactive Au material. However, the Au catalyst prepared by the COL exhibited a high activity with only $0.32 \%$ Au loading, reaching a full glycerol conversion in $\sim 3 \mathrm{~h}$, in the standard conditions tested (with $\sim 60 \%$ selectivity to glyceraldehyde). In contrast, only $44 \%$ was achieved with the reference $\mathrm{Au} / \mathrm{C}$ catalyst (supplied by the World Gold Council, consisting on $0.8 \%$ Au on carbon black).

The same authors also tested Au nanoparticles supported on (multi-walled) CNTs prepared by different methods (Rodrigues et al., 2012a,b). COL was the most suitable method, yielding $47 \%$ selectivity toward glyceric acid (Rodrigues et al., 2012a,b). This reaction was also studied on Au nanoparticles deposited on carbon xerogels with different mesopore sizes (prepared by condensation of resorcinol and formaldehyde at different values of $\mathrm{pH}$ ) by the COL method (Rodrigues et al., 2012c). It was found that larger pores $(20 \mathrm{~nm})$ enhanced the oxidation toward dihydroxyacetone, whereas smaller pores $(5 \mathrm{~nm})$ favored the formation of glyceric acid (Scheme 3).

Prati and co-workers also tested $\mathrm{Au}$ on metal oxides $\left(\mathrm{Al}_{2} \mathrm{O}_{3}, \mathrm{MgO}, \mathrm{MgAl}_{2} \mathrm{O}_{4}\right.$ spinel) prepared by $\mathrm{DP}$ and $\mathrm{COL}$ (Bogdanchikova et al., 2017). In terms of materials prepared by $\mathrm{DP}, \mathrm{Au} / \mathrm{Al}_{2} \mathrm{O}_{3}$ was more active than $\mathrm{Au} / \mathrm{MgO}$, but for catalysts prepared by $\mathrm{COL}, \mathrm{Au} / \mathrm{MgO}$ was more active than $\mathrm{Au} /$ alumina. $\mathrm{Au} / \mathrm{MgAl}_{2} \mathrm{O}_{4}$ spinel showed high activities, similar to materials prepared by both methods. The same group also used a weak basic anion resin as support for $\mathrm{Au}$ nanoparticles (Villa et al., 2010).

Those authors also studied mono- and bimetallic Au catalysts on activated carbon (Bianchi et al., 2005), graphite (Dimitratos et al., 2005a), acidic ( $\mathrm{SiO}_{2}, \mathrm{MCM}-41, \mathrm{H}$-mordenite and sulphated $\mathrm{ZrO}_{2}$ ), and basic ( $\mathrm{MgO}$ and $\mathrm{NiO}$ ) oxide supports (Villa et al., 2015a), using the COL method. Bimetallic materials were more active than the monometallics, showing a synergistic effect between $\mathrm{Au}$ and Pt or Pd (Bianchi et al., 2005; Dimitratos et al., 2005a). This effect was especially significant for Pt, as it could be poisoned before full conversion. Au-Pd/C catalysts showed better selectivity to glyceric acid than Au-Pt/C. Pd mainly promoted the obtention of tartronic acid and $\mathrm{Pt}$ of glycolic acid. The total selectivity to glyceric acid was larger for $\mathrm{Au}-\mathrm{Pd} / \mathrm{C}$ compared to $\mathrm{Au} / \mathrm{C}$ and $\mathrm{Pd} / \mathrm{C}$. At $30^{\circ} \mathrm{C}$, authors obtained a very high selectivity to glyceric acid of $69 \%$ at $90 \%$ conversion with $\mathrm{Au}-\mathrm{Pd} / \mathrm{C}$ (Bianchi et al., 2005). Graphite based materials were less active (Dimitratos et al., 2005a). In terms of gold on oxides, it was found that basic $\mathrm{MgO}$ and $\mathrm{NiO}$ supports increased not only the activity, but also the reactions of $\mathrm{C}$ $\mathrm{C}$ bond cleavage, thus decreasing the selectivity to the wanted products. However, the acidic supports led to a higher selectivity to products of C-3 oxidation. Au/MCM-41, in particular, showed a high selectivity to glyceraldehyde (Villa et al., 2015a). It is now widely accepted that the glycerol oxidation mechanism includes oxidative dehydrogenation. The $\beta$-hydride abstraction is enhanced if a base is present, this being the limiting step of the reaction (Besson and Gallezot, 2000; Mallat and Baiker, 2004; Dimitratos et al., 2012; Villa et al., 2015a).

Recently, activated carbon supported $\mathrm{Au}-\mathrm{Pt}$ and $\mathrm{Bi}-\mathrm{Au}-\mathrm{Pt}$ materials were prepared by IMP by Prati's group (Motta et al., 2018). The materials were used for the oxidation of glycerol in a base free medium in mild conditions. Au-Pt/C had $68 \%$ selectivity to glyceric acid, while $\mathrm{Bi}-\mathrm{Au}-\mathrm{Pt} / \mathrm{C}$ led to the secondary alcohol oxidation, with a selectivity of $48 \%$ to dihydroxyacetone, at $28 \%$ conversion, which is among the best values found in the literature so far.

\section{Oxidation of Aminoalcohols}

Prati's group showed that aminoalcohols can be transformed into aminoacids by oxidation in slightly alkaline conditions with a high selectivity (Biella et al., 2002a; Prati and Porta, 2005; Gaiassi and Prati, 2009). Au nanoparticles deposited on activated carbon (Biella et al., 2002a; Prati and Porta, 2005; Gaiassi and Prati, 2009), MgO (Gaiassi and Prati, 2009), $\mathrm{TiO}_{2}$ (Biella et al., 2002a; Gaiassi and Prati, 2009) and $\mathrm{Al}_{2} \mathrm{O}_{3}$ (Biella et al., 2002a) were used. Au was again amazingly better than other metals. The reason is that the free amino group can strongly interact with other metals, like Pd and Pt. Aminoalcohols (serinol and ethanolamine, Scheme 4) were also be oxidized to the corresponding polyols (glycerol and ethylene glycol), using $\mathrm{Au}$ on $\mathrm{Al}_{2} \mathrm{O}_{3}, \mathrm{TiO}_{2}, \mathrm{MgAl}_{2} \mathrm{O}_{4}$, and $\mathrm{MgO}$ (Villa et al., 2013a) by the same group.

\section{Oxidation of Aliphatic Alcohols}

Hutchings and co-workers also used Au/carbon catalysts for the oxidation of geraniol (Scheme 5) (Hutchings et al., 2006). 
Cis- and trans-citral were the main products, but at higher conversions, many products such as $\beta$-pinene, limonene, $\gamma$ terpinene, linalool, nerol, and some traces of geranic acid were identified (structures seen in Scheme 5).

Corma and co-workers reported $2-5 \mathrm{~nm}$ sized $\mathrm{Au}$ nanoparticles on nanocrystalline ceria $(\sim 5 \mathrm{~nm})$, as being very active, selective and recyclable for the oxidation of several alcohols (like $n$-hexanol, 3-octanol, 1-octen-3-ol, shown in Scheme 6), to the corresponding carbonyl products, using $\mathrm{O}_{2}$, atmospheric pressure, in the absence of any solvent and base<smiles>NC(CO)CO</smiles>

(2-aminopropane-1,3-diol)

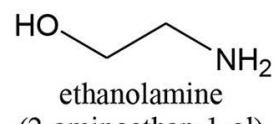

(2-aminoethan-1-ol)
SCHEME 4 | Examples of aminoalcohols used in selective oxidation reactions.
(Abad et al., 2005, 2006a,b, 2008; Corma and Garcia, 2008). $\mathrm{Au} /$ ceria was highly selective for the oxidation of allylic alcohols to unsaturated ketones and was active without solvent and base (Abad et al., 2006b). Selected results can be found in Table 1. As an example, 1-octen-3-ol (Scheme 6) oxidation yielded mostly 1 -octen-3-one, with a $90 \%$ selectivity, but $\mathrm{Pd} /$ ceria showed $58 \%$ selectivity (due to isomerization promotion and of $\mathrm{C}=\mathrm{C}$ bond hydrogenation, yielding saturated ketones as a by-products) (Abad et al., 2006a).

Au-Pd nanoparticles were dispersed on titania/graphene oxide (GO) composites and used for the selective oxidation of several alcohols, including $n$-octanol, shown in Scheme 6 (Wang et al., 2015). Similar, yet slightly better results $\left(\mathrm{TOF}=228 \mathrm{~h}^{-1}\right.$ ) were achieved for the Au-Pd/titania/GO composite, compared to the $\mathrm{Au}-\mathrm{Pd} /$ titania material $\left(\mathrm{TOF}=207 \mathrm{~h}^{-1}\right)$.

\section{Oxidation of Cycloalcohols}

Tatsumi and co-workers (Wang H. et al., 2013) studied the selective oxidation of cycloalcohols, like cyclohexanol, cyclooctanol, cyclododecanol, 4-methyl cyclohexanol<smiles>CC(C)=CCC/C(C)=C/CO</smiles>

geraniol ((E)-3,7-dimethylocta-2,6-dien-1-ol) $\downarrow$ oxidation<smiles>CC(C)=CCC/C(C)=C\C=O</smiles>

cis-citral (3,7-dimethyl-octa-2,6-dienal) main products

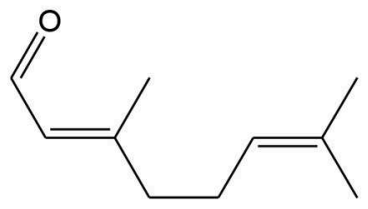

trans-citral (3,7-dimethyl-octa-2,6-dienal)

\section{other products}

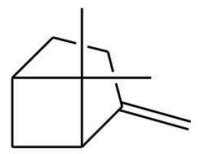

beta-pinene (6,6-dimethyl-2-methylenebicyclo[3.1.1]heptane)<smiles>CC(C)=CCC/C(C)=C\CO</smiles>

(3,7-dimethyl-octa-2,6-dien-1-ol)

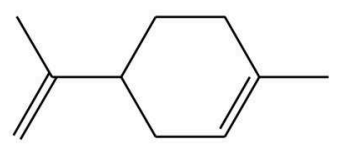

limonene (4-isopropenyl-1-methyl-cyclohexene)

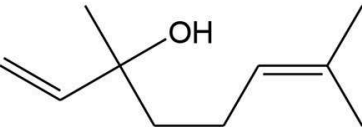

linalool (3,7-dimethyl-octa-1,6-dien-3-ol)

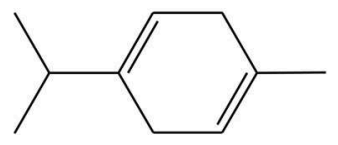

gamma-terpinene (1-iopropyl-4-methyl-cyclohexa-1,4-diene)

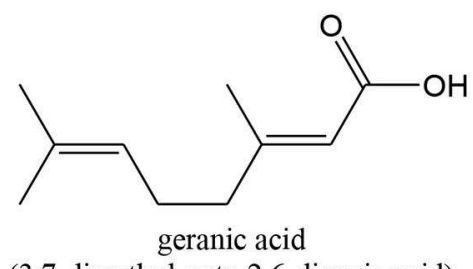

(3,7-dimethyl-octa-2,6-dienoic acid)

SCHEME 5 | Possible products obtained in geraniol oxidation. 
<smiles>CCCCCCCCO</smiles><smiles>C=CC(O)CCCCC</smiles>

1-octen-3-ol (oct-1-en-3-ol)<smiles>CCCCCCCCO</smiles><smiles>CCCCCC(O)CC</smiles>

3-octanol (octan-3-ol)
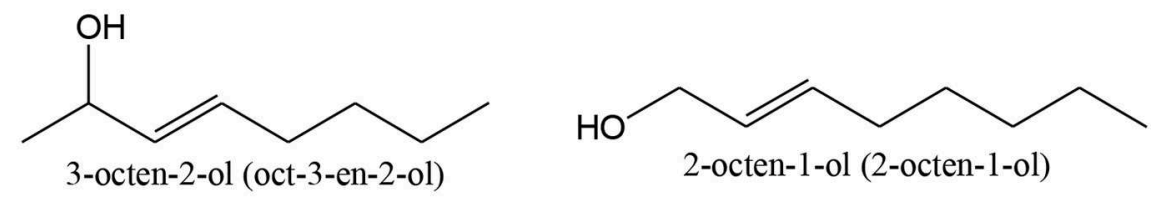

SCHEME 6 | Examples of aliphatic alcohols used in selective oxidation reactions.

TABLE 1 | Catalytic activity of gold on ceria for the oxidation of several alcohols to the corresponding $\alpha, \beta$-unsaturated carbonyl compounds (Abad et al., 2005; Corma and Garcia, 2008).

\begin{tabular}{lcc}
\hline Substrate & Conversion (\%) & Selectivity (\%) \\
\hline 1-Octen-3-ol & $>99$ & 90 \\
3-Octen-2-ol & 96 & 91 \\
2-Octen-1-ol & 90 & 91 \\
3-octanol & 97 & $>99$ \\
n-hexanol & $>99$ & $>99$ \\
\hline
\end{tabular}

(Scheme 7) to aldehydes/ketones with $\mathrm{O}_{2}$ over Au nanoparticles on $\mathrm{CuO}, \mathrm{MnO}_{2}, \mathrm{NiO}, \mathrm{CoO}_{\mathrm{x}}, \mathrm{Fe}_{2} \mathrm{O}_{3}, \mathrm{Cr}_{2} \mathrm{O}_{3}$, and $\mathrm{Al}_{2} \mathrm{O}_{3}, \mathrm{TiO}_{2}$ and $\mathrm{SiO}_{2}$. The catalytic activity of $\mathrm{Au}$ catalysts was greatly influenced by the support and the preparation method. The best results were obtained for $\mathrm{Au} / \mathrm{CuO}$ co-precipitated at $\mathrm{pH} 10$. The reaction might occur via oxidative dehydroxylation by direct $\beta$ - $\mathrm{CH}$ elimination. The conversion and selectivity to ketone were above $99 \%$ for cyclooctanol and cyclododecanol. Introduction of a base greatly increased the catalyst stability. The reaction occurred via an integrated oxidation mechanism, involving the lattice oxygen of $\mathrm{CuO}$.

Buonerba et al. obtained good results in the oxidation of 2-thiophenemethanol. The structures are shown in Scheme 7, using gold nanoparticles incarcerated in nanoporous syndiotactic polystyrene matrices (Buonerba et al., 2012). As syndiotactic polystyrene has a crystalline nanoporous structure, which favored the easy and selective access of the reagents to the gold catalyst located inside the polymer matrix, it was considerably accountable for the good activities found. Results suggested that the active catalysts were the $\sim 9 \mathrm{~nm}$ twinned defective nanoparticles, present in large numbers.

$\mathrm{Au}-\mathrm{Pd}$ nanoparticles were dispersed on titania/graphene oxide composites and used for the selective oxidation of cyclohexanol (Scheme 7) (Wang et al., 2015). Better results (TOF $=4,700 \mathrm{~h}^{-1}$ ) were achieved for the Au-Pd/titania/GO composite, compared to the $\mathrm{Au}-\mathrm{Pd} /$ titania material $\left(\mathrm{TOF}=4,130 \mathrm{~h}^{-1}\right)$.

Corma and co-workers reported $2-5 \mathrm{~nm}$ sized $\mathrm{Au}$ nanoparticles on nanocrystalline ceria $(\sim 5 \mathrm{~nm})$, as being very active, selective, and recyclable for the oxidation of 2,6-dimethylcyclohexanol (Scheme 7), using $\mathrm{O}_{2}$, atmospheric pressure, in the absence of any solvent and base (Abad et al., 2005). $78 \%$ conversion with $94 \%$ selectivity to 2,6-dimethylcyclohexanone was achieved in $2.5 \mathrm{~h}$ reaction time.

\section{Oxidation of Aromatic Alcohols}

The first report on the use of a gold catalyst for alcohol oxidation dates from 1992 and deals with the oxidation of an aromatic alcohol (4-methoxybenzyl alcohol, shown in Scheme 8) to the corresponding aldehyde, performed by a $\left[\mathrm{Au}\left(\mathrm{IO}_{5}(\mathrm{OH})\right)_{2}\right]^{5-}$ complex (Dengel et al., 1992).

Corma and co-workers reported 2-5 nm sized $\mathrm{Au}$ nanoparticles on nanocrystalline ceria $(\sim 5 \mathrm{~nm})$, as being very active, selective and recyclable for the oxidation of several alcohols (like 2-phenylethanol, cinnamyl alcohol, 3,4-dimethoxybenzyl alcohol, 3-phenyl-1-propanol, vanillin alcohol, 2-hydroxybenzyl alcohol, shown in Scheme 8), using $\mathrm{O}_{2}$, atmospheric pressure, in the absence of any solvent and base (Abad et al., 2005, 2006a,b, 2008; Corma and Garcia, 2008). Selected results are shown in Table 2. Milder conditions are needed and better results are obtained for the oxidation of cinnamyl and 3,4dimethoxybenzyl alcohols to the corresponding acids, than to the corresponding aldehydes.

$\mathrm{Wu}$ X. C. et al. (2016) used nanocomposites of graphene quantum dots and $\mathrm{Au}$ nanoparticles immobilized on $\mathrm{Fe}_{3} \mathrm{O}_{4}$ nanoparticles (GQDs/Au/ $/ \mathrm{Fe}_{3} \mathrm{O}_{4}$ ternary composites with superparamagnetic properties being easy to remove from the reaction mixture) for the solvent-free oxidation of aromatic alcohols (containing an aromatic benzyl group) with air as oxidant. Materials showed good catalytic performance with the aromatic alcohols being oxidized to the corresponding aldehydes with high selectivity (>99\%) and conversion.

$\mathrm{Au}-\mathrm{Pd}$ nanoparticles were dispersed on titania/graphene oxide composites and used for the selective oxidation of benzyl alcohol, 4-methoxy benzyl alcohol, cinnamyl alcohol, 1phenylethanol, shown in Scheme 8 (Wang et al., 2015). Results are shown in Table 3. The resulting optimized catalyst showed activities compared to the $\mathrm{Au}-\mathrm{Pd} / \mathrm{TiO}_{2}$ material prepared by $\mathrm{COL}$ (although much better for 4-methoxy benzyl alcohol), but the GO composite was more stable and could reused for three cycles without loss of activity. 
<smiles>OCc1cccs1</smiles>

2-thiophenemethanol (thiophen-2-ylmethanol)

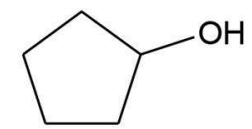

cyclopentanol<smiles>OC1CCCCC1</smiles>

cyclohexanol<smiles>CC1CCCC(C)C1O</smiles>

2,6-dimethylcyclohexanol (2,6-dimethylcyclohexan-1-ol)<smiles>CC1CCC(O)CC1</smiles>

4-methyl cyclohexanol (4-methylcyclohexan-1-ol)

SCHEME 7 | Examples of cycloalcohols used in selective oxidation reactions.
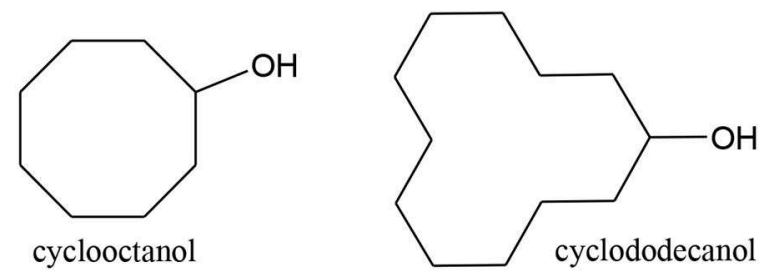<smiles>O=C(O)C=Cc1ccccc1</smiles>

((E)-3-phenylprop-2-en-1-ol)<smiles>COc1cc(C=O)ccc1OO</smiles>

vanillin alcohol

(4-hydroperoxy-3-methoxybenzaldehyde)<smiles>COc1ccc(CO)cc1</smiles>

4-methoxy benzyl alcohol ((4-methoxyphenyl)methanol)<smiles>OC1CCc2ccccc21</smiles>

(2,3-dihydro- $1 H$-inden-1-ol)

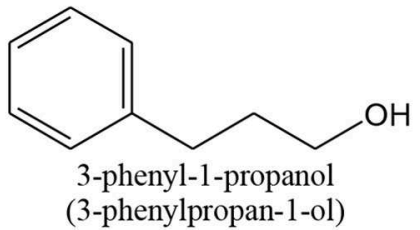

(3-phenylpropan-1-ol)<smiles>COc1ccc(CO)cc1OC</smiles>

3,4-dimethoxybenzyl alcohol ((3,4-dimethoxyphenyl)methanol)<smiles>Cc1ccccc1CO</smiles>

(2-methyl benzyl alcohol)<smiles>OC1CCCc2ccccc21</smiles>

alpha-tetralol

(1,2,3,4-tetrahydronaphthalen-1-ol)

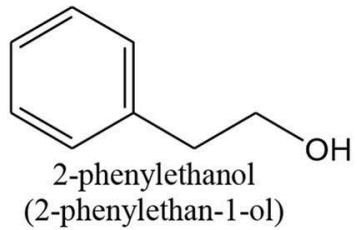<smiles>OCc1ccccc1O</smiles>

2-hydroxybenzyl alcohol (2-(hydroxymethyl)phenol)

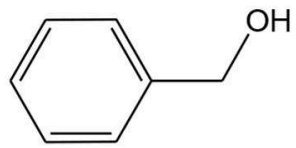

benzyl alcohol

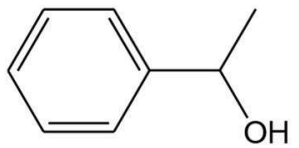

1-phenylethanol 
TABLE 2 | Catalytic activity of gold on ceria for the oxidation of several alcohols to the corresponding carbonyl compounds (Abad et al., 2005).

\begin{tabular}{|c|c|c|c|c|}
\hline Substrate (S) & Time (h) & $\begin{array}{c}\text { Conversion } \\
(\%)\end{array}$ & Product & Selectivity (\%) \\
\hline 2-phenylethanol ${ }^{a}$ & 2.5 & 92 & acetophenone & 97 \\
\hline cinnamyl alcohola & 7 & 66 & cinnamaldehyde & 73 \\
\hline cinnamyl alcoholb & 3 & $>99$ & cinnamylic acid & 98 \\
\hline $\begin{array}{l}\text { 3,4- } \\
\text { dimethoxybenzyl } \\
\text { alcohol }^{\mathrm{a}}\end{array}$ & 7 & 73 & $\begin{array}{l}\text { 3,4- } \\
\text { dimethoxybenzaldehyde }\end{array}$ & 83 \\
\hline $\begin{array}{l}\text { 3,4- } \\
\text { dimethoxybenzyl } \\
\text { alcohol }^{\text {b }}\end{array}$ & 2 & $>99$ & $\begin{array}{l}\text { 3,4- } \\
\text { dimethoxybenzylic } \\
\text { acid }\end{array}$ & $>99$ \\
\hline $\begin{array}{l}\text { 3-phenyl-1- } \\
\text { propanol }^{a}\end{array}$ & 6 & 70 & $\begin{array}{l}\text { 3-phenylpropyl } \\
\text { 3-phenylpropanoate }\end{array}$ & 98 \\
\hline vanillin alcoholb & 2 & 96 & vanillin & 98 \\
\hline $\begin{array}{l}\text { 2-hydroxybenzyl } \\
\text { alcohol }^{\mathrm{b}}\end{array}$ & 2 & $>99$ & $\begin{array}{l}\text { 2- } \\
\text { hydroxybenzaldehyde }\end{array}$ & 87 \\
\hline
\end{tabular}

a Substrate (4.85 mmol), $\mathrm{Au} / \mathrm{CeO}_{2}(0.5 \mathrm{~mol} \%), 353 \mathrm{~K}, \mathrm{p}=1 \mathrm{~atm} \mathrm{O}_{2}$ (flow: $25 \mathrm{~mL} \mathrm{~min}^{-1}$ ). ${ }^{b}$ Substrate (0.4 mmol), $\mathrm{Au} / \mathrm{CeO}_{2}(0.66 \mathrm{~mol} \%), \mathrm{H}_{2} \mathrm{O}(5 \mathrm{~mL}), \mathrm{Na}_{2} \mathrm{CO}_{3}(0.3 \mathrm{~g}), 323 \mathrm{~K}, \mathrm{p}=$ $1 \mathrm{~atm} \mathrm{O}_{2}$ (flow: $25 \mathrm{~mL} \mathrm{~m}^{-1}$ ).

TABLE 3 | Alcohol oxidation for supported Au-Pd Catalysts (Wang et al., 2015).

\begin{tabular}{lll}
\hline Substrate & Catalyst & TOF $\left(\mathbf{h}^{\mathbf{- 1}}\right)$ \\
\hline benzyl alcohol & $\mathrm{Au}-\mathrm{Pd} / \mathrm{TiO}_{2}$ & 10,300 \\
& $\mathrm{Au}-\mathrm{Pd} / \mathrm{TiO}_{2} / \mathrm{GO}$ & 10,400 \\
4-methoxy benzyl alcohol & $\mathrm{Au}-\mathrm{Pd} / \mathrm{TiO}_{2}$ & 12,800 \\
& $\mathrm{Au}-\mathrm{Pd} / \mathrm{TiO}_{2} / \mathrm{GO}$ & 15,000 \\
cinnamyl alcohol & $\mathrm{Au}-\mathrm{Pd} / \mathrm{TiO}_{2}$ & 3,360 \\
& $\mathrm{Au}-\mathrm{Pd} / \mathrm{TiO}_{2} / \mathrm{GO}$ & 4,070 \\
1-phenylethanol & $\mathrm{Au}-\mathrm{Pd} / \mathrm{TiO}_{2}$ & 6,000 \\
& $\mathrm{Au}-\mathrm{Pd} / \mathrm{TiO}_{2} / \mathrm{GO}$ & 6,390 \\
\hline
\end{tabular}

Tatsumi and co-workers (Wang H. et al., 2013) studied the selective oxidation of cycloalcohols, like benzyl alcohol, 2methyl benzyl alcohol, 4-methyl benzyl alcohol, cinnamyl alcohol (Scheme 8) to aldehydes/ketones with $\mathrm{O}_{2}$ over Au nanoparticles on $\mathrm{CuO}, \mathrm{MnO}_{2}, \mathrm{NiO}, \mathrm{CoO}_{\mathrm{x}}, \mathrm{Fe}_{2} \mathrm{O}_{3}, \mathrm{Cr}_{2} \mathrm{O}_{3}$, and $\mathrm{Al}_{2} \mathrm{O}_{3}, \mathrm{TiO}_{2}$ and $\mathrm{SiO}_{2}$. A larger amount of methyl groups lead to an activity increase. The catalytic of Au catalysts was greatly influenced by the support and the preparation method. The best results were obtained for $\mathrm{Au} / \mathrm{CuO}$ co-precipitated at $\mathrm{pH} 10$. The reaction might occur via oxidative dehydroxylation by direct $\beta-\mathrm{CH}$ elimination. Giorgi et al. also showed that Au/alumina could also be efficiently used in the oxidation of benzylic (and allylic alcohols) under $\mathrm{O}_{2}$, in good yields (68-99\%) and with excellent selectivity (ca. 100\%) (Giorgi et al., 2017).

Buonerba et al. obtained good results in the oxidation of cinnamyl alcohol, indanol, and $\alpha$-tetralol (secondary alcohols). The structures are shown in Scheme 8, using gold nanoparticles incarcerated in nanoporous syndiotactic polystyrene matrices (Buonerba et al., 2012). As said above, the crystalline nanoporous structure of syndiotactic polystyrene favored access of the reagents to the gold catalyst located inside the polymer matrix, improving activity. The active catalysts were the abundant $\sim 9 \mathrm{~nm}$ twinned defective nanoparticles.

Miyamura et al. also proved the catalytic activity of polymersupported gold for "greener" liquid phase selective oxidation of several aromatic alcohols, like phenylmethanol (benzyl alcohol) and 1-phenylethanol (Scheme 9) and cyclopentanol (Scheme 7) (Miyamura et al., 2007). Those materials showed higher activity than Au on metal oxides. Choudhary and Dumbre also tested similar aromatic alcohols, using a $\mathrm{Au} / \mathrm{MgO}$ catalyst prepared by DP (Choudhary and Dumbre, 2011). The highest activity was found for the oxidation of 4-methoxy benzyl alcohol (Scheme 8) with 68\% conversion (and a 95\% selectivity to the aldehyde). Fristrup and co-workers discussed the substituted benzyl alcohols aerobic oxidation mechanism and concluded that the rate-determining step involved hydride abstraction, that is, the formation of a partial positive charge in the benzylic moiety (Fristrup et al., 2008).

Among aromatic alcohols, the already referred benzyl alcohol (Scheme 9) and methylbenzyl alcohol (Scheme 10) are low toxic naturally produced examples. Their partial oxidation can yield benzaldehyde (Scheme 9) and acetophenone (Scheme 10), respectively. These products have a large importance in industrial organic synthesis (since they are precursors to other organic compounds, ranging from plastic additives to pharmaceuticals).

Gold catalysts have been successfully used for oxidation of benzyl alcohol to benzaldehyde (Choudhary et al., 2005, 2007, 2009; Hutchings et al., 2006; Su et al., 2007; Mitsudome et al., 2009; Zhu et al., 2010; Prati et al., 2011; Xie et al., 2012; Xu et al., 2012; He et al., 2013; Wang H. et al., 2013; Yu et al., 2013; Alhumaimess et al., 2014; Hong et al., 2014; Morad et al., 2014; Movahed et al., 2014; Silva T. A. G. et al., 2014; Nepak and Srinivas, 2015; Ferraz et al., 2016; Sun et al., 2016; Giorgi et al., 2017; Liu et al., 2018; Gualteros et al., 2019). Other formed by-products can be toluene, benzene and benzoic acid (Prati et al., 2011; Wang et al., 2015), as seen in Scheme 8. Choudhary et al. (Choudhary et al., 2005, 2007, 2009; Choudhary and Dumbre, 2009a,b, 2010, 2011) were one of the first groups to study this oxidation reaction. They used $\mathrm{Au}$ on $\mathrm{MgO}, \mathrm{BaO}$, $\mathrm{CaO}$, and $\mathrm{SrO}$ (alkaline earth oxides), $\mathrm{Al}_{2} \mathrm{O}_{3}, \mathrm{In}_{2} \mathrm{O}_{3}, \mathrm{Ga}_{2} \mathrm{O}_{3}$, and $\mathrm{Tl}_{2} \mathrm{O}_{3}$ (group IIIa metal oxides), $\mathrm{TiO}_{2}, \mathrm{U}_{3} \mathrm{O}_{8}, \mathrm{Cr}_{2} \mathrm{O}_{3}, \mathrm{Fe}_{2} \mathrm{O}_{3}$, $\mathrm{CoO}_{\mathrm{x}}, \mathrm{MnO}_{2}, \mathrm{CuO}, \mathrm{ZnO}, \mathrm{NiO}, \mathrm{Y}_{2} \mathrm{O}_{3}$, and $\mathrm{ZrO}_{2}$ (transition metal oxides), $\mathrm{Ce}_{2} \mathrm{O}_{3}, \mathrm{La}_{2} \mathrm{O}_{3}, \mathrm{Sm}_{2} \mathrm{O}_{3}, \mathrm{Eu}_{2} \mathrm{O}_{3}, \mathrm{~Tb}_{2} \mathrm{O}_{3}, \mathrm{Er}_{2} \mathrm{O}_{3}$ $\mathrm{Nd}_{2} \mathrm{O}_{3}$, and $\mathrm{Yb}_{2} \mathrm{O}_{3}$ (rare earth metal oxides) prepared by $\mathrm{DP}$, for the liquid-phase oxidation of benzyl alcohol to benzaldehyde. The $\mathrm{Au} / \mathrm{TiO}_{2}$ and $\mathrm{Au} / \mathrm{ZrO}_{2}$ catalysts showed high activity and selectivity for the reaction.

Other authors used $\mathrm{Au}$ on $\mathrm{CuO}$ (Wang H. et al., 2013), $\mathrm{MnO}_{2}$ (Alhumaimess et al., 2014), $\mathrm{TiO}_{2}$ (Ferraz et al., 2016), and titanate nanotubes (Nepak and Srinivas, 2015). Su et al. found that gold on $\mathrm{Ga}_{3} \mathrm{Al}_{3} \mathrm{O}_{9}$ can be very efficient and active for the benzyl alcohol oxidation at room temperature (Su et al., 2007). Carabineiro and co-authors used gold on different metal oxide supports by $\mathrm{DP}\left(\mathrm{Al}_{2} \mathrm{O}_{3}, \mathrm{Fe}_{2} \mathrm{O}_{3}, \mathrm{ZnO}\right.$, and $\left.\mathrm{TiO}_{2}\right)$ (Martins et al., 2017). The obtained materials were tested for the benzyl alcohol oxidation using tert-butyl hydroperoxide (TBHP) as oxidant, for $1 \mathrm{~h}$, under microwave irradiation, at $100^{\circ} \mathrm{C}$. The materials exhibited good activity for benzaldehyde formation, with no 


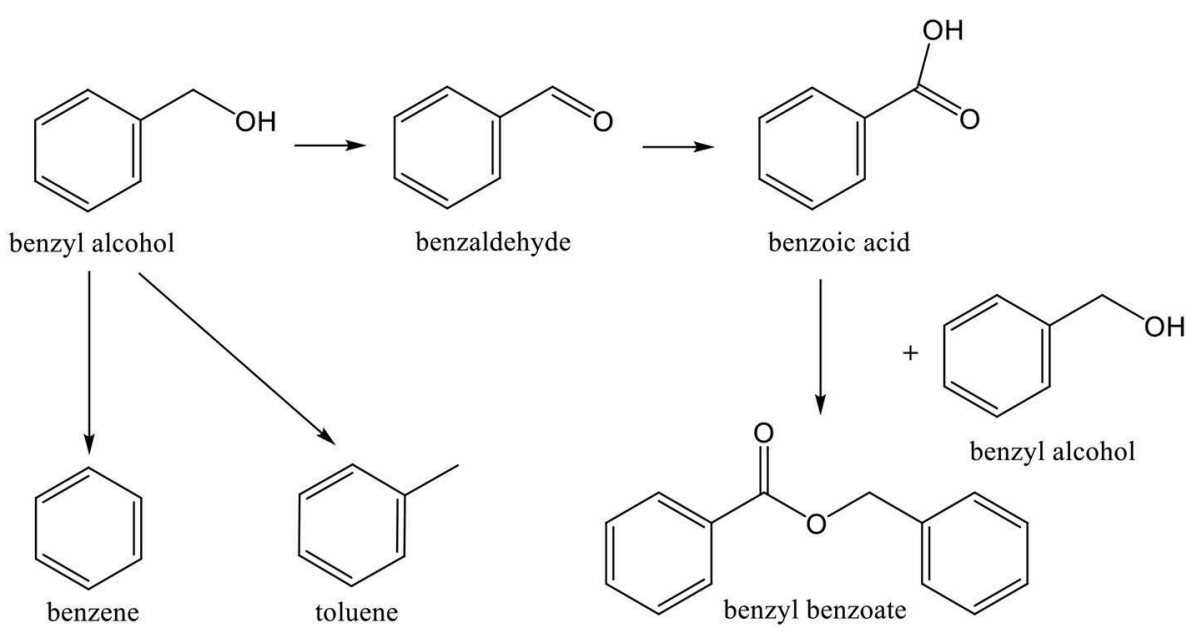

SCHEME 9 | Reactions of benzyl alcohol oxidation.

traces of by-products. The use of microwave is regarded as much more effective, when compared with conventional heating, usually with similar yields achieved in a shorter time and at lower temperatures (Varma, 2007; Dudley et al., 2015). Other authors also used TBHP (Choudhary and Dumbre, 2009a,b, 2010; Choudhary et al., 2009; Li H. R. et al., 2009; Peneau et al., 2013; Zhang B. et al., 2016; Martins et al., 2017; Ndolomingo and Meijboom, 2017; Gogoi et al., 2018; Kashani et al., 2018) and $\mathrm{H}_{2} \mathrm{O}_{2}$ (Zhan et al., 2012, 2013; Hallett-Tapley et al., 2013; Moreno et al., 2013; Santonastaso et al., 2014; Tang et al., 2014; Long and Quan, 2015; Mehri et al., 2015; Restrepo et al., 2015a,b; Emayavaramban et al., 2016a; Zhang B. et al., 2016; Gogoi et al., 2018; Khawaji and Chadwick, 2018; Tareq et al., 2018) as oxidants for alcohol oxidation reactions, although more studies deal with the use of oxygen (Besson and Gallezot, 2000; Prati and Porta, 2005; Bond et al., 2006; Hashmi and Hutchings, 2006; Hutchings et al., 2006; Carabineiro and Thompson, 2007, 2010; Ishida and Haruta, 2007; Fristrup et al., 2008; Della Pina and Falletta, 2011; Della Pina et al., 2012; Dimitratos et al., 2012; Takei et al., 2012; Hutchings, 2014; Freakley et al., 2015; Sharma et al., 2016).

Recently, gold nanoparticles on alumina, silica and titration, prepared by DP with urea, for the oxidation of benzyl alcohol, in the absence of solvent, with low metal (0.08-0.05 mol\% of $\mathrm{Au}$ ) loadings, using $\mathrm{O}_{2}$ as oxidant (Gualteros et al., 2019). A small amount of base was enough to activate the catalyst. $\mathrm{Au} / \mathrm{Al}_{2} \mathrm{O}_{3}$ showed a good catalytic performance $(\mathrm{TOF}=443,624$ $\mathrm{h}^{-1}$ at $100^{\circ} \mathrm{C}$ ) for $0.08 \mathrm{~mol} \% \mathrm{Au}$ loading, in optimized conditions, being the most stable material, being stable up to 5 cycles.

Carbon materials have also been utilized. Hutchings and coworkers used $\mathrm{Au}$ /activated, which showed high selectivity at low conversion (Hutchings et al., 2006). Benzyl alcohol oxidation was also studied on $\mathrm{Au} / \mathrm{CNT}$ and $\mathrm{Au} / \mathrm{CNF}$ by Prati's group (Prati et al., 2011). Gold on carbon xerogels (Xu et al., 2012) and on graphene derivatives (Xie et al., 2012; Yu et al., 2013; Movahed et al., 2014) has also been reported. Carabineiro and co-authors also tested the liquid phase selective oxidation of benzyl alcohol on $\mathrm{Au}$ /activated carbon and $\mathrm{Au} / \mathrm{C}_{3} \mathrm{~N}_{4}$ (Zhu et al.,

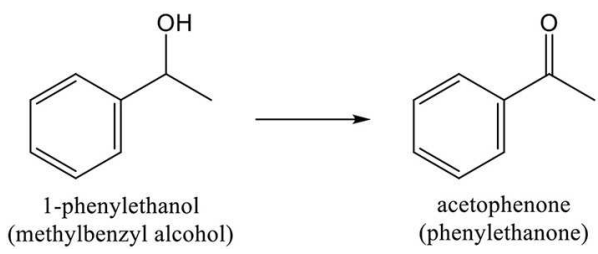

SCHEME 10 | Oxidation of 1-phenylethanol to acetophenone.

2010). The catalyst without oxygen showed negligible activity for oxidation reactions, showing that the metal only is ineffective for the activation of molecular oxygen. Also it was found that the oxidation activity depended on the amount of oxygen containing species of the catalyst, suggesting that the oxygen sites are where molecular oxygen adsorption and activation take place.

Bimetallic Au-Pd (Hong et al., 2014; Morad et al., 2014; Silva T. A. G. et al., 2014; Sun et al., 2016) and trimetallic Au-PdPt (He et al., 2013) catalysts have also been reported by several authors. They showed significant enhanced activity, compared to monometallic Au and Pd materials. The addition of Pt promoted the selectivity to benzaldehyde, suppressing toluene formation (He et al., 2013).

The oxidation of 1-phenylethanol (methylbenzyl alcohol) to acetophenone (phenylthenone), shown in Scheme 10, has also been studied on gold catalysts (Abad et al., 2005; Miyamura et al., 2007; Haider et al., 2009; Mitsudome et al., 2009; Ni et al., 2009; Wang et al., 2010; Buonerba et al., 2012; Hosseini-Monfared et al., 2013; Imura et al., 2016; Wang S. et al., 2016; Martins et al., 2017). For example, Corma and co-workers reported that $\mathrm{Au} /$ ceria catalysts showed a TOF value of $12,480 \mathrm{~h}^{-1}$, at 160 ${ }^{\circ} \mathrm{C}$, with $>99 \%$ selectivity, for this reaction (Abad et al., 2005). That value was larger than the reported for Pd on hydroxyapatite $\left(9,800 \mathrm{~h}^{-1}\right)$, as reported by Mori et al. (2004).

Takato and co-workers (Mitsudome et al., 2009) observed that a hydrotalcite supported nanoparticle $(\mathrm{Au} / \mathrm{HT})$ was a good 
heterogeneous catalyst for the oxidation of 1-phenylethanol under mild conditions. The turnover number (TON, mol of product per mol of Au catalyst) and TOF were 200,000 and $8,300 \mathrm{~h}^{-1}$, respectively. Moreover, the catalyst could be effortlessly filtrated and recycled without much loss of activity and selectivity. Imura et al. used surface clean $\mathrm{Au}$ nanoflowers and $\mathrm{Au}$ nanoparticles supported on $\gamma-\mathrm{Al}_{2} \mathrm{O}_{3}$ (Imura et al., 2016). The formation rate of acetophenone on nanoflowers was 10-fold higher than on (spherical) nanoparticles with a similar diameter.

As referred above, Buonerba et al. used gold nanoparticles incarcerated in nanoporous syndiotactic polystyrene matrices to study the oxidation of several alcohols, suggesting that nanoparticles of $\sim 9 \mathrm{~nm}$ diameter were the active catalyst (Buonerba et al., 2012). High yields (96\%) of acetophenone were obtained in $1 \mathrm{~h}$, at $35^{\circ} \mathrm{C}$. Haider et al. used $\mathrm{Au}$ nanoparticles on $\mathrm{CuMg}_{2} \mathrm{Al}_{1} \mathrm{O}_{\mathrm{x}}$ and also found higher activity for gold particles of $c a .9 \mathrm{~nm}$, with yields near $90 \%$, at $90^{\circ} \mathrm{C}$ for $1 \mathrm{~h}$ (Haider et al., 2009).

Hosseini-Monfared et al. used gold nanoparticles with a similar size (8 $\mathrm{nm}$ average) dispersed in 1-n-butyl-3methylimidazolium tetrafluoroborate ionic liquid and found $100 \%$ selectivity to acetophenone, with intermediate $\alpha$-hydroxy carbon radical formation (Hosseini-Monfared et al., 2013). The TON was 200. This value could be increased with the addition of N-hydroxyphthalimide, but at a cost of a selectivity drop to $58 \%$. Tests were carried out at $100^{\circ} \mathrm{C}$, under 4 bar of $\mathrm{O}_{2}$, without any base. However, the use of molecular oxygen should be undertaken with proper safety precautions, as reported by other authors (Bay et al., 2016).

Wang et al. used gold nanoparticles supported on a layered double hydroxide and obtained a acetophenone around $100 \%$, using $\mathrm{O}_{2}$, atmospheric pressure, room temperature, $2 \mathrm{~h}$ conditions (Wang et al., 2010). Upon 6 recycling cycles, the activity dropped to $97 \%$. The gold nanoparticles had sizes in the $1-5 \mathrm{~nm}$ range. Furthermore, $\mathrm{Ni}$ et al. reported an efficient $\mathrm{H}_{2} \mathrm{O}_{2}$ - $\mathrm{Au}$ approach for the 1-phenylethanol oxidation under solvent free conditions, which was considered as a "green" oxidation of heterogeneous metal complexes (Ni et al., 2009). For example, the $\mathrm{Au} / \mathrm{TiO}_{2}$ catalyst obtained a conversion of $99 \%$, and the yield of acetophenone was between 98 and 100\%, which means that the formation of well-dispersed $\mathrm{Au}$ nanoparticles, together with a beneficial interaction with the $\mathrm{TiO}_{2}$ support, is the major factor for obtaining high activity in the $\mathrm{H}_{2} \mathrm{O}_{2}$ mediated oxidation of 1-phenylethanol.

Nickel-containing layered double hydroxides supporting atomic precise $\mathrm{Au}-25$ nanoclusters were reported by other authors (Wang S. et al., 2016). The catalysts exhibited excellent activity for selective oxidation of 1-phenylethanol to acetophenone, with $\mathrm{O}_{2}$, under base-free conditions. The highest activity showed a TOF of $118,500 \mathrm{~h}^{-1}$ in a solventfree environment and could be applied for a wide range of alcohols. The material could be recycled 5 times without mich loss of activity.

Carabineiro and co-authors used gold loaded on different metal oxide supports $\left(\mathrm{Al}_{2} \mathrm{O}_{3}, \mathrm{Fe}_{2} \mathrm{O}_{3}, \mathrm{ZnO}\right.$, and $\left.\mathrm{TiO}_{2}\right)$, by $\mathrm{DP}$, in the oxidation of 1-phenylethanol, using TBHP as oxidant, under microwave irradiation (Martins et al., 2017). Those catalytic

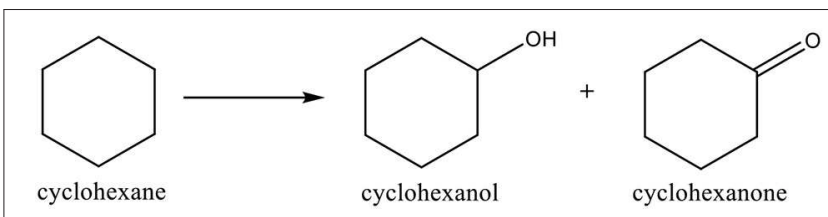

SCHEME 11 | Oxidation of cyclohexane to cyclohexanol and cyclohexanone.

systems exhibited good activity in the formation of acetophenone (Figure 4, left). No traces of by-products were found. Adding $\mathrm{Au}$ increased the alcohol conversion from $5 \%\left(\mathrm{TiO}_{2}\right)$ to $91 \%$ $\left(\mathrm{Au} / \mathrm{TiO}_{2}\right)$, which was the best result obtained in this study. $\mathrm{Au} / \mathrm{TiO}_{2}$ recyclability was tested up to a maximum of 10 cycles and the catalytic activity was very high in the initial 4 cycles (Figure 4, right). The loss of activity was due to a large increase in gold nanoparticle size and gold leaching (in the 10th cycle).

\section{ALKANE OXIDATION}

Hydrocarbons, in particular alkanes, are the main components of gas and oil. The $\mathrm{C}-\mathrm{H}$ bond(s) of these compounds can be transformed into $\mathrm{C}-\mathrm{OH}$ or $\mathrm{C}=\mathrm{O}$ groups that will lead to the production of high added value products that will have applications in fine chemistry. The selective oxidation of hydrocarbons is a very important reaction taking place in industrial processes based on petroleum, since the oxygenated compounds produced can be used as intermediates for organic synthesis (Kalvachev et al., 1999). However, it is difficult to activate such bonds in these very stable compounds, and that prevents that they are more commonly used in the synthesis of other important products (Weissermel and Arpe, 1993; Derouane et al., 1998, 2005; Clark and Macquarrie, 2002; Sheldon et al., 2007).

\section{Oxidation of Cyclohexane}

A good example with increasing industrial importance is the oxidation of cyclohexane to cyclohexanol and cyclohexanone (Scheme 11), that are important compounds to be used in the production of caprolactam and adipic acid, utilized in the nylon6 and nylon- 66 polymers manufacture. These products can also be used as solvents, homogenizers, and stabilizers (Carabineiro and Thompson, 2007). The cyclohexanol and cyclohexanone mixture is also called KA (ketone-alcohol) oil. The industrial process for KA oil production includes a homogeneous cobalt catalyst and $\mathrm{O}_{2}$ as oxidant, at high temperature $\left(150^{\circ} \mathrm{C}\right)$, with products being formed at low yields (4-12\%), with only $80-85 \%$ selectivity (Weissermel and Arpe, 1993; Whyman, 2001; Clark and Macquarrie, 2002; Mears and Eastman, 2004; Derouane et al., 2005). Thus, there is a need for more effective systems to be used under milder conditions (Weissermel and Arpe, 1993; Schuchardt et al., 2001; Clark and Macquarrie, 2002; Shulpin, 2009; Kirillov and Shul'pin, 2013).

Shulpin first studied the (photo)oxidation of cyclohexane with oxygen (Lederer et al., 1992; Nizova and Shulpin, 1992; Shulpin and Nizova, 1993) and oxidation of other alkanes with $\mathrm{H}_{2} \mathrm{O}_{2}$ (Shul'pin et al., 2001), using gold chloride compounds. Not much 
studies on cyclohexane oxidation have been done afterwards with gold complexes, apart from the work of Carabineiro and coauthors (Peixoto De Almeida et al., 2013; Carabineiro et al., 2018). Moreover, the oxidation of other alkanes (with gold complexes) is also scarce (Nikitenko and Shestakov, 2013).

The first reports dealing with the selective oxidation of cyclohexane to cyclohexanone and cyclohexanol using $\mathrm{Au}$ supported catalysts were reported by Suo and co-workers in 2004 (Lu et al., 2004, 2005; Zhao et al., 2004). The initial studies were carried out using a calcined Au/ZSM-5 catalyst, with $\mathrm{O}_{2}$, without solvent (Zhao et al., 2004). Authors reported that this catalyst was very active and could be used up to two cycles without much loss of activity. The yield decreased with temperature (from 140 to $180^{\circ} \mathrm{C}$ ), and also the total selectivity of cyclohexanol and cyclohexanone (at $180^{\circ} \mathrm{C}$ ) (Zhao et al., 2004). Those authors studied this reaction over a $\mathrm{Au} / \mathrm{MCM}-41$ catalyst, also in the absence of solvent, with $1 \mathrm{MPa} \mathrm{O}_{2}$, at $140-160^{\circ} \mathrm{C}$, for $6-8 \mathrm{~h}(\mathrm{Lu}$ et al., 2004, 2005). The conversion was $\sim 16 \%$ and the selectivity to cyclohexanone up to $\sim 76 \%$. Authors claimed that their work was the first reporting such excellent values of conversion and selectivity for these reaction systems. The catalyst could be recycled for at least three times, without much loss of conversion and selectivity (Lu et al., 2004, 2005).

In 2005; Hutchings et al. showed that Au/graphite could also be used to promote this reaction, using TBHP as initiator (Xu et al., 2005; Hutchings et al., 2006). A modest activity at $70^{\circ} \mathrm{C}$ and $0.3 \mathrm{MPa} \mathrm{O}_{2}$ was reported, with high selectivities to cyclohexanol and cyclohexanone only for very low conversions, after $17 \mathrm{~h}$ of reaction (Xu et al., 2005). The work of those authors was the only reference to $\mathrm{Au} /$ carbon combination for cyclohexane oxidation for some time.

In 2013; Carabineiro et al. tested gold nanoparticles on several carbon supports: activated carbon (AC), carbon xerogels-two different samples, one with smaller mesopore width $(13.6 \mathrm{~nm})$, prepared at $\mathrm{pH}=6(\mathrm{CX})$, and another with larger width $(32.3 \mathrm{~nm})$, prepared at $\mathrm{pH}=5.5(\mathrm{CXL})$, carbon nanotubes (CNT), microdiamonds (MD) and nanodiamonds (ND) in powder (NDPW) and liquid dispersion (NDLIQ), graphite (GR), and silicon carbide (SC) (Carabineiro et al., 2013). Gold was loaded by DIM and COL. The materials were tested at room temperature and atmospheric pressure, using a "green" oxidant $\left(\mathrm{H}_{2} \mathrm{O}_{2}\right) . \mathrm{Au} / \mathrm{CNT}-\mathrm{COL}$ was the most active catalyst (Figure 5), with a yield of $3.6 \%$ and a TON of $\sim 171$ ( $6 \mathrm{~h}$ reaction). The yield is similar to the industrial process (which needs high amounts of a Co catalyst and $150^{\circ} \mathrm{C}$ ), but has the advantage of being obtained at room temperature and much lower amount of catalyst (Au catalyst/substrate molar ratio below $1 \times 10^{-3}$ ), being thus "greener." Also very high selectivity toward the formation of cyclohexanol and cyclohexanone was obtained, without any by-products. The $3.6 \%$ yield obtained for this sample is similar to that reported by Hutchings and co-workers (3.7\%) for $1 \% \mathrm{Au}$ on graphite (Xu et al., 2005). But these authors needed $0.3 \mathrm{MPa}$ $\mathrm{O}_{2}, 17 \mathrm{~h}$ reaction and $70^{\circ} \mathrm{C}$, and the total selectivity for KA oil was $23.1 \%$. Only for low conversions $(\sim 1 \%)$, higher selectivities ( $\sim 91.6 \%$ ) could be obtained, under the same conditions, with with $0.5 \% \mathrm{Au}$ and with TBHP as additive (Xu et al., 2005). Therefore, the results of Carabineiro et al. (2013), showing a higher selectivity and a similar yield are more favorable, environmentally friendly and adequate for industry.

It was shown that an acidic medium could have a promoting effect as also found in previous studies dealing with homogeneous (Nizova et al., 2002; Shul'pin et al., 2004; Alegria et al., 2007; Silva et al., 2008, 2010, 2011; Fernandes et al., 2009; Mishra et al., 2009), and supported complexes (Mishra et al., 2008) and other metal catalysts (Kirillov and Shul'pin, 2013). The used pyrazine carboxylic acid might activate the metal center by protonation of a ligand, causing further unsaturation, enhance the oxidation capacity of metal complexes, and stabilize the peroxide preventing decomposition and promoting the formation of peroxo (or hydroperoxo)-complexes (Carabineiro et al., 2018). The recycling tests showed that the best catalyst was able to maintain the high activity up to five cycles, with very high selectivity and no leaching.

Liu et al. used Au nanoparticles on CNT composites for the photocatalytic oxidation of cyclohexane, achieving $\sim 14.6 \%$ conversion with a selectivity of $\sim 86.9 \%$ to cyclohexanol, using air and visible light, at room temperature (Liu et al., 2014a). Other authors also used $\mathrm{Au}$ nanoparticles on carbon quantum dots as photocatalysts, achieving a conversion of $63.8 \%$ and a selectivity of $99.9 \%$ to cyclohexane and cyclohexanone, using $\mathrm{H}_{2} \mathrm{O}_{2}$, at room temperature, under visible light (Liu R. H. et al., 2014). Kang and co-workers also tested the photocatalytic oxidation of cyclohexane using $\mathrm{Au}$ on carbon nitride $\left(\mathrm{C}_{3} \mathrm{~N}_{4}\right)$ and obtained $10.54 \%$ conversion and $100 \%$ selectivity to cyclohexanone without the need of initiator or oxidant, under visible light (Liu et al., 2014b). Authors showed that $\mathrm{C}_{3} \mathrm{~N}_{4}$ could photocatalyse water oxidation to generate $\mathrm{H}_{2} \mathrm{O}_{2}$, which would then act as oxidant.

More recently, Mayani et al. reported on $\mathrm{Au}, \mathrm{Pd}$ and and $\mathrm{Au}-$ Pd anchored carbon composites with 25 and $170 \mathrm{~nm}$ size carbon cages, synthesized using nano-silica sphere templates and fuel oil from pyrolysis of pitch residue as carbon source (Mayani et al., 2016). Such materials were used for cyclohexane oxidation at room temperature and atmospheric pressure, using $\mathrm{H}_{2} \mathrm{O}_{2}$ as oxidant, in $\mathrm{N}_{2}$ atmosphere. The most active catalyst (Aubased) showed a yield of $7.7 \%$ after $4 \mathrm{~h}$ reaction, superior to Pd- and Au-Pd- based analogs. Recyclability did not show much activity loss.

Metal oxides have also been referred as supports for $\mathrm{Au}$ for the same reaction (Zhu et al., 2005; Xu et al., 2007a,b, 2008; Carneiro et al., 2009, 2011; Li et al., 2009a,b; Xie et al., 2009, 2011; Hereijgers and Weckhuysen, 2010; Wu P. P. et al., 2010; Wan et al., 2011; Wu et al., 2011a,b,c, 2016b; Alshammari et al., 2012, 2015, 2016; Conte et al., 2012; Sun et al., 2012; Sannino et al., 2013; Wang C. H. et al., 2013; Zhou et al., 2014; Gui et al., 2015; Liu et al., 2015; Mohamed, 2015; Chen L. F. et al., 2017; Martins et al., 2017). Most studies were carried out using $\mathrm{O}_{2}$ as oxidant (Zhu et al., 2005; Xu et al., 2007a,b, 2008; Li et al., 2009a; Xie et al., 2009, 2011; Hereijgers and Weckhuysen, 2010; Wu P. P. et al., 2010; Wan et al., 2011; Wu et al., 2011a,b,c, 2016b; Alshammari et al., 2012; Sun et al., 2012; Wang C. H. et al., 2013; Zhou et al., 2014; Gui et al., 2015; Chen L. F. et al., 2017). Many reports refer the use of $\mathrm{TiO}_{2}$ based materials (Carneiro et al., 2009, 2011; Hereijgers and Weckhuysen, 2010; Alshammari et al., 2012; 

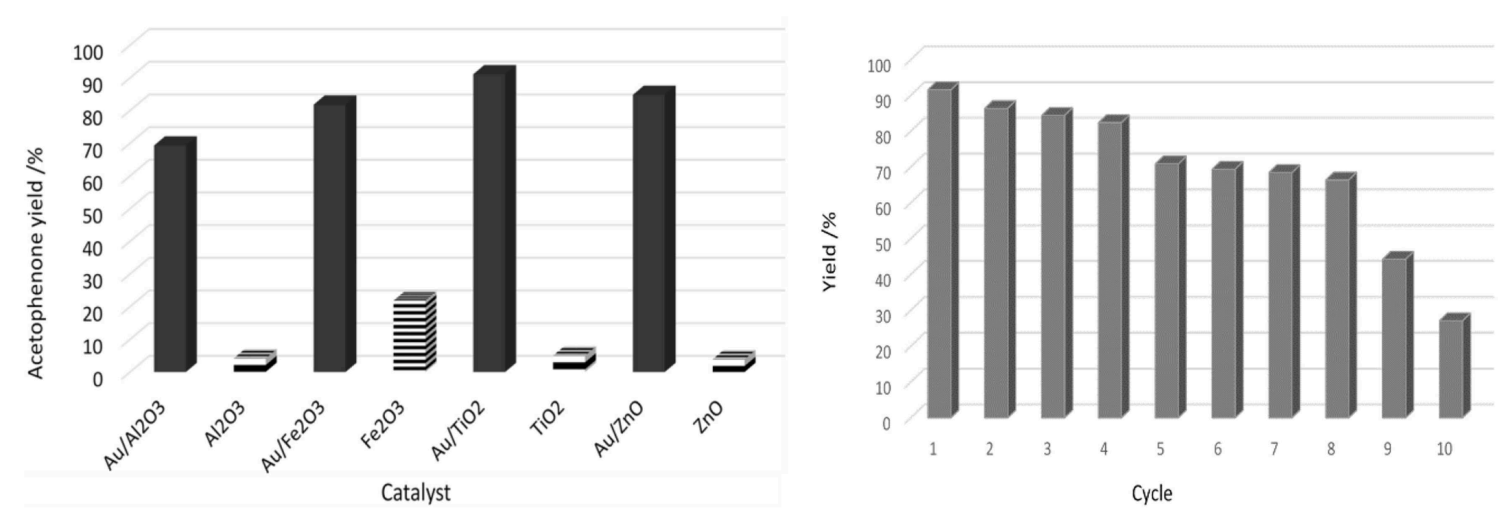

FIGURE 4 | (Left) Comparison of the acetophenone yield obtained by microwave assisted 1-phenylethanol oxidation with TBHP, using Au nanoparticles supported at different oxides and the metal oxides as catalysts. Conditions: $100^{\circ} \mathrm{C}, 1 \mathrm{~h}, 10 \mathrm{~W}$ microwave, $600 \mathrm{rpm}$. (Right) Recyclability of the Au/TiO 2 affecting the yield of acetophenone for the microwave assisted oxidation of 1-phenylethanol. Conditions: $100^{\circ} \mathrm{C}, 1 \mathrm{~h}, 10 \mathrm{~W}$ microwave, $600 \mathrm{rpm}$. Copyright (2017) Wiley. Adapted with permission from Martins et al. (2017).

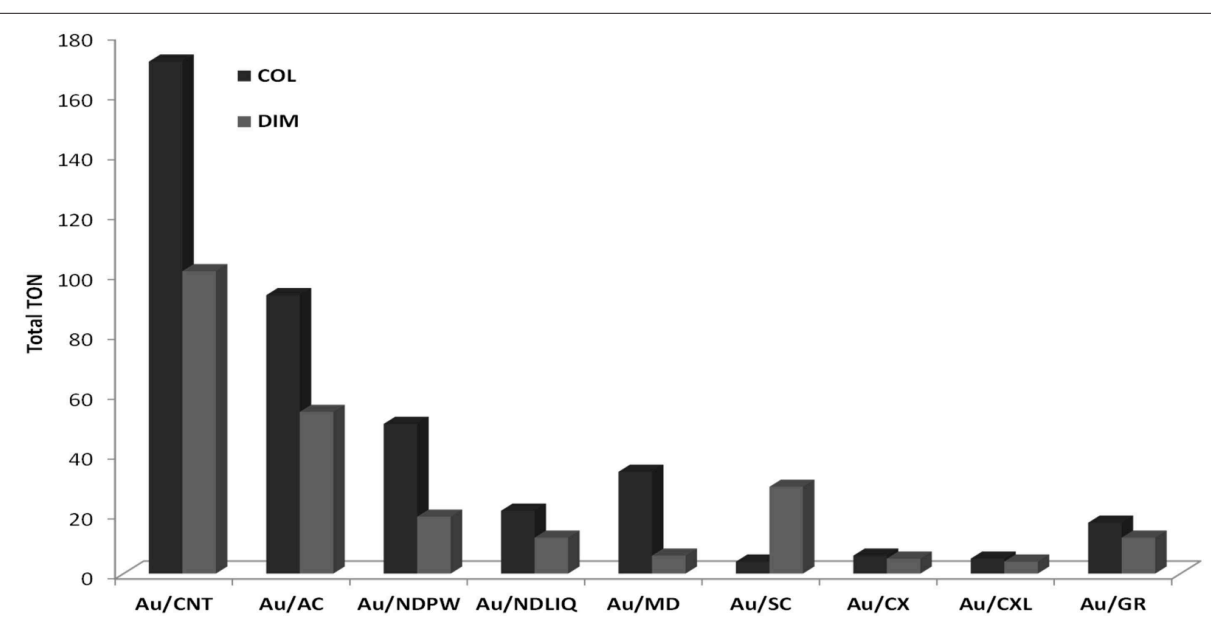

FIGURE 5 | Dependence of the overall TON (moles of cyclohexanol + cyclohexanone per mole of Au nanoparticles loaded on the carbon material) of the products on the type of support and impregnation method. Reaction conditions: $\mathrm{CH}_{3} \mathrm{CN}(3.0 \mathrm{~mL})$, cyclohexane $(5.0 \mathrm{mmol})$, $\mathrm{n}_{\text {pyrazinecarboxylicacid }} / \mathrm{n}_{\text {catalyst }}(50)$, room temperature, $6 \mathrm{~h}$. Reprinted from Carabineiro et al. (2013). Copyright (2013), with permission from Elsevier.

Sun et al., 2012; Sannino et al., 2013; Zhou et al., 2014; Martins et al., 2017). Interestingly, for the photo-oxidation of cyclohexane with air, the photocatalytic activity of $\mathrm{TiO}_{2}$ (Hombikat) was not enhanced by $\mathrm{Au}$ deposition, as shown by Mul and co-workers (Carneiro et al., 2009, 2011). The reason is that the deposition of gold caused a large decrease in the amount of $\mathrm{OH}$ - groups of the support, suggesting that such moieties were more determinant for the catalytic activity than the presence or absence of $\mathrm{Au}$ (Carneiro et al., 2009).

However, the photocatalytic cyclohexane partial oxidation in the gas-phase was effectively achieved on $\mathrm{Au} / \mathrm{TiO}_{2}$ (Sannino et al., 2013). The products obtained were cyclohexanol, cyclohexanone, and $\mathrm{CO}_{2}$. Authors showed that an increase in the $\mathrm{Au}$ content, could revert the process selectivity from cyclohexanol (75\%) to cyclohexanone (80\%).

Mohamed also reported on the photocatalytic oxidation of cyclohexane, with $\mathrm{H}_{2} \mathrm{O}_{2}$ as oxidant, using gold on reduced graphene oxide $(\mathrm{Au} / \mathrm{rGO})$, titania nanotubes (Au/TNT) and titania nanotubes-multi-walled carbon nanotubes composites (Au/TNT-CNT), under UV irradiation (Mohamed, 2015). Both $\mathrm{Au} / \mathrm{rGO}$ and $\mathrm{Au} / \mathrm{TNT}-\mathrm{CNT}$ can promote the oxidation with conversions ranging from 6 to $9.0 \%$ and selectivities from 60 to $75 \%$ for cyclohexanone, with the latter giving the best result. The oxidation followed a radical-chain mechanism.

Silica-based materials have also been used (Zhao et al., 2005; Zhu et al., 2005; Xu et al., 2007b, 2008; Li et al., 2009a; Wu et al., 2011a,b,c, 2016b; Wang C. H. et al., 2013; Zhou et al., 2014; Gui et al., 2015; Saxena et al., 2016; Chen L. F. et al., 2017). Au/mesoporous silica showed high catalytic activity and selectivity for cyclohexane oxidation using $\mathrm{O}_{2}$ in solvent-free conditions (Zhu et al., 2005; Wu et al., 2011a,b,c, 2016b). Li et al. used $\mathrm{Au}$ nanoparticles $(3-8 \mathrm{~nm})$ on $\mathrm{SBA}-15$, under an $\mathrm{O}_{2} / \mathrm{N}_{2}$ atmosphere (Li et al., 2009b). At $1.0 \mathrm{MPa}$ and $150^{\circ} \mathrm{C}$, when the 
reaction time increased from 3 to $6 \mathrm{~h}$, conversion also rose from 15 to $20 \%$, but with an overall decline of selectivity to KA-oil.

Cyclohexane oxidation was also tested over a $\mathrm{Au} / \mathrm{SiO}_{2}$ catalyst, with propylene carbonate significantly enhancing the reaction of cyclohexane oxidation to $21.9 \%$ conversion, while maintaining a high selectivity of $83.2 \%$ toward $\mathrm{KA}$ oil, using $\mathrm{O}_{2}$ as oxidant and TBHP as initiator, at $140^{\circ} \mathrm{C}$, for $2 \mathrm{~h}$ (Gui et al., 2015). The effect of propylene carbonate can be attributed to its high polarity and it can facilitate the reaction by promoting the decomposition of cyclohexyl hydroperoxide. Recycling tests showed no significant changes in the conversion of cyclohexane and selectivity to KA oil up to four reaction cycles, with no $\mathrm{Au}$ leaching. Gold nanoparticles on amorphous silica were used and gave a $22.7 \%$ conversion and $80.6 \%$ selectivity to cyclohexanol and cyclohexanone, under dipolar non-hydrogen bond donor acetone solvent, at $150^{\circ} \mathrm{C}, 1.5 \mathrm{MPa} \mathrm{O}_{2}$, after $3 \mathrm{~h}$ (Wang $\mathrm{C} . \mathrm{H}$. et al., 2013).

Silica-titania supported gold catalysts were tested at $150^{\circ} \mathrm{C}$, $1.5 \mathrm{MPa} \mathrm{O}_{2}$ and $3 \mathrm{~h}$ reaction, achieving a $91.7 \%$ selectivity with a conversion of $8.4 \%$ (Xu et al., 2007b). In similar conditions, $\mathrm{Au}$ on $\mathrm{TiO}_{2} / \mathrm{MCM}-41$ was promising for the cyclohexane oxidation, achieving a TOF of $29,145 \mathrm{~h}^{-1}$ with $\sim 9.9 \%$ conversion of cyclohexane (Zhou et al., 2014). Gold nanoparticles on silicaalumina were also used, in the absence of any solvent and initiator, achieving a $9.8 \%$ conversion and a $88.8 \%$ selectivity to $\mathrm{KA}$ oil, at $150{ }^{\circ} \mathrm{C}, 1.5 \mathrm{MPa} \mathrm{O}_{2}$, after $3 \mathrm{~h}$ (Xu et al., 2008).

Gold nanoparticles ( $<2 \mathrm{~nm}$ diameter) were highly dispersed and well-confined in the hybrid shells of silica nanospheres, through the anchorage of organic functional groups, under a condensation process (Chen L. F. et al., 2017). The materials exhibited good catalytic activity for solvent-free catalytic oxidation of cyclohexane with $94.8 \%$ selectivity to KA oil and adipic acid, at $150^{\circ} \mathrm{C}, 1.5 \mathrm{MPa} \mathrm{O}_{2}$, after $3 \mathrm{~h}$.

Saxena et al. encapsulated gold nanoparticles by silica, further encapsulated them with zeolites (MCM-22 and ZSM5) nanoshells and used the resulting material for the oxidation of cyclohexane, at $150^{\circ} \mathrm{C}$, under $1 \mathrm{MPa} \mathrm{O}_{2}$ pressure, in a solvent-free system, for $2 \mathrm{~h}$ (Saxena et al., 2016). Au@MCM-22 exhibited the highest TON (1788) and TOF $\left(596 \mathrm{~h}^{-1}\right)$ among the analyzed samples, due to a higher concentration of strong acid sites. The nano-capsules acted as bifunctional catalysts, with the nanoparticles prevented from agglomeration during synthesis or catalytic applications, and the zeolitic-shell enhanced conversion and reusability of the nanocatalysts.

Alshammari et al. compared $\mathrm{Au} / \mathrm{CaO}, \mathrm{Au} / \mathrm{MgO}, \mathrm{Au} / \mathrm{ZrO}_{2}$, $\mathrm{Au} / \mathrm{TiO}_{2}, \quad \mathrm{Au} / \mathrm{Al}_{2} \mathrm{O}_{3}$ (Alshammari et al., 2012, 2016). A conversion of over $25 \%$, with $70 \%$ selectivity to KA oil, was achieved over a $\mathrm{Au} / \mathrm{TiO}_{2}$ (anatase) catalyst, in the temperature range of $100^{\circ} \mathrm{C}$, at 10 bar $\mathrm{O}_{2}$, with TBHP as initiator. The high activity of this material was due to the smaller size $(2 \mathrm{~nm})$ of Au nanoparticles.

9.07\% conversion of cyclohexane and $91.90 \%$ selectivity to $\mathrm{KA}$ oil were obtained using $3.0 \% / \mathrm{Co}_{3} \mathrm{O}_{4}$ as catalyst, at $150^{\circ} \mathrm{C}$, after $3 \mathrm{~h}$, with $1.5 \mathrm{MPa}_{2}$ (Wan et al., 2011). Under similar conditions, $0.2 \% \mathrm{Au} / \mathrm{Al}_{2} \mathrm{O}_{3}$ achieved $12.6 \%$ conversion, with $84.7 \%$ selectivity to the ketone and alcohol mixture (Xu et al., 2007a).

$$
\begin{aligned}
& \mathrm{Au}^{0}+\mathrm{H}_{2} \mathrm{O}_{2} \rightarrow \mathrm{HO}^{\bullet}+\mathrm{Au}^{\mathrm{I}}+\mathrm{HO}^{-} \\
& \mathrm{Au}^{\mathrm{I}}+\mathrm{H}_{2} \mathrm{O}_{2} \rightarrow \mathrm{HOO}^{\bullet}+\mathrm{H}^{+}+\mathrm{Au}^{0} \\
& \mathrm{HO}^{\bullet}+\mathrm{CyH} \rightarrow \mathrm{H}_{2} \mathrm{O}+\mathrm{Cy}^{\bullet} \\
& \mathrm{Cy}^{\bullet}+\mathrm{O}_{2} \rightarrow \mathrm{CyOO}^{\bullet} \\
& \mathrm{CyOO}^{\bullet}+\mathrm{H}_{2} \mathrm{O}_{2} \rightarrow \mathrm{CyOOH}+\mathrm{HOO}^{\bullet} \\
& \mathrm{CyOOH}+\mathrm{Au}^{0} \rightarrow \mathrm{CyO}^{\bullet}+\mathrm{Au}^{\mathrm{I}}+\mathrm{HO}^{-} \\
& \mathrm{CyOOH}+\mathrm{Au}^{\mathrm{I}} \rightarrow \mathrm{CyOO}^{\bullet}+\mathrm{H}^{+}+\mathrm{Au}^{0} \\
& \mathrm{CyO}+\mathrm{CyH} \rightarrow \mathrm{CyOH}+\mathrm{Cy}^{\bullet} \\
& 2 \mathrm{CyOO}^{\bullet} \rightarrow \mathrm{CyOH}+\mathrm{Cy}-\mathrm{H}=\mathrm{O}+\mathrm{O}_{2}
\end{aligned}
$$

SCHEME 12 | Proposed reaction mechanism or oxidation of cyclohexane to cyclohexanol and cyclohexanone in supported gold nanoparticles. Reprinted from Carabineiro et al. (2013). Copyright (2013), with permission from Elsevier.

$\mathrm{Au}$ nanoparticles supported on Cr-based metal-organic frameworks (MOFs), and other oxides, like $\mathrm{TiO}_{2}$ and $\mathrm{Fe}_{2} \mathrm{O}_{3}$, prepared by DP with urea, were used for the reaction using $\mathrm{O}_{2}$, without solvent and initiator (Sun et al., 2012). The best result was $30.5 \%$ conversion, $26.7 \%$ yield, with $87.7 \%$ selectivity to $\mathrm{KA}$ oil, for $\mathrm{Au}$ on a Cr-MIL-101 type of MOF.

Gold nanoparticles were successfully supported on $\mathrm{Al}_{2} \mathrm{O}_{3}$, $\mathrm{Fe}_{2} \mathrm{O}_{3}, \mathrm{ZnO}$, and $\mathrm{TiO}_{2}$ by Carabineiro and co-authors by DP (Martins et al., 2017). Their catalytic activity was assessed for the oxidation of cyclohexane at $60^{\circ} \mathrm{C}$, atmospheric pressure, using $\mathrm{H}_{2} \mathrm{O}_{2}$ or TBHP (environmentally friendly oxidants). The results showed that $\mathrm{Au}$ nanoparticles were very active with no traces of by-products being detected under optimized conditions. $\mathrm{Au} / \mathrm{Al}_{2} \mathrm{O}_{3}$ was the least active material ( $1.3 \%$ yield with TBHP), possibly due to its lower reducibility (shown by TPR). The yields achieved with $\mathrm{Au} / \mathrm{TiO}_{2}$ and $\mathrm{Au} / \mathrm{ZnO}$ were 4.0 and $3.2 \%$, respectively (with TBHP). However, $\mathrm{Au}$ on $\mathrm{Fe}_{2} \mathrm{O}_{3}$ (with $\mathrm{H}_{2} \mathrm{O}_{2}$ ) showed a yield of $13.5 \%$ and was the best result obtained. It seems that, under those conditions, $\mathrm{Au}^{+}$initial oxidation state (shown by $\mathrm{Au} / \mathrm{Fe}_{2} \mathrm{O}_{3}$ and $\mathrm{Au} / \mathrm{TiO}_{2}$ ) was more suitable for the oxidation of cyclohexane than $\mathrm{Au}^{0}$ (found on $\mathrm{Au} / \mathrm{ZnO}$ and $\mathrm{Au} / \mathrm{Al}_{2} \mathrm{O}_{3}$ ), as it lead to higher yields of cyclohexanol and cyclohexanone, in shorter reaction times. Notably, these yields were obtained at $60^{\circ} \mathrm{C}$ and atmospheric pressure, with low catalyst loads (Au catalyst to substrate molar ratio $=4 \times 10^{-3}$ ), not requiring the presence of acid (as it was an inhibitor for these systems), being this more environmentally friendly. This system showed an almost exclusive unusual cyclohexanol formation by control of the reaction time $(4 \mathrm{~h})$. Catalyst recycling showed that the material was able to maintain high activity for 3 cycles (Figure 6), with not much leaching. The loss of activity shown for the 5th cycle is most likely due to adsorbed species on the surface, as shown by thermogravimetric experiments.

It has been controversially debated if $\mathrm{Au}$ acts as catalyst or as promotor of the oxidation reaction (Della Pina et al., 2012). 
Some authors believe that gold behaved as a real catalyst, as $10 \%$ conversion and $90 \%$ selectivity were obtained for with $\mathrm{Au} / \mathrm{TiO}_{2}$ $\mathrm{SiO}_{2}$, but not on the support with no gold (Xu et al., 2007b, 2008). Nevertheless, Hereijgers and Weckhuysen studied the same reaction on $\mathrm{Au} / \mathrm{SBA}-15, \mathrm{Au} / \mathrm{Al}_{2} \mathrm{O}_{3}$, and $\mathrm{Au} / \mathrm{TiO}{ }_{2}$, concluding that it follows a pure radical pathway with typical autoxidation products, being fully inhibited when radical scavengers are present (Hereijgers and Weckhuysen, 2010). However, Liu et al. demonstrated that gold/hydroxyapatite had high activity and that no reaction occurred in the support with no gold, although radical initiators, like TBHP, were needed (Liu et al., 2011). Hutchings and co-workers, when using $\mathrm{Au} / \mathrm{MgO}$ catalysts, suggested an intermediate scenario, that is, Au could indeed accelerate the reaction and not need initiators (thus behaving like a real catalyst), but the acceleration took place when the amount of some species were increased $\left(\mathrm{C}_{6} \mathrm{H}_{11}-\mathrm{OOH}\right.$ or $\mathrm{C}_{5} \mathrm{H}_{11^{-}}$$\mathrm{OO}^{\bullet}$ ), which promoted the catalytic processes by a radical chain mechanism (Conte et al., 2012).

Several authors report that the oxidation of cyclohexane by $\mathrm{H}_{2} \mathrm{O}_{2}$, catalyzed by metallic systems, proceeds mainly though a radical mechanism involving both $\mathrm{C}$ - and $\mathrm{O}$-centered radicals (Alegria et al., 2007; Silva et al., 2008, 2009, 2010, 2011, 2013). Therefore, by analogy with the proposed mechanisms for several metallic systems (like $\mathrm{Cu}, \mathrm{Fe}, \mathrm{Re}, \mathrm{V}$ ) (Shulpin et al., 1993; Shul'pin et al., 2004; Nizova et al., 2002; Kopylovich et al., 2003, 2011; Shul'pin, 2003; Tanase et al., 2005, 2008; Alegria et al., 2007; Kozlov et al., 2007; Mishra et al., 2008, 2009; Silva et al., 2008, 2009, 2010, 2011, 2013; Di Nicola et al., 2009; Fernandes et al., 2009, 2011; Kirillova et al., 2009b; Shul'pina et al., 2009; Nesterov et al., 2012), a metal-catalyzed (and pyrazine carboxylic acid-assisted) decomposition of $\mathrm{H}_{2} \mathrm{O}_{2}$ was proposed by Carabineiro et al. (2013), shown in Scheme 12, based on what was observed by other authors (Quintanilla et al., 2012). Water can catalyze $\mathrm{H}^{+}$-shift steps leading the formation of $\mathrm{HO}^{\bullet}$ from $\mathrm{H}_{2} \mathrm{O}_{2}$ (Kirillova et al., 2009a,b, 2011; Kuznetsov and Pombeiro, 2009). As suggested by Hutchings and co-workers for $\mathrm{Au} / \mathrm{MgO}$ (Conte et al., 2012), gold can increase the reaction rate due to an increase in $\mathrm{CyOOH}$ or $\mathrm{CyOO}^{\bullet}$ species.

Bimetallic $\mathrm{Au} / \mathrm{Pd}$ catalysts on carbon based materials showed inferior activity than gold on the same supports (Mayani et al., 2016), and the same happened on $\mathrm{TiO}_{2}$ supports (Alshammari et al., 2015, 2016). However, $\mathrm{Au}-\mathrm{Ag} / \mathrm{TiO}_{2}$ showed better activity than $\mathrm{Au} / \mathrm{TiO}_{2}$ (Alshammari et al., 2015). Also Au-Pd nanoparticles (on $\mathrm{MgO}$ ) showed a significant positive influence on the overall catalytic performance, inhibiting the production of unwanted by-products (Liu et al., 2015). Au-Ag alloy catalysts, with metal nanoparticles immobilized on mesoporous silica, were also used (Wu et al., 2016a). A high catalytic activity and a high KA oil selectivity (>95\%) were observed, due to the electronic structure modification caused by the synergistic effect of $\mathrm{Au}-\mathrm{Ag}$ alloy nanoparticles.

\section{Oxidation of Other Alkanes}

Gold catalysts have also been used also in other alkane oxidation reactions. As an example, $\mathrm{Au}$ on $\mathrm{SiO}_{2}, \mathrm{SBA}-15, \mathrm{Al}_{2} \mathrm{O}_{3}, \mathrm{ZSM}$ 5, $\mathrm{TiO}_{2}, \mathrm{ZrO}_{2}, \mathrm{CeO}_{2}$, and $\mathrm{Nb}_{2} \mathrm{O}_{5}$ catalysts were used for the selective oxidation of methane to methanol with $\mathrm{O}_{2}$ (Hereijgers

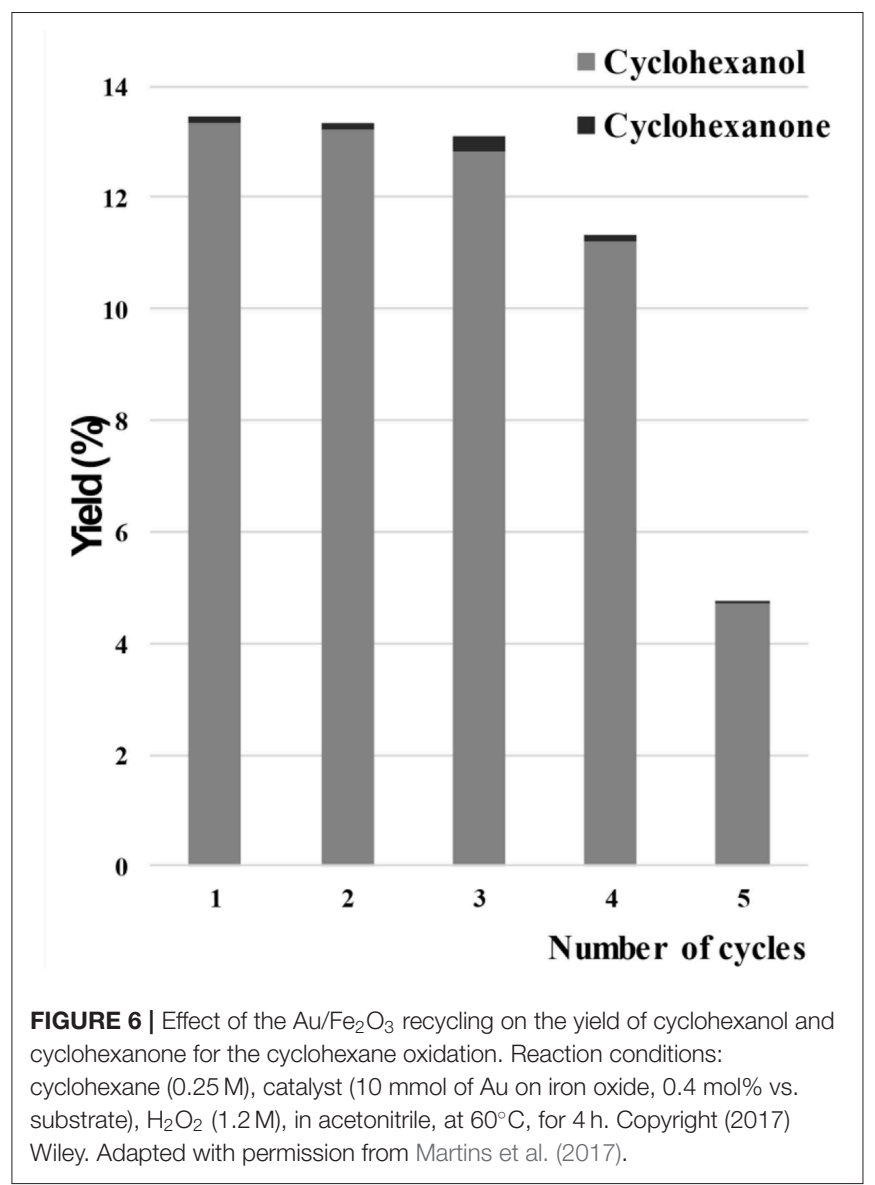

and Weckhuysen, 2011). Although all of them showed small gold nanoparticles, for temperatures above $250^{\circ} \mathrm{C}$, very low activity was found, showing they were not active for this reaction. However, other authors (Kulikova and Shestakov, 2008) showed that Au nanoparticles, stabilized by a 1-dodecanethiol monolayer, were able to oxidize methane in a dichloromethane medium, to originate methanol and ethane. $\mathrm{Au} / \mathrm{SiO}_{2}$ was also used to oxidize methane in ionic liquids, using $\mathrm{K}_{2} \mathrm{~S}_{2} \mathrm{O}_{8}$ as oxidant, at $90^{\circ} \mathrm{C}$, to produce methanol (Li T. et al., 2011).

Au-Ba/TS- 1 catalysts $(0.11 \% \mathrm{Au}$, Ti:Si ratio $=3: 100)$ were found to be very selective toward the formation of acetone $(90 \%)$, isopropanol (5\%), and $\mathrm{CO}_{2}(5 \%)$ from propane, $\mathrm{O}_{2}$ and $\mathrm{H}_{2}$, at $170^{\circ} \mathrm{C}$, after $0.5 \mathrm{~h}$ (Bravo-Suarez et al., 2008). Biradar and Asefa showed that SBA-15 supported Au nanoparticles were able to oxidize $n$-hexane (Biradar and Asefa, 2012). A 95\% conversion, with a $92 \%$ selectivity to 2 -hexanone and $8 \%$ selectivity to 2-hexanol, at $70^{\circ} \mathrm{C}$, after $8 \mathrm{~h}$ reaction, using with TBHP as oxidant, were obtained (Biradar and Asefa, 2012). Larger alkanes are more difficult to oxidize, as shown by Hutchings and co-workers, that obtained very low conversion $(\sim 1 \%)$ in the oxidation of $n$-decane, with azobisisobutyronitrile, at $90^{\circ} \mathrm{C}$, with 1.2 $\mathrm{MPa} \mathrm{O}_{2}$, using a $\mathrm{Au} /$ ceria catalyst, even for $20 \mathrm{~h}$ reaction (Lloyd et al., 2011).

Recently, the aerobic oxidation of several alkanes (cyclohexane, propane, ethane and methane) to the 
corresponding alcohols, over $\mathrm{Au}_{55}(\sim 1 \mathrm{~nm}$ size $)$ nanoparticles with icosahedron symmetry, was investigated using density functional theory calculations (Staykov et al., 2018). Authors estimated that alkane hydroxylation proceeds through a two-step radical reaction mechanism. First, a hydrogen atom is abstracted from the alkane yielding a surface hydroxyl group and an alkyl radical. Then a reaction between the alkyl radical and hydroxyl radical takes place on the gold surface, being the rate limiting step for the overall oxidation.

\section{CONCLUSIONS}

The obvious conclusion is that gold catalysts are very efficient for alcohol and alkane oxidation. The gold nanoparticle size and type of support continues to play a critical role, with smaller nanoparticles being more active, as in many other reactions. Gold has shown to be more active and selective than other noble metal catalysts. Gold on carbon is a very good catalyst for several reactions, but also gold on reducible oxides. However, composite supports and bimetallic gold catalysts are now emerging as new promising materials.

\section{REFERENCES}

Abad, A., Almela, C., Corma, A., and García, H. (2006a). Efficient chemoselective alcohol oxidation using oxygen as oxidant. Superior performance of gold over palladium catalysts. Tetrahedron 62, 6666-6672. doi: 10.1016/j.tet.2006.01.118

Abad, A., Almela, C., Corma, A., and García, H. (2006b). Unique gold chemoselectivity for the aerobic oxidation of allylic alcohols. Chem. Commun. 3178-3180. doi: 10.1039/B606257A

Abad, A., Concepción, P., Corma, A., and García, H. (2005). A collaborative effect between gold and a support induces the selective oxidation of alcohols. Angew. Chem. Int. Ed. 44, 4066-4069. doi: 10.1002/anie.200500382

Abad, A., Corma, A., and Garcia, H. (2008). Catalyst parameters determining activity and selectivity of supported gold nanoparticles for the aerobic oxidation of alcohols: the molecular reaction mechanism. Chem. Eur. J. 14, 212-222. doi: 10.1002/chem.200701263

Alegria, E. C. B., Kirillova, M. V., Martins, L. M. D. R. S., and Pombeiro, A. J. L. (2007). Pyrazole and trispyrazolylmethane rhenium complexes as catalysts for ethane and cyclohexane oxidations. Appl. Catal. A Gen. 317, 43-52. doi: 10.1016/j.apcata.2006.09.038

Alex, S., and Tiwari, A. (2015). Functionalized gold nanoparticles: synthesis, properties and applications-A review. J. Nanosci. Nanotechnol. 15, 1869-1894. doi: 10.1166/jnn.2015.9718

Alhumaimess, M., Lin, Z., He, Q., Lu, L., Dimitratos, N., Dummer, N. F., et al. (2014). Oxidation of benzyl alcohol and carbon monoxide using gold nanoparticles supported on $\mathrm{MnO}_{2}$ nanowire microspheres. Chem. Eur. J. 20, 1701-1710. doi: 10.1002/chem.201303355

Alshammari, A., Kalevaru, V. N., and Martin, A. (2016). Bimetallic catalysts containing gold and palladium for environmentally important reactions. Catalysts 6:97. doi: 10.3390/catal6070097

Alshammari, A., Kockritz, A., Kalevaru, V. N., Bagabas, A., and Martin, A. (2015). Potential of supported gold bimetallic catalysts for green synthesis of adipic acid from cyclohexane. Top. Catal.s 58, 1069-1076. doi: 10.1007/s11244-015-0 $475-9$

Alshammari, A., Koeckritz, A., Kalevaru, V. N., Bagabas, A., and Martin, A. (2012). Significant formation of adipic acid by direct oxidation of cyclohexane using supported nano-gold catalysts. ChemCatChem 4, 1330-1336. doi: $10.1002 /$ cctc. 201200008
Looking into the future, gold nanoparticles have the potential to become very active catalysts leading to potential application of these reactions in industry, allowing them to occur in much milder and "greener" conditions. Nevertheless, the issue of durability might hinder such applications. The use of composite materials might be the way to overcome these challenges and obtain more active, selective and durable materials with potential industrial importance.

\section{AUTHOR'S NOTE}

Dedicated to Prof. Armando Pombeiro on the occasion of his 70th birthday.

\section{AUTHOR CONTRIBUTIONS}

SC did the literature search and wrote the paper.

\section{FUNDING}

This work has been supported by Fundação para a Ciência e a Tecnologia, Portugal (projects PTDC/QEQ-QIN/3967/2014 and UID/QUI/00100/2019).

Andrade, G. R. S., Nascimento, C. C., Silva, E. C., Mendes, D., and Gimenez, I. F. (2017). $\mathrm{ZnO} / \mathrm{Au}$ nanocatalysts for enhanced decolorization of an azo dye under solar, UV-A and dark conditions. J. Alloys Compd. 710, 557-566. doi: 10.1016/j.jallcom.2017.03.295

Ayastuy, J. L., Gurbani, A., and Gutierrez-Ortiz, M. A. (2016). Effect of calcination temperature on catalytic properties of $\mathrm{Au} / \mathrm{Fe}_{2} \mathrm{O}_{3}$ catalysts in CO-PROX. Int. J. Hydrogen Energy 41, 19546-19555. doi: 10.1016/j.ijhydene.2016.02.080

Ayastuy, J. L., Iriarte-Velasco, U., Gurbani, A., and Gutierrez-Ortiz, M. A. (2017). Investigation of the calcination temperature effect on the interaction between $\mathrm{Au}$ nanoparticles and the catalytic support alpha- $\mathrm{Fe}_{2} \mathrm{O}_{3}$ for the low temperature CO oxidation. J. Taiwan Inst. Chem. Eng. 75, 18-28. doi: 10.1016/j.jtice.2017.03.032

Azizi, Y., Pitchon, V., and Petit, C. (2010). Effect of support parameters on activity of gold catalysts: studies of $\mathrm{ZrO}_{2}, \mathrm{TiO}_{2}$ and mixture. Appl. Catal. Gen. 385, 170-177. doi: 10.1016/j.apcata.2010.07.010

Bacsa, R. R., Dexpert-Ghys, J., Verelst, M., Falqui, A., Machado, B., Bacsa, W. S., et al. (2009). Synthesis and structure-property correlation in shapecontrolled $\mathrm{ZnO}$ nanoparticles prepared by chemical vapor synthesis and their application in dye-sensitized solar cells. Adv. Funct. Mater. 19, 875-886. doi: 10.1002/adfm.200801049

Bamwenda, G. R., Tsubota, S., Nakamura, T., and Haruta, M. (1997). The influence of the preparation methods on the catalytic activity of platinum and gold supported on $\mathrm{TiO}_{2}$ for CO oxidation. Catal. Lett. 44, 83-87. doi: 10.1023/A:1018925008633

Bastos, S. S. T., Carabineiro, S. A. C., Órfão, J. J. M., Pereira, M. F. R., Delgado, J. J., and Figueiredo, J. L. (2012). Total oxidation of ethyl acetate, ethanol and toluene catalyzed by exotemplated manganese and cerium oxides loaded with gold. Catal. Today 180, 148-154. doi: 10.1016/j.cattod.2011.01.049

Bay, S., Baumeister, T., Hashmi, A. S. K., and Röder, T. (2016). Safe and fast flow synthesis of functionalized oxazoles with molecular oxygen in a microstructured reactor. Org. Process Res. Dev. 20, 1297-1304. doi: 10.1021/acs.oprd.6b00118

Behera, M., and Ram, S. (2012). "Synthesis of gold nanoparticles in presence of poly(vinyl pyrrolidone) from gold hydroxide precursor salt," in Advances in Materials and Processing: Challenges and Opportunities, Vol. 585, eds B. S. S. Daniel and G. P. Chaudhari (Baech: Trans Tech Publications), 115. doi: 10.4028/www.scientific.net/AMR.585.115 
Behravesh, E., Kumar, N., Balme, Q., Roine, J., Salonen, J., Schukarev, A., et al. (2017). Synthesis and characterization of Au nano particles supported catalysts for partial oxidation of ethanol: influence of solution $\mathrm{pH}, \mathrm{Au}$ nanoparticle size, support structure and acidity. J. Catal. 353, 223-238. doi: 10.1016/j.jcat.2017.07.014

Beltrame, P., Comotti, M., Della Pina, C., and Rossi, M. (2006). Aerobic oxidation of glucose II. Catalysis by colloidal gold. Appl. Catal.Gen. 297, 1-7. doi: 10.1016/j.apcata.2005.08.029

Besson, M., and Gallezot, P. (2000). Selective oxidation of alcohols and aldehydes on metal catalysts. Catal. Today 57, 127-141. doi: 10.1016/S0920-5861(99)00315-6

Bianchi, C., Porta, F., Prati, L., and Rossi, M. (2000). Selective liquid phase oxidation using gold catalysts. Top. Catal. 13, 231-236. doi: 10.1023/A:1009065812889

Bianchi, C. L., Biella, S., Gervasini, A., Prati, L., and Rossi, M. (2003). Gold on carbon: influence of support properties on catalyst activity in liquid-phase oxidation. Catal. Lett. 85, 91-96. doi: 10.1023/A:1022176909660

Bianchi, C. L., Canton, P., Dimitratos, N., Porta, F., and Prati, L. (2005). Selective oxidation of glycerol with oxygen using mono and bimetallic catalysts based on Au, Pd and Pt metals. Catal. Today 102-103, 203-212. doi: 10.1016/j.cattod.2005.02.003

Biella, S., Castiglioni, G. L., Fumagalli, C., Prati, L., and Rossi, M. (2002a). Application of gold catalysts to selective liquid phase oxidation. Catal. Today 72, 43-49. doi: 10.1016/S0920-5861(01)00476-X

Biella, S., Porta, F., Prati, L., and Rossi, M. (2003a). Surfactant-protected gold particles: new challenge for gold-on-carbon catalysts. Catal. Lett. 90, 23-29. doi: 10.1023/A:1025808024943

Biella, S., Prati, L., and Rossi, M. (2002b). Selective oxidation of D-glucose on gold catalyst. J. Catal. 206, 242-247. doi: 10.1006/jcat.2001.3497

Biella, S., Prati, L., and Rossi, M. (2003b). Gold catalyzed oxidation of aldehydes in liquid phase. J. Mol. Catal. Chem. 197, 207-212. doi: 10.1016/S1381-1169(02)00618-0

Biella, S., Prati, L., and Rossi, M. (2003c). Selectivity control in the oxidation of phenylethane-1,2-diol with gold catalyst. Inorg. Chim. Acta 349, 253-257. doi: 10.1016/S0020-1693(03)00040-9

Biener, J., Biener, M. M., Madix, R. J., and Friend, C. M. (2015). Nanoporous gold: understanding the origin of the reactivity of a 21 st Century catalyst made by Pre-Columbian technology. ACS Catal. 5, 6263-6270. doi: $10.1021 /$ acscatal.5b01586

Biradar, A. V., and Asefa, T. (2012). Nanosized gold-catalyzed selective oxidation of alkyl-substituted benzenes and n-alkanes. Appl. Catal.Gen. 435, 19-26. doi: 10.1016/j.apcata.2012.05.029

Boccuzzi, F., Chiorino, A., Manzoli, M., Lu, P., Akita, T., Ichikawa, S., et al. (2001). Au/ $\mathrm{TiO}_{2}$ nanosized samples: a catalytic, TEM, and FTIR study of the effect of calcination temperature on the CO oxidation. J. Catal. 202, 256-267. doi: 10.1006/jcat.2001.3290

Bogdanchikova, N., Simakov, A., Smolentseva, E., Pestryakov, A., Farias, M. H., Diaz, J. A., et al. (2008). Stabilization of catalytically active gold species in Fe-modified zeolites. Appl. Surf. Sci. 254, 4075-4083. doi: 10.1016/j.apsusc.2007.12.060

Bogdanchikova, N., Tuzovskaya, I., Prati, L., Villa, A., Pestryakov, A., and Farias, M. (2017). More insights into support and preparation method effects in gold catalyzed glycerol oxidation. Curr. Org. Synth. 14, 377-382. doi: 10.2174/1570179413666161031114833

Boitsova, T. B., Loginov, A. V., and Gorbunova, V. V. (1999). Photochemical deposition of nanophase gold films on quartz. Inorg. Mater. 35, 1239-1243.

Bond, G., and Thompson, D. (1999). Catalysis by Gold. Catal. Rev. Sci. Eng. 41, 319-388. doi: 10.1081/CR-100101171

Bond, G. C. (2002). Gold: a relatively new catalyst. Catal. Today 72, 5-9. doi: 10.1016/S0920-5861(01)00522-3

Bond, G. C., Louis, C., and Thompson, D. T. (2006). Catalysis by Gold. London: Imperial College Press. doi: 10.1142/p450

Bond, G. C., and Thompson, D. T. (2000). Gold-catalysed oxidation of carbon monoxide. Gold Bull. 33, 41-50. doi: 10.1007/BF03216579

Bowker, M., Nuhu, A., and Soares, J. (2007). High activity supported gold catalysts by incipient wetness impregnation. Catal. Today 122, 245-247. doi: 10.1016/j.cattod.2007.01.021
Brady, J. T., Jones, M. E., Brey, L. A., Buccellato, G. M., Chamberlain, C. S., Huberty, J. S., et al. (2006). Heterogeneous, Composite Carbonaceous Catalyst system and Methods that Use Catalytically Active Gold. WO Patent 2006/074126. St. Paul, MN: 3M Innovative Properties Co.

Bravo-Suarez, J. J., Bando, K. K., Akita, T., Fujitani, T., Fuhrer, T. J., and Oyama, S. T. (2008). Propane reacts with $\mathrm{O}_{2}$ and $\mathrm{H}_{2}$ on gold supported TS-1 to form oxygenates with high selectivity. Chem. Commun. 3272-3274. doi: $10.1039 / \mathrm{b} 800620 \mathrm{~b}$

Brey, L., Wood, T. E., Buccellato, G. M., Jones, M. E., Chamberlain, C. S., and Siedle, A. R. (2005). Catalysts, Activating Agents, Support Media, and Related Methodologies Useful for Making Catalyst Systems Especially When the Catalyst Is Deposited Onto the Support Media Using Physical Vapor Deposition. WO Patent 2005/030382. St. Paul, MN: 3M Innovative Properties Co.

Broqvist, P., Molina, L. M., Gronbeck, H., and Hammer, B. (2004). Promoting and poisoning effects of $\mathrm{Na}$ and $\mathrm{Cl}$ coadsorption on $\mathrm{CO}$ oxidation over $\mathrm{MgO}$-supported $\mathrm{Au}$ nanoparticles. J. Catal. 227, 217-226. doi: 10.1016/j.jcat.2004.07.009

Buonerba, A., Cuomo, C., Sanchez, S. O., Canton, P., and Grassi, A. (2012). Gold nanoparticles incarcerated in nanoporous syndiotactic polystyrene matrices as new and efficient catalysts for alcohol oxidations. Chem. Eur. J. 18, 709-715. doi: 10.1002/chem.201101034

Carabineiro, S. A. C., Bastos, S. S. T., Órfão, J. J. M., Pereira, M. F. R., Delgado, J. J., and Figueiredo, J. L. (2010a). Carbon monoxide oxidation catalysed by exotemplated manganese oxides. Catal. Lett. 134, 217-227. doi: 10.1007/s10562-009-0251-1

Carabineiro, S. A. C., Bastos, S. S. T., Órfão, J. J. M., Pereira, M. F. R., Delgado, J. J., and Figueiredo, J. L. (2010b). Exotemplated ceria catalysts with gold for CO oxidation. Appl. Catal. A Gen. 381, 150-160. doi: 10.1016/j.apcata.2010.04.001

Carabineiro, S. A. C., Bogdanchikova, N., Avalos-Borja, M., Pestryakov, A., Tavares, P. B., and Figueiredo, J. L. (2011a). Gold supported on metal oxides for carbon monoxide oxidation. Nano Res. 4, 180-193. doi: 10.1007/s12274-010-0068-7

Carabineiro, S. A. C., Bogdanchikova, N., Pestryakov, A., Tavares, P. B., Fernandes, L. S. G., and Figueiredo, J. L. (2011b). Gold nanoparticles supported on magnesium oxide for CO oxidation. Nanoscale Res. Lett. 6, 1-6. doi: 10.1186/1556-276X-6-435

Carabineiro, S. A. C., Bogdanchikova, N., Tavares, P. B., and Figueiredo, J. L. (2012a). Nanostructured iron oxide catalysts with gold for the oxidation of carbon monoxide. RSC Adv. 2, 2957-2965. doi: 10.1039/c2ra00724j

Carabineiro, S. A. C., Machado, B. F., Bacsa, R. R., Serp, P., Dražić, G., Faria, J. L., et al. (2010c). Catalytic performance of $\mathrm{Au} / \mathrm{ZnO}$ nanocatalysts for $\mathrm{CO}$ oxidation. J. Catal. 273, 191-198. doi: 10.1016/j.jcat.2010.05.011

Carabineiro, S. A. C., Machado, B. F., Dražić, G., Bacsa, R. R., Serp, P., Figueiredo, J. L., et al. (2010d). "Photodeposition of Au and Pt on $\mathrm{ZnO}$ and $\mathrm{TiO}_{2}$," in Scientific Bases for the Preparation of Heterogeneous Catalysts: Proceedings of the 10th International Symposium, Studies in Surface Science and Catalysis, Vol. 175. eds E. M. Gaigneaux, M. Devillers, S. Hermans, P. A. Jacobs, J. A. Martens, and P. Ruiz (Amsterdam: Elsevier), 629-633. doi: 10.1016/S0167-2991(10)75124-7 Carabineiro, S. A. C., Martins, L. M. D. R. S., Buijnsters, J. G., Avalos-Borja, M., Pombeiro, A. J. L., and Figueiredo, J. L. (2013). Gold nanoparticles supported on carbon materials for cyclohexane oxidation with hydrogen peroxide. Appl. Catal. A Gen. 467, 279-290. doi: 10.1016/j.apcata.2013.07.035

Carabineiro, S. A. C., Martins, L. M. D. R. S., Pombeiro, A. J. L., and Figueiredo, J. L. (2018). Commercial Gold(I) and Gold(III) compounds supported on carbon materials as greener catalysts for the oxidation of alkanes and alcohols. ChemCatChem 10, 1804-1813. doi: 10.1002/cctc.201701886

Carabineiro, S. A. C., Papista, E., Marnellos, G. E., Tavares, P. B., MaldonadoHódar, F. J., and Konsolakis, M. (2017). Catalytic decomposition of $\mathrm{N}_{2} \mathrm{O}$ on inorganic oxides: effect of doping with Au nanoparticles. Mol. Catal. 436(Suppl. C), 78-89. doi: 10.1016/j.mcat.2017.04.009

Carabineiro, S. A. C., Santos, V. P., Pereira, M. F. R., Órfão, J. J. M., and Figueiredo, J. L. (2016). CO oxidation over gold supported on Cs, Li and Ti-doped cryptomelane materials. J. Colloid Interface Sci. 480, 17-29. doi: 10.1016/j.jcis.2016.06.072

Carabineiro, S. A. C., Silva, A. M. T., Dražić, G., and Figueiredo, J. L. (2010f). Preparation of Au nanoparticles on Ce-Ti-O supports. Stud. Surf. Sci. Catal. 175, 457-461. doi: 10.1016/S0167-2991(10)75084-9 
Carabineiro, S. A. C., Silva, A. M. T., Dražić, G., Tavares, P. B., and Figueiredo, J. L. (2010e). Gold nanoparticles on ceria supports for the oxidation of carbon monoxide. Catal. Today 154, 21-30. doi: 10.1016/j.cattod.2010.01.036

Carabineiro, S. A. C., Silva, A. M. T., Dražić, G., Tavares, P. B., and Figueiredo, J. L. (2010g). Effect of chloride on the sinterization of $\mathrm{Au} / \mathrm{CeO}_{2}$ catalysts. Catal. Today 154, 293-302. doi: 10.1016/j.cattod.2009.12.017

Carabineiro, S. A. C., Tavares, P. B., and Figueiredo, J. L. (2012b). Gold on oxidedoped alumina supports as catalysts for CO oxidation. Appl. Nanosci. 2, 35-46. doi: 10.1007/s13204-011-0037-9

Carabineiro, S. A. C., and Thompson, D. (2007). "Catalytic applications for gold nanotechnology," in Nanocatalysis. eds U. Heiz and U. Landman (Berlin; Heidelberg: Springer), 377-489. doi: 10.1007/978-3-540-32646-5_6

Carabineiro, S. A. C., and Thompson, D. (2010). "Gold Catalysis," in Gold: Science and Applications, eds C. Corti and R. Holliday (Boca Raton, FL; London, New York, NY: CRC Press; Taylor and Francis Group), 89-122. doi: 10.1201/9781420065268-c6

Cardenas-Lizana, F., De Pedro, Z. M., Gomez-Quero, S., Kiwi-Minsker, L., and Keane, M. A. (2015). Carbon supported gold and silver: application in the gas phase hydrogenation of m-dinitrobenzene. J. Mol. Catal. Chem. 408, 138-146. doi: 10.1016/j.molcata.2015.07.019

Carneiro, J. T., Savenije, T. J., Moulijn, J. A., and Mul, G. (2011). The effect of $\mathrm{Au}$ on $\mathrm{TiO}_{2}$ catalyzed selective photocatalytic oxidation of cyclohexane. J. Photochem. Photobiol. Chem. 217, 326-332. doi: 10.1016/j.jphotochem.2010. 10.027

Carneiro, J. T., Yang, C. C., Moma, J. A., Moulijn, J. A., and Mul, G. (2009). How gold deposition affects anatase performance in the photo-catalytic oxidation of cyclohexane. Catal. Lett. 129, 12-19. doi: 10.1007/s10562-008-9801-1

Carrettin, S., Mcmorn, P., Johnston, P., Griffin, K., and Hutchings, G. J. (2002). Selective oxidation of glycerol to glyceric acid using a gold catalyst in aqueous sodium hydroxide. Chem. Commun. 696-697. doi: 10.1039/b201112n

Carrettin, S., Mcmorn, P., Johnston, P., Griffin, K., Kiely, C. J., Attard, G. A., et al. (2004). Oxidation of glycerol using supported gold catalysts. Top. Catal. 27, 131-136. doi: 10.1023/B:TOCA.0000013547.35106.0d

Carrettin, S., Mcmorn, P., Johnston, P., Griffin, K., Kiely, C. J., and Hutchings, G. J. (2003). Oxidation of glycerol using supported Pt, Pd and Au catalysts. Phys. Chem. Chem. Phys. 5, 1329-1336. doi: 10.1039/b212047j

Chan, S. C., and Barteau, M. A. (2005). Preparation of highly uniform Ag/ $/ \mathrm{TiO}_{2}$ and $\mathrm{Au} / \mathrm{TiO}_{2}$ supported nanoparticle catalysts by photodeposition. Langmuir 21, 5588-5595. doi: 10.1021/la046887k

Chasse, M., and Hallett-Tapley, G. L. (2018). Gold nanoparticle-functionalized niobium oxide perovskites as photocatalysts for visible light-induced aromatic alcohol oxidations. Can. J. Chem. 96, 664-671. doi: 10.1139/cjc-2017-0673

Chen, B. B., Zhu, X. B., Wang, Y. D., Yu, L. M., Lu, J. Q., and Shi, C. (2017). Nano-sized gold particles dispersed on HZSM-5 and $\mathrm{SiO}_{2}$ substrates for catalytic oxidation of HCHO. Catal. Today 281, 512-519. doi: 10.1016/j.cattod.2016.06.023

Chen, J. H., Lin, J. N., Kang, Y. M., Yu, W. Y., Kuo, C. N., and Wan, B. Z. (2005). Preparation of nano-gold in zeolites for CO oxidation: effects of structures and number of ion exchange sites of zeolites. Appl. Catal. Gen. 291, 162-169. doi: 10.1016/j.apcata.2005.02.038

Chen, L. F., Zhou, Y. Y., Gui, Z. Y., Cheng, H. Y., and Qi, Z. W. (2017). Au nanoparticles confined in hybrid shells of silica nanospheres for solvent-free aerobic cyclohexane oxidation. J. Mater. Sci. 52, 7186-7198. doi: 10.1007/s10853-017-0954-4

Chen, Y., Li, W. Z., Wang, J. Y., Yang, Q., Hou, Q. D., and Ju, M. T. (2016). Gold nanoparticle-modified $\mathrm{TiO}_{2} / \mathrm{SBA}-15$ nanocomposites as active plasmonic photocatalysts for the selective oxidation of aromatic alcohols. RSC Adv. 6, 70352-70363. doi: 10.1039/C6RA11390G

Chen, Z., Della Pina, C., Falletta, E., Lo Faro, M., Pastaa, M., Rossi, M., et al. (2008). Facile synthesis of polyaniline using gold catalyst. J. Catal. 259, 1-4. doi: $10.1016 /$ j.jcat.2008.07.006

Chiu, T. W., Lin, Y. T., and Chen, Y. A. (2014). Photodeposition of Au nanocatalysts onto $\mathrm{CuCrO}_{2}$ powders. J. Ceram. Soc. Jpn. 122, 256-259. doi: 10.2109/jcersj2.122.256

Choudhary, V. R., Dhar, A., Jana, P., Jha, R., and Uphade, B. S. (2005). A green process for chlorine-free benzaldehyde from the solvent-free oxidation of benzyl alcohol with molecular oxygen over a supported nano-size gold catalyst. Green Chem. 7, 768-770. doi: 10.1039/b509003b
Choudhary, V. R., and Dumbre, D. K. (2009a). Magnesium oxide supported nano-gold: a highly active catalyst for solvent-free oxidation of benzyl alcohol to benzaldehyde by TBHP. Catal. Commun. 10, 1738-1742. doi: 10.1016/j.catcom.2009.05.020

Choudhary, V. R., and Dumbre, D. K. (2009b). Supported nano-gold catalysts for epoxidation of styrene and oxidation of benzyl alcohol to benzaldehyde. Top. Catal. 52, 1677-1687. doi: 10.1007/s11244-009-9306-1

Choudhary, V. R., and Dumbre, D. K. (2010). Solvent-free selective oxidation of benzyl alcohol to benzaldehyde by tert-butyl hydroperoxide over $\mathrm{U}_{3} \mathrm{O}_{8}$-supported nano-gold catalysts. Appl. Catal. Gen. 375, 252-257. doi: 10.1016/j.apcata.2010.01.007

Choudhary, V. R., and Dumbre, D. K. (2011). Solvent-free selective oxidation of primary alcohols-to-aldehydes and aldehydes-to-carboxylic acids by molecular oxygen over MgO-supported nano-gold catalyst. Catal. Commun. 13, 82-86. doi: 10.1016/j.catcom.2011.07.001

Choudhary, V. R., Dumbre, D. K., and Bhargava, S. K. (2009). Oxidation of benzyl alcohol to benzaldehyde by tert-butyl hydroperoxide over nanogold supported on $\mathrm{TiO}_{2}$ and other transition and rare-earth metal oxides. Indust. Eng. Chem. Res. 48, 9471-9478. doi: 10.1021/ie801883d

Choudhary, V. R., Jha, R., and Jana, P. (2007). Solvent-free selective oxidation of benzyl alcohol by molecular oxygen over uranium oxide supported nanogold catalyst for the production of chlorine-free benzaldehyde. Green Chem. 9, 267-272. doi: 10.1039/b608304h

Ciriminna, R., Della Pina, C., Rossi, M., and Pagliaro, M. (2014). Understanding the glycerol market. Eur. J. Lipid Sci. Technol. 116, 1432-1439. doi: 10.1002/ejlt.201400229

Clark, J. H., and Macquarrie, D. J. (2002). Handbook of Green Chemistry and Technology. Oxford, UK: Wiley. doi: 10.1002/9780470988305

Comotti, M., Della Pina, C., Matarrese, R., and Rossi, M. (2004). The catalytic activity of naked gold particles. Angew. Chem. Int. Ed. 43, 5812-5815. doi: 10.1002/anie.200460446

Comotti, M., Della Pina, C., Matarrese, R., Rossi, M., and Siani, A. (2005). Oxidation of alcohols and sugars using Au/C catalysts - Part 2. Sugars. Appl. Catal. Gen. 291, 204-209. doi: 10.1016/j.apcata.2004.11.051

Conte, M., Liu, X., Murphy, D. M., Whiston, K., and Hutchings, G. J. (2012). Cyclohexane oxidation using $\mathrm{Au} / \mathrm{MgO}$ : an investigation of the reaction mechanism. Phys. Chem. Chem. Phys. 14, 16279-16285. doi: $10.1039 / \mathrm{c} 2 \mathrm{cp} 43363 \mathrm{j}$

Corma, A., and Garcia, H. (2008). Supported gold nanoparticles as catalysts for organic reactions. Chem. Soc. Rev. 37, 2096-2126. doi: 10.1039/b70 $7314 n$

Corti, C. W., Holliday, R. J., and Thompson, D. T. (2005). Commercial aspects of gold catalysis. Appl. Catal. Gen. 291, 253-261. doi: 10.1016/j.apcata.2005.01.051

Della Pina, C., and Falletta, E. (2011). Gold-catalyzed oxidation in organic synthesis: a promise kept. Catal. Sci. Technol. 1, 1564-1571. doi: $10.1039 /$ clcy00283j

Della Pina, C., Falletta, E., Matarrese, R., and Rossi, M. (2008a). "Gold nanoparticles: from preparation to catalytic evaluation," in Metal Nanoclusters in Catalysis and Material Science: The Issue of Size-Control - Part II: Methodologies, eds B. Corain, N. Toshima, and G. Schmid (New York, NY: Elsevier), 253-262.

Della Pina, C., Falletta, E., Prati, L., and Rossi, M. (2008b). Selective oxidation using gold. Chem. Soc. Rev. 37, 2077-2095. doi: 10.1039/b707319b

Della Pina, C., Falletta, E., and Rossi, M. (2007). Selective oxidation of tertiary amines on gold catalysts. Top. Catal. 44, 325-329. doi: $10.1007 / \mathrm{s} 11244-007-0306-8$

Della Pina, C., Falletta, E., and Rossi, M. (2012). Update on selective oxidation using gold. Chem. Soc. Rev. 41, 350-369. doi: 10.1039/C1CS15089H

Demirel, S., Kern, P., Lucas, M., and Claus, P. (2007a). Oxidation of mono- and polyalcohols with gold: comparison of carbon and ceria supported catalysts. Catal. Today 122, 292-300. doi: 10.1016/j.cattod.2006.12.002

Demirel, S., Lehnert, K., Lucas, M., and Claus, P. (2007b). Use of renewables for the production of chemicals: glycerol oxidation over carbon supported gold catalysts. Appl. Catal. B Environ. 70, 637-643. doi: 10.1016/j.apcatb.2005. 11.036

Demirel, S., Lucas, M., Warna, J., Murzin, D., and Claus, P. (2007c). Reaction kinetics and modelling of the gold catalysed glycerol oxidation. Top. Catal. 44, 299-305. doi: 10.1007/s11244-007-0303-y 
Demirel-Gulen, S., Lucas, M., and Claus, P. (2005). Liquid phase oxidation of glycerol over carbon supported gold catalysts. Catal. Today 102, 166-172. doi: 10.1016/j.cattod.2005.02.033

Dengel, A. C., Elhendawy, A. M., Griffith, W. P., Mostafa, S. I., and Williams, D. J. (1992). Transition-metal periodato complexes - their preparations and properties as catalytic oxidants, and X-ray crystal-structure of $\mathrm{Na}_{4} \mathrm{~K}$ $\left[\mathrm{Au}\left(\mathrm{IO}_{5}(\mathrm{OH})\right)_{2}\right] \cdot \mathrm{KOH} \cdot 15 \mathrm{H}_{2} \mathrm{O}$. J. Chem Soc. Dalton Trans. 3489-3495. doi: 10.1039/DT9920003489

Derouane, E. D., Haber, J., Lemos, F., Ramôa Ribeiro, F., and Guinet, M. E. (1998). Catalytic Activation and Functionalisation of Light Alkanes. Dordrecht: NATO ASI Series; Kluwer Academic Publ. doi: 10.1007/978-94-017-0982-8

Derouane, E. G., Parmon, V., Lemos, F., and Râmoa Ribeiro, F. (2005). Sustainable Strategies for the Upgrading of Natural Gas: Fundamentals, Challenges, and Opportunities. Dordrecht: Springer. doi: 10.1007/1-4020-3310-9

Di Nicola, C., Garau, F., Karabach, Y. Y., Martins, L. M. D. R. S., Monari, M., Pandolfo, L., et al. (2009). Trinuclear triangular copper(II) clusters - Synthesis, electrochemical studies and catalytic peroxidative oxidation of cycloalkanes. Eur. J. Inorg. Chem. 666-676. doi: 10.1002/ejic.200800842

Dimitratos, N., Lopez-Sanchez, J. A., and Hutchings, G. J. (2012). Selective liquid phase oxidation with supported metal nanoparticles. Chem. Sci. 3, 20-44. doi: 10.1039/C1SC00524C

Dimitratos, N., Porta, F., and Prati, L. (2005a). Au, Pd (mono and bimetallic) catalysts supported on graphite using the immobilisation method: Synthesis and catalytic testing for liquid phase oxidation of glycerol. Appl. Catal. A Gen. 291, 210-214. doi: 10.1016/j.apcata.2005.01.044

Dimitratos, N., Porta, F., Prati, L., and Villa, A. (2005b). Synergetic effect of platinum or palladium on gold catalyst in the selective oxidation of D-sorbitol. Catal. Lett. 99, 181-185. doi: 10.1007/s10562-005-2114-8

Dimitratos, N., and Prati, L. (2005). Gold based bimetallic catalysts for liquid phase applications. Gold Bull. 38, 73-77. doi: 10.1007/BF03215236

Dimitratos, N., Villa, A., Prati, L., Hammond, C., Chan-Thaw, C. E., Cookson, J., et al. (2016). Effect of the preparation method of supported Au nanoparticles in the liquid phase oxidation of glycerol. Appl. Catal. Gen. 514, 267-275. doi: 10.1016/j.apcata.2015.12.031

Dobrosz, I., Jiratova, K., Pitchon, V., and Rynkowski, J. M. (2005). Effect of the preparation of supported gold particles on the catalytic activity in $\mathrm{CO}$ oxidation reaction. J. Mol. Catal.Chem. 234, 187-197. doi: 10.1016/j.molcata.2005.02.032

Dobrosz-Gomez, I., Kocemba, I., and Rynkowski, J. M. (2009). Factors influencing structure and catalytic activity of $\mathrm{Au} / \mathrm{Ce}_{1-\mathrm{x}} \mathrm{Zr}_{\mathrm{x}} \mathrm{O}_{2}$ catalysts in $\mathrm{CO}$ oxidation. Appl. Catal. B Environ. 88, 83-97. doi: 10.1016/j.apcatb.2008.09.028

Donoeva, B., and De Jongh, P. E. (2018). Colloidal Au catalyst preparation: selective removal of polyvinylpyrrolidone from active $\mathrm{Au}$ sites. ChemCatChem 10, 989-997. doi: 10.1002/cctc.201701760

Du, W. L., Jiang, L., Liao, L., Qin, A. M., and Chen, S. P. (2016). "Photoluminescence from gold nanoparticles modified by polyvinylpyrrolidone (PVP) via hydrothermal synthesis," in Proceedings of the 2015 6th International Conference on Manufacturing Science and Engineering, Vol. 32, ed Z. Y. Jiang (Paris: Atlantis Press), 850-853.

Dudley, G. B., Richert, R., and Stiegman, A. E. (2015). On the existence of and mechanism for microwave-specific reaction rate enhancement. Chem. Sci. 6, 2144-2152. doi: 10.1039/C4SC03372H

Edwards, J., Landon, P., Carley, A. F., and Hutchings, G. J. (2007). Nanocrystalline gold and gold-palladium as effective catalysts for selective oxidation. J. Mater. Res. 22, 831-837. doi: 10.1557/jmr.2007.0117

Emayavaramban, P., Babu, S. G., Karvembu, R., Kadirvelu, K., and Dharmaraj, N. (2016a). Gold nanoparticles supported on magnesium oxide nanorods for oxidation of alcohols. J. Nanosci. Nanotechnol. 16, 2517-2526. doi: $10.1166 /$ jnn.2016.10778

Emayavaramban, P., Kadirvelu, K., and Dharmaraj, N. (2016b). Gold modified zeolite: an efficient heterogeneous catalyst for $\mathrm{N}$-arylation of indazole. J. Nanosci. Nanotechnol. 16, 9093-9103. doi: 10.1166/jnn.2016. 12905

Enache, D. I., Edwards, J. K., Landon, P., Solsona-Espriu, B., Carley, A. F., Herzing, A. A., et al. (2006). Solvent-free oxidation of primary alcohols to aldehydes using $\mathrm{Au}-\mathrm{Pd} / \mathrm{TiO}_{2}$ catalysts. Science 311, 362-365. doi: $10.1126 /$ science. 1120560
Fang, W. N., Lu, S., Wang, L. H., Fan, C. H., and Liu, H. J. (2017). Synthesis and applications of triangular gold nanoplates. Prog. Chem. 29, 459-466. doi: $10.7536 / p c 170132$

Fernandes, R. R., Kirillova, M. V., Da Silva, J. a. L., Fraústo Da Silva, J. J. R., and Pombeiro, A. J. L. (2009). Oxidations of cycloalkanes and benzene by hydrogen peroxide catalyzed by an $\left\{\mathrm{Fe}^{\mathrm{III}} \mathrm{N}_{2} \mathrm{~S}_{2}\right\}$ centre. Applied Catalysis A: General 353 , 107-112. doi: 10.1016/j.apcata.2008.10.027

Fernandes, R. R., Lasri, J., Da Silva, M. F. C. G., Da Silva, J. a. L., Fraústo Da Silva, J. J. R., and Pombeiro, A. J. L. (2011). Mild alkane C-H and O-H oxidations catalysed by mixed-N,S copper, iron and vanadium systems. Appl. Catal. A Gen. 402, 110-120. doi: 10.1016/j.apcata.2011.05.035

Fernando, J. F. S., Shortell, M. P., Noble, C. J., Harmer, J. R., Jaatinen, E. A., and Waclawik, E. R. (2016). Controlling Au photodeposition on large $\mathrm{ZnO}$ nanoparticles. ACS Appl. Mater. Interfaces 8, 14271-14283. doi: 10.1021 /acsami.6b03128

Ferraz, C. P., Garcia, M. a. S., Teixeira-Neto, E., and Rossi, L. M. (2016). Oxidation of benzyl alcohol catalyzed by gold nanoparticles under alkaline conditions: weak vs. strong bases. RSC Adv. 6, 25279-25285. doi: 10.1039/C6RA01795A

Fisher, J. M. (2003). Fulminating gold. Gold Bull. 36, 155. doi: 10.1007/BF03215508

Freakley, S. J., He, Q., Kiely, C. J., and Hutchings, G. J. (2015). Gold catalysis: a reflection on where we are now. Catal. Lett. 145, 71-79. doi: 10.1007/s10562-014-1432-0

Fristrup, P., Johansen, L. B., and Christensen, C. H. (2008). Mechanistic investigation of the gold-catalyzed aerobic oxidation of alcohols. Catal. Lett. 120, 184-190. doi: 10.1007/s10562-007-9301-8

Fu, Q., Kudriavtseva, S., Saltsburg, H., and Flytzani-Stephanopoulos, M. (2003). Gold-ceria catalysts for low-temperature water-gas shift reaction. Chem. Eng. J. 93, 41-53. doi: 10.1016/S1385-8947(02)00107-9

Gaiassi, A., and Prati, L. (2009). Gold catalysts for the direct oxidation of aminoalcohols to aminoacids. Catal. Today 141, 378-384. doi: 10.1016/j.cattod.2008.07.017

Garcia, R., Besson, M., and Gallezot, P. (1995). Chemoselective catalytic-oxidation of glycerol with air on platinum metals. Appl. Catal. Gen. 127, 165-176. doi: 10.1016/0926-860X(95)00048-8

Giorgi, P. D., Elizarov, N., and Antoniotti, S. (2017). Selective oxidation of activated alcohols by supported gold nanoparticles under an atmospheric pressure of O-2: batch and continuous-flow studies. ChemCatChem 9, 1830-1836. doi: $10.1002 /$ cctc. 201700179

Gluhoi, A. C., and Nieuwenhuys, B. E. (2007). Structural and chemical promoter effects of alkali (earth) and cerium oxides in CO oxidation on supported gold. Catal. Today 122, 226-232. doi: 10.1016/j.cattod.2007.01.066

Gogoi, N., Borah, G., Gogoi, P. K., and Chetia, T. R. (2018). $\mathrm{TiO}_{2}$ supported gold nanoparticles: an efficient photocatalyst for oxidation of alcohol to aldehyde and ketone in presence of visible light irradiation. Chem. Phys. Lett. 692, 224-231. doi: 10.1016/j.cplett.2017.12.015

Gualteros, J. A. D., Garcia, M. A. S., Da Silva, A. G. M., Rodrigues, T. S., Candido, E. G., Silva, F. A. E., et al. (2019). Synthesis of highly dispersed gold nanoparticles on $\mathrm{Al}_{2} \mathrm{O}_{3}, \mathrm{SiO}_{2}$, and $\mathrm{TiO}_{2}$ for the solvent-free oxidation of benzyl alcohol under low metal loadings. J. Mater. Sci. 54, 238-251. doi: 10.1007/s10853-0182827-x

Gui, Z. Y., Cao, W. R., Chen, L. F., and Qi, Z. W. (2015). Propene carbonate intensified cyclohexane oxidation over $\mathrm{Au} / \mathrm{SiO}_{2}$ catalyst. Catal. Commun. 64, 58-61. doi: 10.1016/j.catcom.2015.02.001

Guo, Z., Liu, B., Zhang, Q., Deng, W., Wang, Y., and Yang, Y. (2014). Recent advances in heterogeneous selective oxidation catalysis for sustainable chemistry. Chem. Soc. Rev. 43, 3480-3524. doi: 10.1039/c3cs60282f

Haider, P., Grunwaldt, J.-D., and Baiker, A. (2009). Gold supported on Mg, Al and $\mathrm{Cu}$ containing mixed oxides: relation between surface properties and behavior in catalytic aerobic oxidation of 1-phenylethanol. Catal. Today 141, 349-354. doi: $10.1016 /$ j.cattod.2008.06.003

Hallett-Tapley, G. L., Silvero, M. J., Bueno-Alejo, C. J., Gonzalez-Bejar, M., Mctiernan, C. D., Grenier, M., et al. (2013). Supported gold nanoparticles as efficient catalysts in the solvent less plasmon mediated oxidation of sec-Phenethyl and benzyl alcohol. J. Phys. Chem. C 117, 12279-12288. doi: $10.1021 /$ jp311069y

Hargittai, M., Schulz, A., Reffy, B., and Kolonits, M. (2001). Molecular structure, bonding, and Jahn-Teller effect in gold chlorides: quantum chemical study of 
$\mathrm{AuCl}_{3}, \mathrm{Au}_{2} \mathrm{Cl}_{6}, \mathrm{AuCl}_{4}^{-}, \mathrm{AuCl}$, and $\mathrm{Au}_{2} \mathrm{Cl}_{2}$ and electron diffraction study of $\mathrm{Au}_{2} \mathrm{Cl}_{6}$. J. Am. Chem. Soc. 123, 1449-1458. doi: 10.1021/ja003038k

Haruta, A. (2003). When gold is not noble: catalysis by nanoparticles. Chem. Rec. 3, 75-87. doi: 10.1002/tcr.10053

Haruta, M. (1997). Size- and support-dependency in the catalysis of gold. Catal. Today 36, 153-166. doi: 10.1016/S0920-5861(96)00208-8

Haruta, M. (2002). Catalysis of gold nanoparticles deposited on metal oxides. CATTECH 6, 102-115. doi: 10.1023/A:1020181423055

Haruta, M. (2004). Gold as a novel catalyst in the 21st century: Preparation, working mechanism and applications. Gold Bull. 37, 27-36. doi: 10.1007/BF03215514

Haruta, M. (2005). Catalysis - Gold rush. Nature 437, 1098-1099. doi: $10.1038 / 4371098$ a

Haruta, M., and Daté, M. (2001). Advances in the catalysis of Au nanoparticles. Appl. Catal.Gen. 222, 427-437. doi: 10.1016/S0926-860X(01)00847-X

Haruta, M., Kobayashi, T., Sano, H., and Yamada, N. (1987). Novel gold catalysts for the oxidation of carbon monoxide at a temperature far below $0^{\circ} \mathrm{C}$. Chem. Lett. 16, 405-408. doi: 10.1246/cl.1987.405

Hashmi, A. S. K., and Hutchings, G. J. (2006). Gold Catalysis. Angew. Chem. Int. Ed. 45, 7896-7936. doi: 10.1002/anie.200602454

Hashmi, A. S. K., and Rudolph, M. (2008). Gold catalysis in total synthesis. Chem. Soc. Rev. 37, 1766-1775. doi: 10.1039/b615629k

He, P. K., Zhang, M., Yang, D. M., and Yang, J. J. (2006). Preparation of Au-loaded $\mathrm{TiO}_{2}$ by photochemical deposition and ozone photocatalytic decomposition. Surface Rev. Lett. 13, 51-55. doi: 10.1142/S0218625X06007810

He, Q., Freakley, S. J., Edwards, J. K., Carley, A. F., Borisevich, A. Y., Mineo, Y., et al. (2016). Population and hierarchy of active species in gold iron oxide catalysts for carbon monoxide oxidation. Nat. Commun. 7:12905. doi: $10.1038 /$ ncomms 12905

He, Q., Miedziak, P. J., Kesavan, L., Dimitratos, N., Sankar, M., Lopez-Sanchez, J. A., et al. (2013). Switching-off toluene formation in the solvent-free oxidation of benzyl alcohol using supported trimetallic Au-Pd-Pt nanoparticles. Faraday Discuss. 162, 365-378. doi: 10.1039/c2fd20153d

Hereijgers, B. P. C., and Weckhuysen, B. M. (2009). Selective oxidation of methanol to hydrogen over gold catalysts promoted by alkaline-earth-metal and lanthanum oxides. ChemSusChem 2, 743-748. doi: 10.1002/cssc.2009 00108

Hereijgers, B. P. C., and Weckhuysen, B. M. (2010). Aerobic oxidation of cyclohexane by gold-based catalysts: new mechanistic insight by thorough product analysis. J. Catal. 270, 16-25. doi: 10.1016/j.jcat.2009. 12.003

Hereijgers, B. P. C., and Weckhuysen, B. M. (2011). An attempt to selectively oxidize methane over supported gold catalysts. Catal. Lett. 141, 1429-1434. doi: 10.1007/s10562-011-0674-3

Hidalgo, M. C., Maicu, M., Navio, J. A., and Colon, G. (2009). Effect of sulfate pretreatment on gold-modified $\mathrm{TiO}_{2}$ for photocatalytic applications. J. Phys. Chem. C 113, 12840-12847. doi: 10.1021/jp903432p

Hidalgo, M. C., Murcia, J. J., Navio, J. A., and Colon, G. (2011). Photodeposition of gold on titanium dioxide for photocatalytic phenol oxidation. Appl. Catal. Gen. 397, 112-120. doi: 10.1016/j.apcata.2011.02.030

Hong, Y. L., Jing, X. L., Huang, J. L., Sun, D. H., Odoom-Wubah, T., Yang, F., et al. (2014). Biosynthesized bimetallic Au-Pd nanoparticles supported on $\mathrm{TiO}_{2}$ for solvent-free oxidation of benzyl alcohol. ACS Sustain. Chem. Eng. 2, 1752-1759. doi: $10.1021 /$ sc500181z

Horvath, D., Polisset-Thfoin, M., Fraissard, J., and Guczi, L. (2001). Novel preparation method and characterization of $\mathrm{Au}-\mathrm{Fe} / \mathrm{HY}$ zeolite containing highly stable gold nanoparticles inside zeolite supercages. Solid State Ionics 141, 153-156. doi: 10.1016/S0167-2738(01)00736-6

Hosseini-Monfared, H., Meyer, H., and Janiak, C. (2013). Dioxygen oxidation of 1-phenylethanol with gold nanoparticles and N-hydroxyphthalimide in ionic liquid. J. Mol. Catal. Chem. 372, 72-78. doi: 10.1016/j.molcata.2013. 02.007

Hu, W. B., Knight, D., Lowry, B., and Varma, A. (2010). Selective oxidation of glycerol to dihydroxyacetone over $\mathrm{Pt}-\mathrm{Bi} / \mathrm{C}$ catalyst: optimization of catalyst and reaction conditions. Indus. Eng. Chem. Res. 49, 10876-10882. doi: 10.1021/ie1005096

Huang, J., Wang, L. C., Liu, Y. M., Cao, Y., He, H. Y., and Fan, K. N. (2011a). Gold nanoparticles supported on hydroxylapatite as high performance catalysts for low temperature CO oxidation. Appl. Catal. B Environ. 101, 560-569. doi: 10.1016/j.apcatb.2010.10.029

Huang, J., Wang, Y., Zheng, J., Dai, W.-L., and Fan, K. (2011b). Influence of support surface basicity and gold particle size on catalytic activity of $\mathrm{Au} / \gamma$ $\mathrm{AlOOH}$ and $\mathrm{Au} / \gamma-\mathrm{Al}_{2} \mathrm{O}_{3}$ catalyst in aerobic oxidation of $\alpha, \omega$-diols to lactones. Appl. Catal. B Environ. 103, 343-350. doi: 10.1016/j.apcatb.2011.01.041

Hugon, A., El Kolli, N., and Louis, C. (2010). Advances in the preparation of supported gold catalysts: mechanism of deposition, simplification of the procedures and relevance of the elimination of chlorine. J. Catal. 274, 239-250. doi: 10.1016/j.jcat.2010.07.008

Hutchings, G. J. (2005). Catalysis by gold. Catal. Today 100, 55-61. doi: 10.1016/j.cattod.2004.12.016

Hutchings, G. J. (2014). Selective oxidation using supported gold bimetallic and trimetallic nanoparticles. Catal. Today 238, 69-73. doi: 10.1016/j.cattod.2014.01.033

Hutchings, G. J., Carrettin, S., Landon, P., Edwards, J. K., Enache, D., Knight, D. W., et al. (2006). New approaches to designing selective oxidation catalysts: $\mathrm{Au} / \mathrm{C}$ a versatile catalyst. Top. Catal. 38, 223-230. doi: 10.1007/s11244-006-0020-y

Ilieva, L., Petrova, P., Pantaleo, G., Zanella, R., Liotta, L. F., Georgiev, V., et al. (2016). Gold catalysts supported on Y-modified ceria for COfree hydrogen production via PROX. Appl.Catal. BEnviron. 188, 154-168. doi: 10.1016/j.apcatb.2016.02.004

Imura, Y., Furukawa, S., Ozawa, K., Morita-Imura, C., Kawai, T., and Komatsu, T. (2016). Surface clean gold nanoflower obtained by complete removal of capping agents: an active catalyst for alcohol oxidation. RSC Adv. 6, 17222-17227. doi: 10.1039/C5RA27146K

Ishida, T., and Haruta, M. (2007). Gold catalysts: towards sustainable chemistry. Angew. Chem. Int. Ed. 46, 7154-7156. doi: 10.1002/anie.200701622

Ishida, T., Koga, H., Okumura, M., and Haruta, M. (2016). Advances in gold catalysis and understanding the catalytic mechanism. Chem. Rec. 16, 2278-2293. doi: 10.1002/tcr.201600046

Ivanova, S., Petit, C., and Pitchon, V. (2004). A new preparation method for the formation of gold nanoparticles on an oxide support. Appl. Catal. Gen. 267, 191-201. doi: 10.1016/j.apcata.2004.03.004

Ivanova, S., Petit, C., and Pitchon, V. (2006a). Application of heterogeneous gold catalysis with increased durability: oxidation of $\mathrm{CO}$ and hydrocarbons at low temperature. Gold Bull. 39, 3-8. doi: 10.1007/BF032 15526

Ivanova, S., Pitchon, V., and Petit, C. (2006b). Application of the direct exchange method in the preparation of gold catalysts supported on different oxide materials. J. Mol. Catal. Chem. 256, 278-283. doi: 10.1016/j.molcata.2006.05.006

Jiang, D., Wang, W. Z., Sun, S. M., Zhang, L., and Zheng, Y. L. (2015). Equilibrating the plasmonic and catalytic roles of metallic nanostructures in photocatalytic oxidation over Au-modified $\mathrm{CeO}_{2}$. ACS Catal. 5, 613-621. doi: $10.1021 / \operatorname{cs} 501633 q$

Jin, Z., Song, Y. Y., Fu, X. P., Song, Q. S., and Jia, C. J. (2018). Nanoceria supported gold catalysts for CO oxidation. Chinese J. Chem. 36, 639-643. doi: $10.1002 /$ cjoc. 201700731

Jouve, A., Stucchi, M., Barlocco, I., Evangelisti, C., Somodic, F., Villa, A., et al. (2018). Carbon-supported Au nanoparticles: catalytic activity ruled out by carbon support. Top. Catal. 61, 1928-1938. doi: 10.1007/s11244-018-1001-7

Kalvachev, Y. A., Hayashi, T., Tsubota, S., and Haruta, M. (1999). Vaporphase selective oxidation of aliphatic hydrocarbons over gold deposited on mesoporous titanium silicates in the Co-presence of oxygen and hydrogen. $J$. Catal. 186, 228-233. doi: 10.1006/jcat.1999.2540

Kang, Y. M., and Wan, B. Z. (1995). Preparation of gold in Y-type zeolite for carbon-monoxide oxidation. Appl. Catal. Gen. 128, 53-60. doi: 10.1016/0926-860X(95)00076-3

Kang, Y. M., and Wan, B. Z. (1997). Gold and iron supported on Ytype zeolite for carbon monoxide oxidation. Catal. Today 35, 379-392. doi: 10.1016/S0920-5861(96)00215-5

Kashani, S. H., Landarani-Isfahani, A., Moghadam, M., Tangestaninejad, S., Mirkhani, V., and Mohammadpoor-Baltork, I. (2018). Nano-silica functionalized with thiol-based dendrimer as a host for gold nanoparticles: an efficient and reusable catalyst for chemoselective oxidation of alcohols. Appl. Organomet. Chem. 32:e4440. doi: 10.1002/aoc.4440 
Kharisov, B. I., Kharissova, O. V., Yacaman, M. J., and Ortiz, U. (2009). State of the art of the bi- and trimetallic nanoparticles on the basis of gold and iron. Recent Pat. Nanotechnol. 3, 81-98. doi: 10.2174/187221009788490031

Khawaji, M., and Chadwick, D. (2018). Au-Pd NPs immobilised on nanostructured ceria and titania: impact of support morphology on the catalytic activity for selective oxidation. Catal. Sci. Technol. 8, 2529-2539. doi: 10.1039/C7CY02329D

Kim, S. H. (2018). Nanoporous gold: preparation and applications to catalysis and sensors. Curr. Appl. Phys. 18, 810-818. doi: 10.1016/j.cap.2018.03.021

Kirillov, A. M., and Shul'pin, G. B. (2013). Pyrazinecarboxylic acid and analogs: highly efficient co-catalysts in the metal-complex-catalyzed oxidation of organic compounds. Coord. Chem. Rev. 257, 732-754. doi: 10.1016/j.ccr.2012.09.012

Kirillova, M. V., Kozlov, Y. N., Shul'pina, L. S., Lyakin, O. Y., Kirillov, A. M., Talsi, E. P., et al. (2009a). Remarkably fast oxidation of alkanes by hydrogen peroxide catalyzed by a tetracopper(II) triethanolaminate complex: promoting effects of acid co-catalysts and water, kinetic and mechanistic features. J. Catal. 268, 26-38. doi: 10.1016/j.jcat.2009.08.016

Kirillova, M. V., Kuznetsov, M. L., Kozlov, Y. N., Shul'pina, L. S., Kitaygorodskiy, A., Pombeiro, A. J. L., et al. (2011). Participation of oligovanadates in alkane oxidation with $\mathrm{H}_{2} \mathrm{O}_{2}$ catalyzed by vanadate anion in acidified acetonitrile: kinetic and DFT studies. ACS Catal. 1, 1511-1520. doi: 10.1021/cs200237m

Kirillova, M. V., Kuznetsov, M. L., Romakh, V. B., Shul'pina, L. S., Fraústo Da Silva, J. J. R., Pombeiro, A. J. L., et al. (2009b). Mechanism of oxidations with $\mathrm{H}_{2} \mathrm{O}_{2}$ catalyzed by vanadate anion or oxovanadium $(\mathrm{V})$ triethanolaminate (vanadatrane) in combination with pyrazine-2-carboxylic acid (PCA): Kinetic and DFT studies. J. Catal. 267, 140-157. doi: 10.1016/j.jcat.2009.08.006

Koczkur, K. M., Mourdikoudis, S., Polavarapu, L., and Skrabalak, S. E. (2015). Polyvinylpyrrolidone (PVP) in nanoparticle synthesis. Dalton Trans. 44, 17883-17905. doi: 10.1039/C5DT02964C

Kominami, H., Tanaka, A., and Hashimoto, K. (2011). Gold nanoparticles supported on cerium(IV) oxide powder for mineralization of organic acids in aqueous suspensions under irradiation of visible light of lambda $=530 \mathrm{~nm}$. Appl. Catal. Gen. 397, 121-126. doi: 10.1016/j.apcata.2011.02.029

Kopylovich, M. N., Kirillov, A. M., Baev, A. K., and Pombeiro, A. J. L. (2003). Heteronuclear iron(III)-chromium(III) hydroxo complexes and hydroxides, and their catalytic activity towards peroxidative oxidation of alkanes. J. Mol. Catal. A Chem. 206, 163-178. doi: 10.1016/S1381-1169(03)00420-5

Kopylovich, M. N., Nunes, A. C. C., Mahmudov, K. T., Haukka, M., Mac Leod, T. C. O., Martins, L. M. D. R. S., et al. (2011). Complexes of copper(II) with 3-(ortho-substituted phenylhydrazo)pentane-2, 4-diones: syntheses, properties and catalytic activity for cyclohexane oxidation. Dalton Trans. 40, 2822-2836. doi: $10.1039 / \mathrm{c} 0 \mathrm{dt} 01527 \mathrm{j}$

Kozlov, A. I., Kozlova, A. P., Asakura, K., Matsui, Y., Kogure, T., Shido, T., et al. (2000). Supported gold catalysts prepared from a gold phosphine precursor and As-precipitated metal-hydroxide precursors: effect of preparation conditions on the catalytic performance. J. Catal. 196, 56-65. doi: 10.1006/jcat.2000.3033

Kozlov, A. I., Kozlova, A. P., Liu, H. C., and Iwasawa, Y. (1999). A new approach to active supported Au catalysts. Appl. Catal. Gen. 182, 9-28. doi: 10.1016/S0926-860X(98)00424-4

Kozlov, Y. N., Romakh, V. B., Kitaygorodskiy, A., Buglyó, P., Süss-Fink, G., and Shul'pin, G. B. (2007). Oxidation of 2-propanol and cyclohexane by the reagent hydrogen peroxide-vanadate anion-pyrazine-2-carboxylic acid: kinetics and mechanism. J. Phys. Chem. A 111, 7736-7752. doi: 10.1021/jp0700884

Kozlova, A. P., Kozlov, A. I., Sugiyama, S., Matsui, Y., Asakura, K., and Iwasawa, Y. (1999). Study of gold species in iron-oxide-supported gold catalysts derived from gold-phosphine complex $\mathrm{Au}\left(\mathrm{PPh}_{3}\right)\left(\mathrm{NO}_{3}\right)$ and As-precipitated wet $\mathrm{Fe}(\mathrm{OH})_{3}$. J. Catal. 181, 37-48. doi: 10.1006/jcat.1998.2290

Kozlova, A. P., Sugiyama, S., Kozlov, A. I., Asakura, K., and Iwasawa, Y. (1998). Iron-oxide supported gold catalysts derived from gold-phosphine complex $\mathrm{Au}\left(\mathrm{PPh}_{3}\right)\left(\mathrm{NO}_{3}\right)$ : state and structure of the support. J. Catal. 176, 426-438. doi: 10.1006/jcat.1998.2069

Kulikova, V. S., and Shestakov, A. F. (2008). Functionalization of alkanes by gold nanoparticles stabilized by 1-dodecanethiol in organic media. Russ. J. Phys. Chem. B 2, 507-511. doi: 10.1134/S1990793107050119

Kung, H. H., Kung, M. C., and Costello, C. K. (2003). Supported Au catalysts for low temperature CO oxidation. J. Catal. 216, 425-432. doi: 10.1016/S0021-9517(02)00111-2
Kuznetsov, M. L., and Pombeiro, A. J. L. (2009). Radical formation in the $\left[\mathrm{MeReO}_{3}\right]^{-}$catalyzed aqueous peroxidative oxidation of alkanes: a theoretical mechanistic study. Inorg. Chem. 48, 307-318. doi: 10.1021/ic801753t

Kydd, R., Scott, J., Teoh, W. Y., Chiang, K., and Amal, R. (2010). Understanding photocatalytic metallization of preadsorbed ionic gold on Titania, Ceria, and Zirconia. Langmuir 26, 2099-2106. doi: 10.1021/la902592p

Kyriakou, V., Vourros, A., Garagounis, I., Carabineiro, S. A. C., Maldonado-Hódar, F. J., Marnellos, G. E., et al. (2017). Highly active and stable $\mathrm{TiO}_{2}$-supported $\mathrm{Au}$ nanoparticles for $\mathrm{CO}_{2}$ reduction. Catal. Commun. 98(Suppl. C), 52-56. doi: 10.1016/j.catcom.2017.05.003

Lederer, P., Nizova, G. V., Kats, M. M., and Shulpin, G. B. (1992). Photooxidation of cyclohexane with dioxygen in acetonitrile in the presence of transition-metal chlorides. Collect. Czech. Chem. Commun. 57, 107-112. doi: $10.1135 / \operatorname{cccc} 19920107$

Lee, S.-J., and Gavriilidis, A. (2002). Supported Au catalysts for lowtemperature CO oxidation prepared by impregnation. J. Catal. 206, 305-313. doi: $10.1006 /$ jcat.2001.3500

Lee, S.-J., Gavriilidis, A., Pankhurst, Q. A., Kyek, A., Wagner, F. E., Wong, P. C. L., et al. (2001). Effect of drying conditions of Au-Mn Co-precipitates for lowtemperature CO oxidation. J. Catal. 200, 298-308. doi: 10.1006/jcat.2001.3209

Lee, W. S., Wan, B. Z., Kuo, C. N., Lee, W. C., and Cheng, S. (2007). Maintaining catalytic activity of $\mathrm{Au} / \mathrm{TiO}_{2}$ during the storage at room temperature. Catal. Commun. 8, 1604-1608. doi: 10.1016/j.catcom.2007.01.021

Li, B. D., He, P., Yi, G. Q., Lin, H. Q., and Yuan, Y. Z. (2009). Performance of Gold Nanoparticles Supported on Carbon Nanotubes for Selective Oxidation of Cyclooctene with Use of $\mathrm{O}_{2}$ and TBHP. Catal. Lett. 133, 33-40. doi: 10.1007/s10562-009-0171-0

Li, H. R., Li, Z. P., and Shi, Z. J. (2009). Gold-catalyzed benzylic oxidation to carbonyl compounds. Tetrahedron 65, 1856-1858. doi: $10.1016 /$ j.tet.2008.12.055

Li, L., Ji, W. J., and Au, C. T. (2009a). Gold nanoparticles supported on mesoporous silica and their catalytic application. Prog. Chem. 21, 1742-1749. Available online at: http://manu56.magtech.com.cn/progchem/EN/abstract/ abstract10121.shtml

Li, L., Jin, C., Wang, X. C., Ji, W. J., Pan, Y., Van Der Knaap, T., et al. (2009b). Cyclohexane oxidation over size-uniform Au nanoparticles (SBA-15 hosted) in a continuously stirred tank reactor under mild conditions. Catal. Lett. 129, 303-311. doi: 10.1007/s10562-009-9853-x

Li, S., Zhang, Y., Li, X., Yang, X., Li, Z., Wang, R., et al. (2018). Preferential oxidation of $\mathrm{CO}$ in $\mathrm{H}_{2}$-rich stream over $\mathrm{Au} / \mathrm{CeO}_{2}-\mathrm{NiO}$ catalysts: effect of the preparation method. Catal. Lett. 148, 328-340. doi: 10.1007/s10562-017-2231-1

Li, T., Wang, S. J., Yu, C. S., Ma, Y. C., Li, K. L., and Lin, L. W. (2011). Direct conversion of methane to methanol over nano- $\mathrm{Au} / \mathrm{SiO}_{2}$ in $\mathrm{Bmim} \mathrm{Cl}$ ionic liquid. Appl. Catal. Gen. 398, 150-154. doi: 10.1016/j.apcata.2011.03.028

$\mathrm{Li}$, Y., Liao, W.-P., and Suo, Z.-H. (2011). Influence of $\mathrm{KOH}$ modification on $\mathrm{TiO}_{2}$ structure and $\mathrm{Au} / \mathrm{TiO}_{2}$ catalyst activity in $\mathrm{CO}$ oxidation. J. Fuel Chem. Technol. 39, 47-53. doi: 10.1016/S1872-5813(11)60009-1

Liao, X. M., Chu, W., Dai, X. Y., and Pitchon, V. (2012). Promoting effect of Fe in preferential oxidation of carbon monoxide reaction (PROX) on $\mathrm{Au} / \mathrm{CeO}_{2}$. Appl. Catal. Gen. 449, 131-138. doi: 10.1016/j.apcata.2012.09.015

Lin, J.-N., and Wan, B.-Z. (2003). Effects of preparation conditions on gold/Y-type zeolite for CO oxidation. Appl. Catal. B Environ. 41, 83-95. doi: 10.1016/S0926-3373(02)00195-9

Liu, J., Liu, R. H., Li, H. T., Kong, W. Q., Huang, H., Liu, Y., et al. (2014a). Au nanoparticles in carbon nanotubes with high photocatalytic activity for hydrocarbon selective oxidation. Dalton Trans. 43, 12982-12988. doi: 10.1039/C4DT01077A

Liu, J., Yang, Y. M., Liu, N. Y., Liu, Y., Huang, H., and Kang, Z. H. (2014b). Total photocatalysis conversion from cyclohexane to cyclohexanone by $\mathrm{C}_{3} \mathrm{~N}_{4} / \mathrm{Au}$ nanocomposites. Green Chem. 16, 4559-4565. doi: 10.1039/C4GC01126K

Liu, L., Gao, Y., Zhao, P., Wang, X., Feng, G., and Zhang, R. (2016). Pillared clay-supported gold catalysts for CO oxidation. RSC Adv. 6, 15121-15126. doi: 10.1039/C5RA26035C

Liu, L. L., Zhou, X. J., Yan, Y. M., Zhou, J., Zhang, W. P., and Tai, X. S. (2018). Bimetallic gold-silver nanoparticles supported on zeolitic imidazolate framework- 8 as highly active heterogenous catalysts for selective oxidation of benzyl alcohol into benzaldehyde. Polymers 10:16. doi: 10.3390/polym1010 1089 
Liu, R., Gao, N., Zhen, F., Zhang, Y., Mei, L., and Zeng, X. (2013). Doping effect of $\mathrm{Al} 2 \mathrm{O} 3$ and $\mathrm{CeO}_{2}$ on $\mathrm{Fe}_{2} \mathrm{O}_{3}$ support for gold catalyst in $\mathrm{CO}$ oxidation at low-temperature. Chem. Eng. J. 225, 245-253. doi: 10.1016/j.cej.2013.03.118

Liu, R. H., Huang, H., Li, H. T., Liu, Y., Zhong, J., Li, Y. Y., et al. (2014). Metal nanoparticle/carbon quantum dot composite as a photocatalyst for high-efficiency cyclohexane oxidation. ACS Catal. 4, 328-336. doi: $10.1021 / \mathrm{cs} 400913 \mathrm{~h}$

Liu, X., Conte, M., Sankar, M., He, Q., Murphy, D. M., Morgan, D., et al. (2015). Liquid phase oxidation of cyclohexane using bimetallic $\mathrm{Au}-\mathrm{Pd} / \mathrm{MgO}$ catalysts. Appl. Catal. Gen. 504, 373-380. doi: 10.1016/j.apcata.2015.02.034

Liu, X. Y., Wang, A. Q., Zhang, T., and Mou, C. Y. (2013). Catalysis by gold: new insights into the support effect. Nano Today 8, 403-416. doi: 10.1016/j.nantod.2013.07.005

Liu, Y., Tsunoyama, H., Akita, T., Xie, S., and Tsukuda, T. (2011). Aerobic oxidation of cyclohexane catalyzed by size-controlled Au clusters on hydroxyapatite: size effect in the Sub-2 $\mathrm{nm}$ regime. ACS Catal. 1, 2-6. doi: $10.1021 / \mathrm{cs} 100043 \mathrm{j}$

Lloyd, R., Jenkins, R. L., Piccinini, M., He, Q., Kiely, C. J., Carley, A. F., et al. (2011). Low-temperature aerobic oxidation of decane using an oxygen-free radical initiator. J. Catal. 283, 161-167. doi: 10.1016/j.jcat.2011.08.003

Long, N. Q., and Quan, N. A. (2015). Highly selective oxidation of benzyl alcohol to benzaldehyde catalyzed by nano $\mathrm{Au} / \mathrm{gamma}-\mathrm{Al}_{2} \mathrm{O}_{3}$ under environment-friendly conditions. React. Kinet. Mech. Catal. 114, 147-155. doi: 10.1007/s11144-014-0773-4

Louie, S. M., Gorham, J. M., Tan, J. J., and Hackley, V. A. (2017). Ultraviolet photo-oxidation of polyvinylpyrrolidone (PVP) coatings on gold nanoparticles. Environ. Sci. Nano 4, 1866-1875. doi: 10.1039/C7EN00411G

Louis, C. (2016). Chemical preparation of supported bimetallic catalysts. GoldBased Bimetallic, a Case Study. Catalysts 6:27. doi: 10.3390/catal6080110

Lu, G. M., Ji, D., Qian, G., Qi, Y. X., Wang, X. L., and Suo, J. S. (2005). Gold nanoparticles in mesoporous materials showing catalytic selective oxidation cyclohexane using oxygen. Appl. Catal. Stud. Surf. Sci. Cataly. Gen. 280, 175-180. doi: 10.1016/j.apcata.2004.10.034

Lu, G. M., Zhao, R., Qian, G., Qi, Y. X., Wang, X. L., and Suo, J. S. (2004). A highly efficient catalyst $\mathrm{Au} / \mathrm{MCM}-41$ for selective oxidation cyclohexane using oxygen. Catal. Lett. 97, 115-118. doi: 10.1023/B:CATL.0000038571.97121.b7

Luken, A., Muhler, M., and Strunk, J. (2015). On the role of gold nanoparticles in the selective photooxidation of 2-propanol over $\mathrm{Au} / \mathrm{TiO}_{2}$. Phys. Chem. Chem. Phys. 17, 10391-10397. doi: 10.1039/C4CP05423G

Ma, Y. C., Shi, F., and Deng, Y. Q. (2003). Advances in gold catalysts and their application in organic reactions. Prog. Chem. 15, 385-392. Available online at: http://manu56.magtech.com.cn/progchem/EN/abstract/abstract8883.shtml

Magadzu, T., Hearne, G. R., and Scurrell, M. S. (2007). "Characteristics of goldzeolite Y catalysts in CO oxidation and ethylene hydrogenation," in From Zeolites to Porous Mof Materials: The 40th Anniversary of International Zeolite Conference, Proceedings of the 15th International Zeolite Conference Studies in Surface Science and Catalysis, Studies in Surface Science and Catalysis, Vol. 170, eds R. Xu, Z. Gao, J. Chen, and W. Yan (Amsterdam: Elsevier), 1059-1064. doi: 10.1016/S0167-2991(07)80960-8

Majdalawieh, A., Kanan, M. C., El-Kadri, O., and Kanan, S. M. (2014). Recent advances in gold and silver nanoparticles: synthesis and applications. J. Nanosci. Nanotechnol. 14, 4757-4780. doi: 10.1166/jnn.2014.9526

Mallat, T., and Baiker, A. (2004). Oxidation of alcohols with molecular oxygen on solid catalysts. Chem. Rev. 104, 3037-3058. doi: 10.1021/cr0200116

Mallat, T., and Baiker, A. (2012). Potential of gold nanoparticles for oxidation in fine chemical synthesis. Annu. Rev. Chem. Biomol. Eng. 3, 11-28. doi: 10.1146/annurev-chembioeng-062011-081046

Manna, S., Kim, J. W., Takahashi, Y., Shpyrko, O. G., and Fullerton, E. E. (2016). Synthesis of single-crystalline anisotropic gold nano-crystals via chemical vapor deposition. J. Appl. Phys. 119, 7. doi: 10.1063/1.4948565

Martins, L. M. D. R. S., Carabineiro, S. A. C., Wang, J., Rocha, B. G. M., Maldonado-Hódar, F. J., and Pombeiro, A. J. L. D. O. (2017). Supported gold nanoparticles as reusable catalysts for oxidation reactions of industrial significance. ChemCatChem 9, 1211-1221. doi: 10.1002/cctc.2016 01442

Mayani, V. J., Mayani, S. V., and Kim, S. W. (2016). Palladium, gold, and goldpalladium nanoparticle-supported carbon materials for cyclohexane oxidation. Chem. Eng. Commun. 203, 539-547. doi: 10.1080/00986445.2015.1048800
Mears, D. E., and Eastman, A. D. (2004). Kirk-Othmer Encyclopedia of Chemical Technology, Vol. 13. New York, NY: Wiley, 706.

Mehri, A., Kochkar, H., Berhault, G., Merchan, D. F. C., and Blasco, T. (2015). Onepot deposition of gold on hybrid $\mathrm{TiO}_{2}$ nanoparticles and catalytic application in the selective oxidation of benzyl alcohol. Mater. Chem. Phys. 149, 59-68. doi: 10.1016/j.matchemphys.2014.09.033

Mei, B., Wiktor, C., Turner, S., Pougin, A., Van Tendeloo, G., Fischer, R. A., et al. (2013). Evidence for metal-support interactions in Au modified $\mathrm{TiO}_{\mathrm{x}} / \mathrm{SBA}-15$ materials prepared by photodeposition. ACS Catal. 3, 3041-3049. doi: $10.1021 / \mathrm{cs} 400964 \mathrm{k}$

Meyer, R., Lemire, C., Shaikhutdinov, S. K., and Freund, H.-J. (2004). Surface chemistry of catalysis by gold. Gold Bull. 37, 72-124. doi: 10.1007/BF03215519

Mishra, G. S., Alegria, E. C. B., Martins, L. M. D. R. S., Fraústo Da Silva, J. J. R., and Pombeiro, A. J. L. (2008). Cyclohexane oxidation with dioxygen catalyzed by supported pyrazole rhenium complexes. J. Mol. Catal. A Chem. 285, 92-100. doi: 10.1016/j.molcata.2008.01.022

Mishra, G. S., Silva, T. F. S., Martins, L. M. D. R. S., and Pombeiro, A. J. L. (2009). Scorpionate complexes of vanadium(III or IV) as catalyst precursors for solvent-free cyclohexane oxidation with dioxygen. Pure Appl. Chem. 81, 1217-1227. doi: 10.1351/PAC-CON-08-10-08

Mishra, M., Park, H., and Chun, D.-M. (2016). Photocatalytic properties of $\mathrm{Au} / \mathrm{Fe}_{2} \mathrm{O}_{3}$ nano-composites prepared by co-precipitation. Adv. Powder Technol. 27, 130-138. doi: 10.1016/j.apt.2015.11.009

Mitsudome, T., Noujima, A., Mizugaki, T., Jitsukawa, K., and Kaneda, K. (2009). Efficient aerobic oxidation of alcohols using a hydrotalcitesupported gold nanoparticle catalyst. Adv. Synth. Catal. 351, 1890-1896. doi: $10.1002 /$ adsc. 200900239

Miyamura, H., Matsubara, R., Miyazaki, Y., and Kobayashi, S. (2007). Aerobic oxidation of alcohols at room temperature and atmospheric conditions catalyzed by reusable gold nanoclusters stabilized by the benzene rings of polystyrene derivatives. Angew. Chem. Int. Ed. 46, 4151-4154. doi: $10.1002 /$ anie. 200700080

Mohamed, M. M. (2015). Gold loaded titanium dioxide-carbon nanotube composites as active photocatalysts for cyclohexane oxidation at ambient conditions. RSC Adv. 5, 46405-46414. doi: 10.1039/C5RA05253J

Morad, M., Sankar, M., Cao, E. H., Nowicka, E., Davies, T. E., Miedziak, P. J., et al. (2014). Solvent-free aerobic oxidation of alcohols using supported gold palladium nanoalloys prepared by a modified impregnation method. Catal. Sci. Technol. 4, 3120-3128. doi: 10.1039/C4CY00387J

Moreau, F., Bond, G. C., and Taylor, A. O. (2005). Gold on titania catalysts for the oxidation of carbon monoxide: control of $\mathrm{pH}$ during preparation with various gold contents. J. Catal. 231, 105-114. doi: 10.1016/j.jcat.2005. 01.030

Moreno, I., Dummer, N. F., Edwards, J. K., Alhumaimess, M., Sankar, M., Sanz, R., et al. (2013). Selective oxidation of benzyl alcohol using in situ generated $\mathrm{H}_{2} \mathrm{O}_{2}$ over hierarchical Au-Pd titanium silicalite catalysts. Catal. Sci. Technol. 3, 2425-2434. doi: $10.1039 / \mathrm{c} 3$ cy00493g

Mori, K., Hara, T., Mizugaki, T., Ebitani, K., and Kaneda, K. (2004). Hydroxyapatite-supported palladium nanoclusters: a highly active heterogeneous catalyst for selective oxidation of alcohols by use of molecular oxygen. J. Am. Chem. Soc. 126, 10657-10666. doi: 10.1021/ja0488683

Motta, D., Trujillo, F. J. S., Dimitratos, N., Villa, A., and Prati, L. (2018). An investigation on AuPt and AuPt-Bi on granular carbon as catalysts for the oxidation of glycerol under continuous flow conditions. Catal. Today 308, 50-57. doi: 10.1016/j.cattod.2017.10.012

Movahed, S. K., Lehi, N. F., and Dabiri, M. (2014). Gold nanoparticle supported on ionic liquid-modified graphene oxide as an efficient and recyclable catalyst for one-pot oxidative $\mathrm{A}(3)$-coupling reaction of benzyl alcohols. RSC Adv. 4, 42155-42158. doi: 10.1039/C4RA05190D

Murcia-Mesa, J. J., Colon, G., Navio, J. A., and Hidalgo, M. C. (2010). "Tuning the features of $\mathrm{Au}$ nanoparticles on $\mathrm{TiO}_{2}$ by the control of the photodeposition parameters," in Proceedings of the 6th European Meeting on Solar Chemistry \& Photocatalysis: Environmental Applications, ed J. Krysa (Prague: Institute of Chemical Technology), 45-46.

Naknam, P., Luengnaruemitchai, A., and Wongkasemjit, S. (2009). Preferential $\mathrm{CO}$ oxidation over $\mathrm{Au} / \mathrm{ZnO}$ and $\mathrm{Au} / \mathrm{ZnO}-\mathrm{Fe}_{2} \mathrm{O}_{3}$ catalysts prepared by photodeposition. Int. J. Hydrogen Energy 34, 9838-9846. doi: 10.1016/j.ijhydene.2009.10.015 
Ndolomingo, M. J., and Meijboom, R. (2017). Selective liquid phase oxidation of benzyl alcohol to benzaldehyde by tert-butyl hydroperoxide over gamma$\mathrm{Al}_{2} \mathrm{O}_{3}$ supported copper and gold nanoparticles. Appl. Surf. Sci. 398, 19-32. doi: 10.1016/j.apsusc.2016.12.020

Negishi, R., Naya, S., Kobayashi, H., and Tada, H. (2017). Gold(Core)-Lead(Shell) Nanoparticle-Loaded Titanium(IV) Oxide prepared by underpotential photodeposition: plasmonic water oxidation. Angew. Chem. Int. Ed. 56, 10347-10351. doi: 10.1002/anie.201703093

Nepak, D., and Srinivas, D. (2015). Effect of alkali and alkaline earth metal ions on benzyl alcohol oxidation activity of titanate nanotube-supported Au catalysts. RSC Adv. 5, 47740-47748. doi: 10.1039/C5RA06496A

Nesterov, D. S., Chygorin, E. N., Kokozay, V. N., Bon, V. V., Boča, R., Kozlov, Y. N., et al. (2012). Heterometallic $\mathrm{Co}_{4}^{\mathrm{III}} \mathrm{Fe}_{2}^{\mathrm{III}}$ schiff base complex: structure, electron paramagnetic resonance, and alkane oxidation catalytic activity. Inorg. Chem. 51, 9110-9122. doi: 10.1021/ic301460q

Ni, J., Yu, W.-J., He, L., Sun, H., Cao, Y., He, H.-Y., et al. (2009). A green and efficient oxidation of alcohols by supported gold catalysts using aqueous $\mathrm{H}_{2} \mathrm{O}_{2}$ under organic solvent-free conditions. Green Chem. 11, 756-759. doi: $10.1039 / \mathrm{b} 820197 \mathrm{~h}$

Nikitenko, N. G., and Shestakov, A. F. (2013). Quantum chemical modeling of the activation and oxidation of light alkanes under mild conditions by $\mathrm{Au}(\mathrm{I})$ complexes with bioflavonoids. Kinet. Catal. 54, 168-178. doi: $10.1134 /$ S0023158413020110

Niu, Z. Q., and Li, Y. D. (2014). Removal and utilization of capping agents in nanocatalysis. Chem. Mater. 26, 72-83. doi: 10.1021/cm4022479

Nizova, G. V., Krebs, B., Süss-Fink, G., Schindler, S., Westerheide, L., Gonzalez Cuervo, L., et al. (2002). Hydroperoxidation of methane and other alkanes with $\mathrm{H}_{2} \mathrm{O}_{2}$ catalyzed by a dinuclear iron complex and an amino acid. Tetrahedron 58, 9231-9237. doi: 10.1016/S0040-4020(02)01182-1

Nizova, G. V., and Shulpin, G. B. (1992). Photochemical oxidation of hydrocarbons by atmospheric oxygen in solutions, catalyzed by $\mathrm{AuCl}_{4}$ complex. Petrol. Chem. $32,36-41$.

Oh, H. S., Yang, J. H., Costello, C. K., Wang, Y. M., Bare, S. R., Kung, H. H., et al. (2002). Selective catalytic oxidation of CO: effect of chloride on supported Au catalysts. J. Catal. 210, 375-386. doi: 10.1006/jcat.2002.3710

Okumura, M., Tsubota, S., and Haruta, M. (2003). Preparation of supported gold catalysts by gas-phase grafting of gold acethylacetonate for lowtemperature oxidation of $\mathrm{CO}$ and of $\mathrm{H}_{2}$. J. Mol. Catal. A Chem. 199, 73-84. doi: 10.1016/S1381-1169(03)00020-7

Olea, M., and Iwasawa, Y. (2004). Transient studies on carbon monoxide oxidation over supported gold catalysts: support effects. Appl. Catal. Gen. 275, 35-42. doi: 10.1016/j.apcata.2004.07.017

Olenin, A. Y., Mingalev, P. G., and Lisichkin, G. V. (2018). Partial catalytic oxidation of alcohols: catalysts based on metals and metal coordination compounds (a Review). Petrol. Chem. 58, 577-592. doi: 10.1134/S0965544118080182

Onal, Y., Schimpf, S., and Claus, P. (2004). Structure sensitivity and kinetics of Dglucose oxidation to D-gluconic acid over carbon-supported gold catalysts. J. Catal. 223, 122-133. doi: 10.1016/j.jcat.2004.01.010

Pagliaro, M., Ciriminna, R., Kimura, H., Rossi, M., and Della Pina, C. (2007). From glycerol to value-added products. Ang. Chem. Int. Ed. 46, 4434-4440. doi: $10.1002 /$ anie. 200604694

Pagliaro, M., Ciriminna, R., Kimura, H., Rossi, M., and Della Pina, C. (2009). Recent advances in the conversion of bioglycerol into value-added products. Eur. J. Lipid Sci. Technol. 111, 788-799. doi: 10.1002/ejlt.200800210

Patil, P., Dhanasingh, S., and Kumar, N. S. (2018). Gold-doped ceria-lanthana solid solution: surfactant assisted preparation, nanostructural and catalytic properties. Chem. Pap. 72, 629-641. doi: 10.1007/s11696-017-0324-3

Pattrick, G., Van Der Lingen, E., Corti, C. W., Holliday, R. J., and Thompson, D. T. (2004). The potential for use of gold in automotive pollution control technologies: a short review. Top. Catal. 30-31, 273-279. doi: 10.1023/B:TOCA.0000029762.14168.d8

Peixoto De Almeida, M., Martins, L. M. D. R. S., Carabineiro, S. A. C., Lauterbach, T., Rominger, F., Hashmi, A. S. K., et al. (2013). Homogeneous and heterogenised new gold C-scorpionate complexes as catalysts for cyclohexane oxidation. Catal. Sci. Technol. 3, 3056-3069. doi: 10.1039/c3cy00552f

Peneau, V., He, Q., Shaw, G., Kondrat, S. A., Davies, T. E., Miedziak, P., et al. (2013). Selective catalytic oxidation using supported gold-platinum and palladium-platinum nanoalloys prepared by sol-immobilisation. Phys. Chem Chem. Phys. 15, 10636-10644. doi: 10.1039/c3cp50361e

Pérez, P., Soria, M. A., Carabineiro, S. A. C., Maldonado-Hódar, F. J., Mendes, A., and Madeira, L. M. (2016). Application of $\mathrm{Au} / \mathrm{TiO}_{2}$ catalysts in the lowtemperature water-gas shift reaction. Int. J. Hydrogen Energy 41, 4670-4681. doi: 10.1016/j.ijhydene.2016.01.037

Pflasterer, D., and Hashmi, A. S. K. (2016). Gold catalysis in total synthesis - recent achievements. Chem. Soc. Rev. 45, 1331-1367. doi: 10.1039/C5CS0 $0721 \mathrm{~F}$

Porta, F., and Prati, L. (2004). Selective oxidation of glycerol to sodium glycerate with gold-on-carbon catalyst: an insight into reaction selectivity. J. Catal. 224, 397-403. doi: 10.1016/j.jcat.2004.03.009

Porta, F., Prati, L., Rossi, M., Coluccia, S., and Martra, G. (2000). Metal sols as a useful tool for heterogeneous gold catalyst preparation: reinvestigation of a liquid phase oxidation. Catal. Today 61, 165-172. doi: 10.1016/S0920-5861(00)00370-9

Porta, F., Prati, L., Rossi, M., and Scari, G. (2002). New Au(0) sols as precursors for heterogeneous liquid-phase oxidation catalysts. J. Catal. 211, 464-469. doi: 10.1016/S0021-9517(02)93745-0

Porta, F., and Rossi, M. (2003). Gold nanostructured materials for the selective liquid phase catalytic oxidation. J. Mol. Catal. Chem. 204, 553-559. doi: 10.1016/S1381-1169(03)00338-8

Pradal, A., Toullec, P. Y., and Michelet, V. (2011). Recent developments in asymmetric catalysis in the presence of chiral gold complexes. Synthesis, 1501-1514. doi: 10.1055/s-0030-1258465

Prati, L., Chan-Thaw, C. E., Campisi, S., and Villa, A. (2016). N-modified carbon-based materials: nanoscience for catalysis. Chem. Rec. 16, 2187-2197. doi: $10.1002 /$ tcr.201500257

Prati, L., and Martra, G. (1999). New gold catalysts for liquid phase oxidation. Gold Bull. 32, 96-101. doi: 10.1007/BF03216617

Prati, L., and Porta, F. (2005). Oxidation of alcohols and sugars using Au/C catalysts: part 1. Alcohols. Appl. Catal. A Gen. 291, 199-203. doi: 10.1016/j.apcata.2004.11.050

Prati, L., and Rossi, M. (1998). Gold on carbon as a new catalyst for selective liquid phase oxidation of diols. J. Catal. 176, 552-560. doi: 10.1006/jcat.1998.2078

Prati, L., and Villa, A. (2012). The art of manufacturing gold catalysts. Catalysts 2, 24-37. doi: $10.3390 /$ catal2010024

Prati, L., and Villa, A. (2014). Gold colloids: from quasi-homogeneous to heterogeneous catalytic systems. Acc. Chem. Res. 47, 855-863. doi: $10.1021 / \operatorname{ar} 400170 \mathrm{j}$

Prati, L., and Villa, A. (2017). Valorization of glycerol to fine chemicals. Chim. Oggi Chem. Today 35, 33-35. doi: 10.1111/1467-8322. 12342

Prati, L., Villa, A., Chan-Thaw, C. E., Arrigo, R., Wang, D., and Su, D. S. (2011). Gold catalyzed liquid phase oxidation of alcohol: the issue of selectivity. Faraday Discuss. 152, 353-365. doi: 10.1039/clfd00016k

Prati, L., Villa, A., Jouve, A., Beck, A., Evangelisti, C., and Savara, A. (2018). Gold as a modifier of metal nanoparticles: effect on structure and catalysis. Faraday Discuss. 208, 395-407. doi: 10.1039/C7FD00223H

Prati, L., Villa, A., Lupini, A. R., and Veith, G. M. (2012). Gold on carbon: one billion catalysts under a single label. Phys. Chem. Chem. Phys. 14, 2969-2978. doi: $10.1039 / \mathrm{c} 2 \mathrm{cp} 23405 \mathrm{j}$

Priecel, P., Salami, H. A., Padilla, R. H., Zhong, Z. Y., and Lopez-Sanchez, J. A. (2016). Anisotropic gold nanoparticles: preparation and applications in catalysis. Chinese J. Catal. 37, 1619-1650. doi: 10.1016/S1872-2067(16)62475-0

Qi, L., Tang, C. J., Zhang, L., Yao, X. J., Cao, Y., Liu, L. C., et al. (2012). Influence of cerium modification methods on catalytic performance of $\mathrm{Au} /$ mordenite catalysts in CO oxidation. Appl. Catal. B Environ. 127, 234-245. doi: 10.1016/j.apcatb.2012.08.013

Quintanilla, A., García-Rodríguez, S., Domínguez, C. M., Blasco, S., Casas, J. A., and Rodriguez, J. J. (2012). Supported gold nanoparticle catalysts for wet peroxide oxidation. Appl. Catal. B Environ. 111-112, 81-89. doi: 10.1016/j.apcatb.2011.09.020

Ranveer, A., V Ranade, S., and K Mistry, C. (2015). Selective oxidation of alcohols to aldehydes by using hydrogen peroxide as an oxidant: a review. Int. J. Adv. Res. Sci. Eng. 4, 277-288. Available online at: https://pdfs.semanticscholar. org/35e5/9017378c9d712051e6467d8097dfb14fb4f4.pdf?_ga=2.85622108. 495310704.1571237696-243268353.1564847347 
Raphulu, M., Mcpherson, J., Pattrick, G., Ntho, T., Mokoena, L., Moma, J., et al. (2009). CO oxidation: deactivation of $\mathrm{Au} / \mathrm{TiO}_{2}$ catalysts during storage. Gold Bull. 42, 328-336. doi: 10.1007/BF03214955

Restrepo, J., Lozano, P., Burguete, M. I., Garcia-Verdugo, E., and Luis, S. V. (2015a). Gold nanoparticles immobilized onto supported ionic liquid-like phases for microwave phenylethanol oxidation in water. Catal. Today 255, 97-101. doi: 10.1016/j.cattod.2014.12.023

Restrepo, J., Porcar, R., Lozano, P., Burguete, M. I., Garcia-Verdugo, E., and Luis, S. V. (2015b). Microwave-assisted selective oxidation of 1-phenyl ethanol in water catalyzed by metal nanoparticles immobilized onto supported ionic liquid like phases. ACS Catal. 5, 4743-4750. doi: 10.1021/acscatal.5b01129

Ribeiro, A. P. C., Martins, L. M. D. R. S., Carabineiro, S. A. C., Figueiredo, J. L., and Pombeiro, A. J. L. (2017a). Gold nanoparticles deposited on surface modified carbon materials as reusable catalysts for hydrocarboxylation of cyclohexane. Appl. Catal. A Gen. 547(Suppl. C), 124-131. doi: 10.1016/j.apcata.2017.08.028

Ribeiro, A. P. C., Martins, L. M. D. R. S., Carabineiro, S. A. C., Figueiredo, J. L., and Pombeiro, A. J. L. (2017b). Gold nanoparticles deposited on surface modified carbon xerogels as reusable catalysts for cyclohexane $\mathrm{C}-\mathrm{H}$ activation in the presence of CO and water. Molecules 22:603. doi: 10.3390/molecules22040603

Rodrigues, C. S. D., Carabineiro, S. A. C., Maldonado-Hódar, F. J., and Madeira, L. M. (2017a). Orange II degradation by wet peroxide oxidation using Au Nanosized catalysts: effect of the support. Indus. Eng. Chem. Res. 56, 1988-1998. doi: 10.1021/acs.iecr.6b04673

Rodrigues, C. S. D., Carabineiro, S. A. C., Maldonado-Hódar, F. J., and Madeira, L. M. (2017b). Wet peroxide oxidation of dye-containing wastewaters using nanosized $\mathrm{Au}$ supported on $\mathrm{Al}_{2} \mathrm{O}_{3}$. Catal. Today 280(Pt 1), 165-175. doi: 10.1016/j.cattod.2016.06.031

Rodrigues, E. G., Carabineiro, S. A. C., Chen, X., Delgado, J. J., Figueiredo, J. L., Pereira, M. F. R., et al. (2011). Selective oxidation of glycerol catalyzed by Rh/activated carbon: importance of support surface chemistry. Catal. Lett. 141, 420-431. doi: 10.1007/s10562-010-0515-9

Rodrigues, E. G., Carabineiro, S. A. C., Delgado, J. J., Chen, X., Pereira, M. F. R., and Órfão, J. J. M. (2012a). Corrigendum to Gold supported on carbon nanotubes for the selective oxidation of glycerol [J. Catal. 285 (2012) 83-91]. J. Catal. 292, 246-247. doi: 10.1016/j.jcat.2012.05.016

Rodrigues, E. G., Carabineiro, S. A. C., Delgado, J. J., Chen, X., Pereira, M. F. R., and Órfão, J. J. M. (2012b). Gold supported on carbon nanotubes for the selective oxidation of glycerol. J. Catal. 285, 83-91. doi: 10.1016/j.jcat.2011.09.016

Rodrigues, E. G., Pereira, M. F. R., and Orfao, J. J. M. (2012c). Glycerol oxidation with gold supported on carbon xerogels: tuning selectivities by varying mesopore sizes. Appl. Catal. B Environ. 115, 1-6. doi: 10.1016/j.apcatb.2011.12.008

Rodriguez, J. A., Grinter, D. C., Ramírez, P. J., Stacchiola, D. J., and Senanayake, S. (2018). High activity of $\mathrm{Au} / \mathrm{K} / \mathrm{TiO}_{2}(110)$ for $\mathrm{CO}$ oxidation: alkali-metalenhanced dispersion of $\mathrm{Au}$ and bonding of CO. J. Phys. Chem. C 122, 4324-4330. doi: 10.1021/acs.jpcc.7b11771

Rudolph, M., and Hashmi, A. S. K. (2012). Gold catalysis in total synthesis-an update. Chem. Soc. Rev. 41, 2448-2462. doi: 10.1039/C1CS15279C

Ruvarac-Bugarcic, I., Jankovic, I., Konstantinovic, Z., Saponjic, Z., and Nedeljkovic, J. (2008). Photocatalytic deposition of gold on nanocrystalline $\mathrm{TiO}_{2}$ films. Acta Chim. Slov. 55, 268-272. Available online at: http://acta-arhiv. chem-soc.si/55/55-2-268.pdf

Saldan, I., Dobrovetska, O., Sus, L., Makota, O., Pereviznyk, O., Kuntyi, O., et al. (2018). Electrochemical synthesis and properties of gold nanomaterials. J. Solid State Electrochem. 22, 637-656. doi: 10.1007/s10008-017-3835-5

Sanada, T., Murakami, C., Gora-Marek, K., Iida, K., Katada, N., and Okumura, K. (2013). Fabrication and catalytic activity of thermally stable gold nanoparticles on ultrastable Y (USY) Zeolites. Catalysts 3, 599-613. doi: 10.3390/catal3030599

Sanchez, A., Abbet, S., Heiz, U., Schneider, W. D., Hakkinen, H., Barnett, R. N., et al. (1999). When gold is not noble: nanoscale gold catalysts. J. Phys. Chem. A 103, 9573-9578. doi: 10.1021/jp9935992

Sangeetha, P., Chang, L. H., and Chen, Y. W. (2009). Preferential oxidation of CO in $\mathrm{H}(2)$ stream on $\mathrm{Au} / \mathrm{TiO}_{2}$ catalysts: effect of preparation method. Indus. Eng. Chem. Res. 48, 5666-5670. doi: 10.1021/ie900403s

Sannino, D., Vaiano, V., Ciambelli, P., Murcia, J. J., Hidalgo, M. C., and Navio, J. A. (2013). Gas-phase photocatalytic partial oxidation of cyclohexane to cyclohexanol and cyclohexanone on $\mathrm{Au} / \mathrm{TiO}_{2}$ photocatalysts. J. Adv. Oxid. Technol. 16, 71-82. doi: 10.1515/jaots-2013-0107

Santonastaso, M., Freakley, S. J., Miedziak, P. J., Brett, G. L., Edwards, J. K., and Hutchings, G. J. (2014). Oxidation of benzyl alcohol using in situ generated hydrogen peroxide. Organ. Process Res. Dev. 18, 1455-1460. doi: 10.1021/op500195e

Santos, V. P., Carabineiro, S. A. C., Bakker, J. J. W., Soares, O. S. G. P., Chen, X., Pereira, M. F. R., et al. (2014). Stabilized gold on cerium-modified cryptomelane: highly active in low-temperature CO oxidation. J. Catal. 309, 58-65. doi: 10.1016/j.jcat.2013.08.030

Santos, V. P., Carabineiro, S. a. C., Tavares, P. B., Pereira, M. F. R., Órfão, J. J. M., and Figueiredo, J. L. (2010). Oxidation of CO, ethanol and toluene over $\mathrm{TiO}_{2}$ supported noble metal catalysts. Appl. Catal. B Environ. 99, 198-205. doi: 10.1016/j.apcatb.2010.06.020

Saxena, S., Singh, R., Pala, R. G. S., and Sivakumar, S. (2016). Sinter-resistant gold nanoparticles encapsulated by zeolite nanoshell for oxidation of cyclohexane. RSC Adv. 6, 8015-8020. doi: 10.1039/C5RA20734G

Schuchardt, U., Cardoso, D., Sercheli, R., Pereira, R., Da Cruz, R. S., Guerreiro, M. C., et al. (2001). Cyclohexane oxidation continues to be a challenge. Appl. Catal. A Gen. 211, 1-17. doi: 10.1016/S0926-860X(01)00472-0

Schulz, A., and Hargittai, M. (2001). Structural variations and bonding in gold halides: a quantum chemical study of monomeric and dimeric gold monohalide and gold trihalide molecules, $\mathrm{AuX}, \mathrm{Au}_{2} \mathrm{X}_{2}$, $\mathrm{AuX}_{3}$, and $\mathrm{Au}_{2} \mathrm{X}_{6}(\mathrm{X}=\mathrm{F}, \mathrm{Cl}, \mathrm{Br}, \mathrm{I})$. Chem. Eur. J. 7, 3657-3670. doi: 10.1002/1521-3765(20010903)7:17<3657::AID-CHEM3657>3.0.CO;2-Q

Scurrell, M. S. (2017). Thoughts on the use of gold-based catalysts in environmental protection catalysis. Gold Bull. 50, 77-84. doi: $10.1007 /$ s13404-017-0194-z

Seker, E., and Gulari, E. (2002). Single step sol-gel made gold on alumina catalyst for selective reduction of $\mathrm{NO}_{x}$ under oxidizing conditions: effect of gold precursor and reaction conditions. Appl. Catal. A Gen. 232, 203-217. doi: 10.1016/S0926-860X(02)00115-1

Shah, A., Latif Ur, R., Qureshi, R., and Zia Ur, R. (2012). Synthesis, characterization and applications of bimetallic (Au-Ag, Au-Pt, Au-Ru) alloy nanoparticles. Rev. Adv. Mater. Sci. 30, 133-149.

Shahzad, S. A., Sajid, M. A., Khan, Z. A., and Canseco-Gonzalez, D. (2017). Gold catalysis in organic transformations: a review. Synth. Commun. 47, 735-755. doi: 10.1080/00397911.2017.1280508

Sharma, A. S., Kaur, H., and Shah, D. (2016). Selective oxidation of alcohols by supported gold nanoparticles: recent advances. RSC Adv. 6, 28688-28727. doi: 10.1039/C5RA25646A

Sheldon, R. A., Arends, I., and Hanefeld, U. (2007). Green Chemistry and Catalysis. Weinheim:Wiley-VCH. doi: 10.1002/9783527611003

Sheldon, R. A., and Van Bekkum, H. (Eds.). (2001). Fine Chemicals Through Heterogeneous Catalysis. Weinheim: Wiley. doi: 10.1002/9783527612963

Shi, L. L., Liu, K. Z., Zou, X. H., Yin, M. S., and Suo, Z. H. (2010). Selective oxidation of glucose in the presence of PVP-protected colloidal gold solutions. Chinese J. Catal. 31, 661-665. doi: 10.3724/SP.J.1088.2010.91137

Shul'pin, G. B. (2003). Metal-catalysed hydrocarbon oxidations. Comptes Rendus Chimie 6, 163-178. doi: 10.1016/S1631-0748(03)00021-3

Shulpin, G. B. (2009). Hydrocarbon oxygenations with peroxides catalyzed by metal compounds. Mini Rev. Org. Chem. 6, 95-104. doi: 10.2174/157019309788167738

Shulpin, G. B., Attanasio, D., and Suber, L. (1993). Efficient $\mathrm{H}_{2} \mathrm{O}_{2}$ oxidation of alkanes and arenes to alkyl peroxides and phenols catalyzed by the system vanadate-pyrazine-2-carboxylic acid. J. Catal. 142, 147-152. doi: 10.1006/jcat.1993.1196

Shulpin, G. B., and Nizova, G. V. (1993). Photoinitiated reactions of organiccompounds with metal-complexes. 25. Photooxidation of cyclohexane by atmospheric oxygen in acetonitrile, catalyzed by chloride complexes of iron, copper and gold. Petrol. Chem. 33, 107-112.

Shul'pin, G. B., Nizova, G. V., Kozlov, Y. N., Cuervo, L. G., and Suss-Fink, G. (2004). Hydrogen peroxide oxygenation of alkanes including methane and ethane catalyzed by iron complexes in acetonitrile. Adv. Synth. Catal. 346, 317-332. doi: 10.1002/adsc.200303147

Shul'pin, G. B., Shilov, A. E., and Suss-Fink, G. (2001). Alkane oxygenation catalysed by gold complexes. Tetrahedron Lett. 42, 7253-7256. doi: 10.1016/S0040-4039(01)01517-9

Shul'pina, L. S., Kirillova, M. V., Pombeiro, A. J. L., and Shul'pin, G. B. (2009). Alkane oxidation by the $\mathrm{H}_{2} \mathrm{O}_{2}-\mathrm{NaVO}_{3}-\mathrm{H}_{2} \mathrm{SO}_{4}$ system in acetonitrile and water. Tetrahedron 65, 2424-2429. doi: 10.1016/j.tet.2009.01.088

Sierraalta, A., Alejos, P., and Ehrmann, E. (2008). Influence of isomorphous substitution on $\mathrm{NO}$ and $\mathrm{N}_{2} \mathrm{O}$ thermochemistry on Au/ZSM-5 catalyst. Int. J. Quantum Chem. 108, 1696-1704. doi: 10.1002/qua.21581 
Silva, C. G., Sampaio, M. J., Carabineiro, S. A. C., Oliveira, J. W. L., Baptista, D. L., Bacsa, R., et al. (2014). Developing highly active photocatalysts: gold-loaded $\mathrm{ZnO}$ for solar phenol oxidation. J. Catal. 316, 182-190. doi: 10.1016/j.jcat.2014.05.010

Silva, T. A. G., Teixeira-Neto, E., Lopez, N., and Rossi, L. M. (2014). Volcanolike behavior of Au-Pd core-shell nanoparticles in the selective oxidation of Alcohols. Sci. Rep. 4:5. doi: 10.1038/srep05766

Silva, T. F. S., Alegria, E. C. B. A., Martins, L. M. D. R. S., and Pombeiro, A. J. L. (2008). Half-sandwich scorpionate vanadium, iron and copper complexes: synthesis and application in the catalytic peroxidative oxidation of cyclohexane under mild conditions. Adv. Synth. Catal. 350, 706-716. doi: 10.1002/adsc.200700529

Silva, T. F. S., Guedes Da Silva, M. F., Mishra, G. S., Martins, L. M. D. R. S., and Pombeiro, A. J. L. (2011). Synthesis and structural characterization of iron complexes with 2,2,2-tris(1-pyrazolyl)ethanol ligands: application in the peroxidative oxidation of cyclohexane under mild conditions. J. Organomet. Chem. 696, 1310-1318. doi: 10.1016/j.jorganchem.2010.12.036

Silva, T. F. S., Luzyanin, K. V., Kirillova, M. V., Fátima Guedes Da Silva, M., Martins, L. M. D. R. S., and Pombeiro, A. J. L. (2010). Novel scorpionate and pyrazole dioxovanadium complexes, catalysts for carboxylation and peroxidative oxidation of alkanes. Adv. Synth. Catal. 352, 171-187. doi: 10.1002/adsc.200900660

Silva, T. F. S., Macleod, T. C. O., Martins, L. M. D. R. S., Guedes Da Silva, M. F. C., Schiavon, M. A., and Pombeiro, A. J. L. (2013). Pyrazole or tris(pyrazolyl)ethanol oxo-vanadium(IV) complexes as homogeneous or supported catalysts for oxidation of cyclohexane under mild conditions. J. Mol. Catal. A Chem. 367, 52-60. doi: 10.1016/j.molcata.2012.10.024

Silva, T. F. S., Mishra, G. S., Guedes Da Silva, M. F., Wanke, R., Martins, L. M. D. R. S., and Pombeiro, A. J. L. (2009). CuII complexes bearing the 2,2,2-tris(1-pyrazolyl)ethanol or 2,2,2-tris(1-pyrazolyl)ethyl methanesulfonate scorpionates. X-Ray structural characterization and application in the mild catalytic peroxidative oxidation of cyclohexane. Dalton Trans. 9207-9215. doi: 10.1039/b911990f

Singh, R., and Pal, B. (2015). Influence of Au photodeposition and doping in CdS nanorods: optical and photocatalytic study. Partic. Sci. Technol. 33, 53-58. doi: 10.1080/02726351.2014.933148

Smirnov, M. Y., Vovk, E. I., Kalinkin, A. V., and Bukhtiyarov, V. I. (2016). Effect of the composition of the reaction atmosphere on the thermal stability of highly dispersed gold particles on an oxide support $\left(\mathrm{Au} / \mathrm{Al}_{2} \mathrm{O}_{3}\right.$ system). Kinet. Catal. 57, 831-839. doi: 10.1134/S002315841606015X

Soares, J. M. C., Hall, M., Cristofolini, M., and Bowker, M. (2006). The role of impurities on the low temperature $\mathrm{CO}$ oxidation on $\mathrm{Au} / \mathrm{TiO}_{2}$. Catal. Lett. 109, 103-108. doi: 10.1007/s10562-006-0064-4

Sokolovskii, V. D. (1990). Principles of oxidative catalysis on solid oxides. Catal. Rev. Sci. Eng. 32, 1-49. doi: 10.1080/01614949009349939

Song, H. Y., Li, G., and Wang, X. S. (2010). Preparation and application of porous material supported gold catalysts. Prog. Chem. 22, 573-579.

Song, K. W., Cha, H. W., Yang, H., and Yang, C. W. (2015). UV-enhanced synthesis of $\mathrm{Au} / \mathrm{TiO}_{2}$ nanocomposites and investigation of the possible synthesis mechanism. Sci. Adv. Mater. 7, 1506-1509. doi: 10.1166/sam.2015.2365

Soria, M. A., Pérez, P., Carabineiro, S. A. C., Maldonado-Hódar, F. J., Mendes, A., and Madeira, L. M. (2014). Effect of the preparation method on the catalytic activity and stability of $\mathrm{Au} / \mathrm{Fe}_{2} \mathrm{O}_{3}$ catalysts in the low-temperature watergas shift reaction. Appl. Catal. A Gen. 470, 45-55. doi: 10.1016/j.apcata.2013. 10.034

Sreethawong, T., Sitthiwechvijit, N., Rattanachatchai, A., Ouraipryvan, P., Schwank, J. W., and Chavadej, S. (2011). Preparation of $\mathrm{Au} / \mathrm{Y}_{2} \mathrm{O}_{3}$ and $\mathrm{Au} / \mathrm{NiO}$ catalysts by co-precipitation and their oxidation activities. Mater. Chem. Phys. 126, 212-219. doi: 10.1016/j.matchemphys.2010.11.037

Staykov, A., Miwa, T., and Yoshizawa, K. (2018). Aerobic oxidation of alkanes on icosahedron gold nanoparticle Au55. J. Catal. 364, 141-153. doi: 10.1016/j.jcat.2018.05.017

Steinhauser, G., Evers, J., Jakob, S., Klapötke, T. M., and Oehlinger, G. (2008). A review on fulminating gold (Knallgold). Gold Bull. 41, 305-317. doi: 10.1007/BF03214888

Su, F. Z., Liu, Y. M., Wang, L. C., Cao, Y., He, H. Y., and Fan, K. N. (2007). Ga-Al mixed-oxide-supported gold nanoparticles with enhanced activity for aerobic alcohol oxidation. Angew. Chem. Int. Ed. 47, 340-343. doi: 10.1002/ange.200704370
Sun, J. Y., Tong, X. L., Liu, Z. H., Liao, S. Y., Zhuang, X. L., and Xue, S. (2016). Gold-catalyzed selectivity-switchable oxidation of benzyl alcohol in the presence of molecular oxygen. Catal. Commun. 85, 70-74. doi: 10.1016/j.catcom.2016.07.018

Sun, Z. G., Li, G., Liu, L. P., and Liu, H. O. (2012). Au nanoparticles supported on Cr-based metal-organic framework as bimetallic catalyst for selective oxidation of cyclohexane to cyclohexanone and cyclohexanol. Catal. Commun. 27, 200-205. doi: 10.1016/j.catcom.2012.07.017

Sunagawa, Y., Yamamoto, K., Takahashi, H., and Muramatsu, A. (2008). Liquidphase reductive deposition as a novel nanoparticle synthesis method and its application to supported noble metal catalyst preparation. Catal. Today 132, 81-87. doi: 10.1016/j.cattod.2007.12.008

Takale, B. S., Bao, M., and Yamamoto, Y. (2014). Gold nanoparticle (AuNPs) and gold nanopore (AuNPore) catalysts in organic synthesis. Org. Biomol. Chem. 12, 2005-2027. doi: 10.1039/c3ob42207k

Takei, T., Akita, T., Nakamura, I., Fujitani, T., Okumura, M., Okazaki, K., et al. (2012). "Heterogeneous catalysis by gold," in Advances in Catalysis, Vol 55, by B. C. Gates and F. C. Jentoft (San Diego, CA: Elsevier Academic Press Inc), 1-126. doi: 10.1016/B978-0-12-385516-9.00001-6

Tanaka, A., Ogino, A., Iwaki, M., Hashimoto, K., Ohnuma, A., Amano, F., et al. (2012). Gold-Titanium(IV) oxide plasmonic photocatalysts prepared by a colloid-photodeposition method: correlation between physical properties and photocatalytic activities. Langmuir 28, 13105-13111. doi: 10.1021/la301944b

Tanaka, A., Sakaguchi, S., Hashimoto, K., and Kominami, H. (2014). Photocatalytic reactions under irradiation of visible light over gold nanoparticles supported on titanium(IV) oxide powder prepared by using a multi-step photodeposition method. Catal. Sci. Technol. 4, 1931-1938. doi: 10.1039/C4CY00042K

Tanase, S., Foltz, C., Gelder, R. D., Hage, R., Bouwman, E., and Reedijk, J. (2005). Control of the catalytic oxidations mediated by an oxo-bridged non-heme diiron complex: role of additives and reaction conditions. J. Mol. Catal. A Chem. 225, 161-167. doi: 10.1016/j.molcata.2004.09.002

Tanase, S., Marques-Gallego, P., Browne, W. R., Hage, R., Bouwman, E., Feringa, B. L., et al. (2008). Mechanistic implications of the active species involved in the oxidation of hydrocarbons by iron complexes of pyrazine-2-carboxylic acid. Dalton Trans. 2026-2033. doi: 10.1039/b716942f

Tang, X., Fang, L. L., and Huang, F. L. (2014). "Recent advance in green catalytic oxidation of alcohols to aldehydes and ketones with hydrogen peroxide as oxidant," in Modern Technologies in Materials, Mechanics and Intelligent Systems, Vol. 1049. eds X. Y. Huang, X. B. Zhu, K. L. Xu, and J. H. Wu (Baech: Trans Tech Publications), 158-166. doi: 10.4028/www.scientific.net/AMR.1049-1050.158

Tareq, S. S., Saiman, M. I., Hin, T. Y. Y., Abdullah, A. H., and Rashid, U. (2018). The impact of hydrogen peroxide as an oxidant for solventfree liquid phase oxidation of benzyl alcohol using Au-Pd supported carbon and titanium catalysts. Bull. Chem. React. Eng. Catal. 13, 373-385. doi: $10.9767 /$ bcrec.13.2.1204.373-385

Thompson, D. (1998). New advances in gold catalysis part I. Gold Bull. 31, 111-118. doi: 10.1007/BF03214775

Thompson, D. (1999). New advances in gold catalysis part II. Gold Bull. 32, 12-19. doi: $10.1007 / \mathrm{BF} 03214784$

Thompson, D. T. (2006). An overview of gold-catalysed oxidation processes. Top. Catal. 38, 231-240. doi: 10.1007/s11244-006-0021-x

Tofighi, G., Lichtenberg, H., Pesek, J., Sheppard, T. L., Wang, W., Schottner, L., et al. (2017). Continuous microfluidic synthesis of colloidal ultrasmall gold nanoparticles: in situ study of the early reaction stages and application for catalysis. React. Chem. Eng. 2, 876-884. doi: 10.1039/C7RE00114B

Tojo, G., and Fernández, M. (2006). Oxidation of Primary Alcohols to Carboxylic Acids: A Guide to Current Common Practice. New York, NY: Springer.

Torbina, V., Vodyankin, A., Ten, S., Mamontov, G., Salaev, M., Sobolev, V., et al. (2018). Ag-based catalysts in heterogeneous selective oxidation of alcohols: a review. Catalysts 8, 447. doi: 10.3390/catal8100447

Tran Thi Minh, N., Tran Que, C., Quach Thi Hoang, Y., Nguyen Thi, T., Nguyen Quoc, T., and Luu Tien, H. (2013). Preparation, characterisation and catalytic activity of gold nanoparticles supported on $\mathrm{Co}_{3} \mathrm{O}_{4}$. Int. J. Nanotechnol. 10, 334-342.

Tran, N. D., Besson, M., and Descorme, C. (2011). $\mathrm{TiO}_{2}$-supported gold catalysts in the catalytic wet air oxidation of succinic acid: influence of the preparation, the storage and the pre-treatment conditions. N. J. Chem. 35, 2095-2104. doi: $10.1039 /$ c1nj20160c 
Tsubota, S., Haruta, M., Kobayashi, T., Ueda, A., and Nakahara, Y. (1991). Preparation of highly dispersed gold on titanium and magnesium oxide. Stud. Surf. Sci. Catal. 63, 695-704. doi: 10.1016/S0167-2991(08)64634-0

Tsubota, S., Nakamura, T., Tanaka, K., and Haruta, M. (1998). Effect of calcination temperature on the catalytic activity of Au colloids mechanically mixed with $\mathrm{TiO}_{2}$ powder for $\mathrm{CO}$ oxidation. Catal. Lett. 56, 131-135. doi: 10.1023/A:1019069315071

Tsukuda, T., Tsunoyama, H., and Sakurai, H. (2011). Aerobic oxidations catalyzed by colloidal nanogold. Chem. Asian J. 6, 736-748. doi: 10.1002/asia.201000611

Tuzovskaya, I., Bogdanchikova, N., Simakov, A., Gurin, V., Pestryakov, A., Avalos, M., et al. (2007). Structure and electronic states of gold species in mordenites. Chem. Phys. 338, 23-32. doi: 10.1016/j.chemphys.2007.07.026

Varma, R. S. (2007). "Greener" chemical syntheses using mechanochemical mixing or microwave and ultrasound irradiation. Green Chem. Lett. Rev. 1, 37-45. doi: $10.1080 / 17518250701756991$

Veith, G. M. (2016). "X-ray photoelectron spectroscopy characterization of gold catalysts,"in Gold Catalysis: Preparation, Characterization and Applications, eds L. Prati and A. Villa (Singapore: Pan Stanford Publishing), 171-204. doi: 10.1201/b19911-8

Vigneron, F., and Caps, V. (2016). Evolution in the chemical making of gold oxidation catalysts. Comptes Rendus Chimie 19, 192-198. doi: 10.1016/j.crci.2015.11.015

Villa, A., Campisi, S., Mohammed, K. M. H., Dimitratos, N., Vindigni, F., Manzoli, M., et al. (2015a). Tailoring the selectivity of glycerol oxidation by tuning the acid-base properties of Au catalysts. Catal. Sci. Technol. 5, 1126-1132. doi: 10.1039/C4CY01246A

Villa, A., Campisi, S., Schiavoni, M., and Prati, L. (2013a). Amino alcohol oxidation with gold catalysts: the effect of amino groups. Materials 6, 2777-2788. doi: $10.3390 /$ ma6072777

Villa, A., Chan-Thaw, C. E., and Prati, L. (2010). Au NPs on anionic-exchange resin as catalyst for polyols oxidation in batch and fixed bed reactor. Appl. Catal. B Environ. 96, 541-547. doi: 10.1016/j.apcatb.2010.03.017

Villa, A., Dimitratos, N., Chan-Thaw, C. E., Hammond, C., Prati, L., and Hutchings, G. J. (2015b). Glycerol oxidation using gold-containing catalysts. Acc. Chem. Res. 48, 1403-1412. doi: 10.1021/ar500426g

Villa, A., Wang, D., Chan-Thaw, C. E., Campisi, S., Veith, G. M., and Prati, L. (2016). The confinement effect on the activity of Au NPs in polyol oxidation. Catal. Sci. Technol. 6, 598-601. doi: 10.1039/C5CY01593F

Villa, A., Wang, D., Su, D. S., and Prati, L. (2015c). New challenges in gold catalysis: bimetallic systems. Catal. Sci. Technol. 5, 55-68. doi: 10.1039/C4CY00976B

Villa, A., Wang, D., Veith, G. M., Vindigni, F., and Prati, L. (2013b). Sol immobilization technique: a delicate balance between activity, selectivity and stability of gold catalysts. Catal. Sci. Technol. 3, 3036-3041. doi: $10.1039 / \mathrm{c} 3 \mathrm{cy} 00260 \mathrm{~h}$

Vourros, A., Garagounis, I., Kyriakou, V., Carabineiro, S. A. C., MaldonadoHódar, F. J., Marnellos, G. E., et al. (2017). Carbon dioxide hydrogenation over supported Au nanoparticles: effect of the support. J. $\mathrm{CO}_{2}$ Utiliz. 19(Suppl. C), 247-256. doi: 10.1016/j.jcou.2017.04.005

Wan, J., Zhao, J., Zhu, M. Q., Dai, H., and Wang, L. (2011). "Selective oxidation of cyclohexane to cyclohexanone and cyclohexanol over $\mathrm{Au} / \mathrm{Co}_{3} \mathrm{O}_{4}$ catalyst," in Materials and Design, Pts 1-3, eds X. M. Sang, P. C. Wang, L. Ai, Y. G. Li and J. L. Bu (Baech: Trans Tech Publications), 284-286, 806. doi: 10.4028/www.scientific.net/AMR.284-286.806

Wang, C. H., Chen, L. F., and Qi, Z. W. (2013). One-pot synthesis of gold nanoparticles embedded in silica for cyclohexane oxidation. Catal. Sci. Technol. 3, 1123-1128. doi: $10.1039 / \mathrm{c} 2 \mathrm{cy} 20692 \mathrm{~g}$

Wang, C. Y., Liu, C. Y., Zheng, X., Chen, J., and Shen, T. (1998). The surface chemistry of hybrid nanometer-sized particles - I. Photochemical deposition of gold on ultrafine $\mathrm{TiO}_{2}$ particles. Colloids Surf. Physicochem. Eng. Aspects 131, 271-280. doi: 10.1016/S0927-7757(97)00086-1

Wang, D., Villa, A., Su, D., Prati, L., and Schloegl, R. (2013). Carbonsupported gold nanocatalysts: shape effect in the selective glycerol oxidation. ChemCatChem 5, 2717-2723. doi: 10.1002/cctc.201200535

Wang, D. H., Hao, Z. P., Cheng, D. Y., Shi, X. C., and Hu, C. (2003). Influence of pretreatment conditions on low-temperature $\mathrm{CO}$ oxidation over Au/ $\mathrm{MO}_{\mathrm{x}} / \mathrm{Al}_{2} \mathrm{O}_{3}$ catalysts. J. Mol. Catal. Chem. 200, 229-238. doi: 10.1016/S1381-1169(03)00007-4

Wang, H., Fan, W., He, Y., Wang, J., Kondo, J. N., and Tatsumi, T. (2013). Selective oxidation of alcohols to aldehydes/ketones over copper oxide-supported gold catalysts. J. Catal. 299, 10-19. doi: 10.1016/j.jcat.2012.11.018
Wang, J. C., Kondrat, S. A., Wang, Y. Y., Brett, G. L., Giles, C., Bartley, J. K., et al. (2015). Au-Pd nanoparticles dispersed on composite titania/graphene oxide-supports as a highly active oxidation catalyst. ACS Catal. 5, 3575-3587. doi: 10.1021 /acscatal.5b00480

Wang, L., Meng, X., and Xiao, F. (2010). Au nanoparticles supported on a layered double hydroxide with excellent catalytic properties for the aerobic oxidation of alcohols. Chinese J. Catal. 31, 943-947. doi: 10.1016/S1872-2067(09)60091-7

Wang, S., Yin, S. T., Chen, G. W., Li, L., and Zhang, H. (2016). Nearly atomic precise gold nanoclusters on nickel-based layered double hydroxides for extraordinarily efficient aerobic oxidation of alcohols. Catal. Sci. Technol. 6, 4090-4104. doi: 10.1039/C6CY00186F

Wang, X. M., Wu, G. J., Li, L. D., and Guan, N. J. (2011). "Preparation of $\mathrm{TiO}_{2}$ supported gold nano-clusters by photo-deposition," in Manufacturing Processes and Systems, Pts 1-2, eds X. H. Liu, Z. Y. Jiang, and J. T. Han (Baech: Trans Tech Publications), 148-149, 1258-1263. doi: 10.4028/www.scientific.net/AMR.148-149.1258

Wang, X. W., Wang, W. Y., Miao, Y. Q., Feng, G., and Zhang, R. B. (2016). Facet-selective photodeposition of gold nanoparticles on faceted $\mathrm{ZnO}$ crystals for visible light photocatalysis. J. Colloid Interface Sci. 475, 112-118. doi: 10.1016/j.jcis.2016.04.048

Wei, J. Y., Fan, G. F., Jiang, F., Zhang, Z. Z., and Zhang, L. (2010). Environmental factors and deactivation mechanism of Au/alpha- $\mathrm{Fe}_{2} \mathrm{O}_{3}$ catalyst during storage in ambient air. Chinese J. Catal. 31, 1489-1495. doi: 10.3724/SP.J.1088.2010.00618

Weissermel, K., and Arpe, H. J. (1993). Industrial Organic Chemistry. Weinheim:VCH Press.

Whyman, R. (2001). Applied Organometallic Chemistry and Catalysis. Oxford:Oxford University Press.

Wolf, A., and Schüth, F. (2002). A systematic study of the synthesis conditions for the preparation of highly active gold catalysts. Appl. Catal. A Gen. 226, 1-13. doi: 10.1016/S0926-860X(01)00772-4

World-Gold-Council (2003). Gold reference catalysts. Gold Bull. 36, 24-24. doi: 10.1007/BF03214864

Wu, J., Zhang, X., Yao, T. J., Li, J., Zhang, H., and Yang, B. (2010). Improvement of the stability of colloidal gold superparticles by polypyrrole modification. Langmuir 26, 8751-8755. doi: 10.1021/la904504d

Wu, P. P., Bai, P., Lei, Z. B., Loh, K. P., and Zhao, X. S. (2011a). Gold nanoparticles supported on functionalized mesoporous silica for selective oxidation of cyclohexane. Microporous Mesoporous Mater. 141, 222-230. doi: 10.1016/j.micromeso.2010.11.011

Wu, P. P., Bai, P., Loh, K. P., and Zhao, X. S. (2010). Au nanoparticles dispersed on functionalized mesoporous silica for selective oxidation of cyclohexane. Catal. Today 158, 220-227. doi: 10.1016/j.cattod.2010.03.027

Wu, P. P., Bai, P., Xia, W., Yang, X. J., Li, J., and Yan, Z. F. (2016a). Onepot synthesis of silica supported Au-Ag alloy nanoparticles for cyclohexane oxidation. Nanosci. Nanotechnol. Lett. 8, 972-977. doi: 10.1166/nnl.2016.2183

Wu, P. P., Bai, P., Yan, Z. F., and Zhao, G. X. S. (2016b). Gold nanoparticles supported on mesoporous silica: origin of high activity and role of Au NPs in selective oxidation of cyclohexane. Sci. Rep. 6:18817. doi: 10.1038/srep18817

Wu, P. P., Loh, K. P., and Zhao, X. S. (2011b). Supported gold catalysts for selective oxidation of organics. Sci. Adv. Mater. 3, 970-983. doi: 10.1166/sam.2011.1227

Wu, P. P., Xiong, Z. G., Loh, K. P., and Zhao, X. S. (2011c). Selective oxidation of cyclohexane over gold nanoparticles supported on mesoporous silica prepared in the presence of thioether functionality. Catal. Sci. Technol. 1, 285-294. doi: $10.1039 / \mathrm{c} 0 \mathrm{cy} 00025 \mathrm{f}$

Wu, X. C., Guo, S. W., and Zhang, J. Y. (2016). Au/graphene quantum dots/ferroferric oxide composites as catalysts for the solvent-free oxidation of alcohols. Mater. Lett. 183, 227-231. doi: 10.1016/j.matlet.2016.07.105

$\mathrm{Wu}, \mathrm{Y}$, Sun, K. Q., Yu, J., and Xu, B. Q. (2008). A key to the storage stability of $\mathrm{Au} / \mathrm{TiO}_{2}$ catalyst. Phys. Chem. Chem. Phys. 10, 6399-6404. doi: $10.1039 / \mathrm{b} 807040 \mathrm{~g}$

Xie, J., Wang, Y. J., and Wei, Y. (2009). Immobilization of manganese tetraphenylporphyrin on $\mathrm{Au} / \mathrm{SiO}_{2}$ as new catalyst for cyclohexane oxidation with air. Catal. Commun. 11, 110-113. doi: 10.1016/j.catcom.2009. 09.006

Xie, J. A., Wang, Y. J., Li, Y. T., and Wei, Y. (2011). Self-assembly preparation of $\mathrm{Au} / \mathrm{SiO}_{2}$ catalyst and its catalysis for cyclohexane oxidation with air. React. Kinet. Mech. Catal. 102, 143-154. doi: 10.1007/s11144-010-0246-3

Xie, X. Q., Long, J. L., Xu, J., Chen, L. M., Wang, Y., Zhang, Z. Z., et al. (2012). Nitrogen-doped graphene stabilized gold nanoparticles for 
aerobic selective oxidation of benzylic alcohols. RSC Adv. 2, 12438-12446. doi: 10.1039/c2ra21291a

Xu, L. X., He, C. H., Zhu, M. Q., and Fang, S. (2007a). A highly active $\mathrm{Au} / \mathrm{Al}_{2} \mathrm{O}_{3}$ catalyst for cyclohexane oxidation using molecular oxygen. Catal. Lett. 114, 202-205. doi: 10.1007/s10562-007-9058-0

Xu, L. X., He, C. H., Zhu, M. Q., Wu, K. J., and Lai, Y. L. (2007b). Silica-supported gold catalyst modified by doping with titania for cyclohexane oxidation. Catal. Lett. 118, 248-253. doi: 10.1007/s10562-007-9178-6

Xu, L. X., He, C. H., Zhu, M. Q., Wu, K. J., and Lai, Y. L. (2008). Surface stabilization of gold by sol-gel post-modification of alumina support with silica for cyclohexane oxidation. Catal. Commun. 9, 816-820. doi: 10.1016/j.catcom.2007.09.005

Xu, Q., Kharas, K. C. C., and Datye, A. K. (2003). The preparation of highly dispersed $\mathrm{Au} / \mathrm{Al}_{2} \mathrm{O}_{3}$ by aqueous impregnation. Catal. Lett. 85, 229-235. doi: 10.1023/A:1022106100033

Xu, X., Zhu, J., Faria, J. L., Li, J., and Figueiredo, J. L. (2012). Tuning the textural and surface properties of carbon xerogels to be used as supports for gold catalysts. Central Eur. J. Chem. 10, 1867-1874. doi: 10.2478/s11532-012-0106-2

Xu, Y. J., Landon, P., Enache, D., Carley, A., Roberts, M., and Hutchings, G. J. (2005). Selective conversion of cyclohexane to cyclohexanol and cyclohexanone using a gold catalyst under mild conditions. Catal. Lett. 101, 175-179. doi: 10.1007/s10562-005-4886-2

Xue, J. J., Ma, S. S., Zhou, Y. M., and Wang, Q. L. (2015). Au-loaded porous graphitic $\mathrm{C}_{3} \mathrm{~N}_{4}$ /graphene layered composite as a ternary plasmonic photocatalyst and its visible-light photocatalytic performance. RSC $A d v$. 5, 88249-88257. doi: 10.1039/C5RA17719G

Yang, Y. F., Sangeetha, P., and Chen, Y. W. (2009). Au/TiO 2 catalysts prepared by photo-deposition method for selective $\mathrm{CO}$ oxidation in $\mathrm{H}_{2}$ stream. Int. J. Hydrogen Energy 34, 8912-8920. doi: 10.1016/j.ijhydene.2009.08.087

Yogi, C., Kojima, K., Takai, T., and Wada, N. (2009). Photocatalytic degradation of methylene blue by Au-deposited $\mathrm{TiO}_{2}$ film under UV irradiation. J. Mater. Sci. 44, 821-827. doi: 10.1007/s10853-008-3151-7

Yu, H., Zhong, S., Zhu, B., Huang, W., and Zhang, S. (2017). Synthesis and $\mathrm{CO}$ oxidation activity of $1 \mathrm{D}$ mixed binary oxide $\mathrm{CeO}_{2}-\mathrm{LaO}_{x}$ supported gold catalysts. Nanoscale Res. Lett. 12:579. doi: 10.1186/s11671-017-2352-x

Yu, J., Li, J. Y., Wei, H. L., Zheng, J. W., Su, H. Q., and Wang, X. J. (2014). Hydrotalcite-supported gold catalysts for a selective aerobic oxidation of benzyl alcohol driven by visible light. J. Mol. Catal. Chem. 395, 128-136. doi: 10.1016/j.molcata.2014.08.023

Yu, X. Q., Huo, Y. J., Yang, J., Chang, S. J., Ma, Y. S., and Huang, W. X. (2013). Reduced graphene oxide supported Au nanoparticles as an efficient catalyst for aerobic oxidation of benzyl alcohol. Appl. Surf. Sci. 280, 450-455. doi: 10.1016/j.apsusc.2013.05.008

Yuan, Y. Z., Kozlova, A. P., Asakura, K., Wan, H. L., Tsai, K., and Iwasawa, Y. (1997). Supported Au catalysts prepared from Au phosphine complexes and As-precipitated metal hydroxides: characterization and low-temperature $\mathrm{CO}$ oxidation. J. Catal. 170, 191-199. doi: 10.1006/jcat.1997.1752

Zahoranova, T., Mori, T., Yan, P., Sevcikova, K., Vaclavu, M., Matolin, V., et al. (2015). Study of the character of gold nanoparticles deposited onto sputtered cerium oxide layers by deposition-precipitation method: influence of the preparation parameters. Vacuum 114, 86-92. doi: 10.1016/j.vacuum.2015.01.005

Zamaro, J. M., Boix, A. V., and Martinez-Hernandez, A. (2015). CO oxidation over Au supported on Mn-ZSM5 and Mn-MOR. Catal. Commun. 69, 212-216. doi: 10.1016/j.catcom.2015.06.018

Zanella, R., Delannoy, L., and Louis, C. (2005). Mechanism of deposition of gold precursors onto $\mathrm{TiO}_{2}$ during the preparation by cation adsorption and deposition-precipitation with $\mathrm{NaOH}$ and urea. Appl. Catal. Gen. 291, 62-72. doi: 10.1016/j.apcata.2005.02.045

Zanella, R., and Louis, C. (2005). Influence of the conditions of thermal treatments and of storage on the size of the gold particles in $\mathrm{Au} / \mathrm{TiO}_{2}$ samples. Catal. Today 107-108, 768-777. doi: 10.1016/j.cattod.2005.07.008

Zeng, S. J., Ding, S., Li, S. Y., Wang, R. W., and Zhang, Z. T. (2014). Controlled growth of gold nanoparticles in zeolite $\mathrm{L}$ via ion-exchange reactions and thermal reduction processes. Inorg. Chem. Commun. 47, 63-66. doi: 10.1016/j.inoche.2014.07.013

Zhan, G. W., Hong, Y. L., Lu, F. F., Ibrahim, A. R., Du, M. M., Sun, D. H., et al. (2013). Kinetics of liquid phase oxidation of benzyl alcohol with hydrogen peroxide over bio-reduced Au/TS-1 catalysts. J. Mol. Catal. Chem. 366, 215-221. doi: 10.1016/j.molcata.2012.09.026

Zhan, G. W., Huang, J. L., Du, M. M., Sun, D. H., Abdul-Rauf, I., Lin, W. S., et al. (2012). Liquid phase oxidation of benzyl alcohol to benzaldehyde with novel uncalcined bioreduction Au catalysts: high activity and durability. Chem. Eng. J. 187, 232-238. doi: 10.1016/j.cej.2012.01.051

Zhang, B., Fang, J., Li, J. G., Lau, J. J., Mattia, D., Zhong, Z. Y., et al. (2016). Soft, oxidative stripping of alkyl thiolate ligands from hydroxyapatite-supported gold nanoclusters for oxidation reactions. Chem. Asian J. 11, 532-539. doi: 10.1002/asia.201501074

Zhang, C. M., Liu, L. Q., Cui, X. J., Zheng, L. R., Deng, Y. Q., and Shi, F. (2013). Chlorine as an indicator in the controllable preparation of active nano-gold catalyst. Sci. Rep. 3:7. doi: 10.1038/srep01503

Zhang, L., Xie, Z. X., and Gong, J. L. (2016). Shape-controlled synthesis of Au-Pd bimetallic nanocrystals for catalytic applications. Chem. Soc. Rev. 45, 3916-3934. doi: 10.1039/C5CS00958H

Zhang, X., and Ding, Y. (2013). Unsupported nanoporous gold for heterogeneous catalysis. Catal. Sci. Technol. 3, 2862-2868. doi: 10.1039/c3cy00241a

Zhang, X. G., Ke, X. B., and Zhu, H. Y. (2012). Zeolite-supported gold nanoparticles for selective photooxidation of aromatic alcohols under visiblelight irradiation. Chem. Eur. J. 18, 8048-8056. doi: 10.1002/chem.201 200368

Zhao, H., Zhou, J. C., Huang, C. Q., and Li, D. H. (2005). Reactivity and stability of Au/TS-1 for the liquid-phase oxidation of cyclohexane. Abstracts Pap. Am. Chem. Soc. 230:U2231.

Zhao, J. B., and Jin, R. C. (2018). Heterogeneous catalysis by gold and gold-based bimetal nanoclusters. Nano Today 18, 86-102. doi: 10.1016/j.nantod.2017.12.009

Zhao, M., Li, J., Song, Z., Desmond, R., Tschaen, D. M., Grabowski, E. J. J., et al. (1998). A novel chromium trioxide catalyzed oxidation of primary alcohols to the carboxylic acids. Tetrahedron Lett. 39, 5323-5326. doi: 10.1016/S0040-4039(98)00987-3

Zhao, P. X., Li, N., and Astruc, D. (2013). State of the art in gold nanoparticle synthesis. Coord. Chem. Rev. 257, 638-665. doi: 10.1016/j.ccr.2012. 09.002

Zhao, R., Ji, D., Lv, G. M., Qian, G., Yan, L., Wang, X. L., et al. (2004). A highly efficient oxidation of cyclohexane over Au/ZSM-5 molecular sieve catalyst with oxygen as oxidant. Chem. Commun. 904-905. doi: 10.1039/b31 $5098 \mathrm{~d}$

Zhou, C. H. C., Beltramini, J. N., Fan, Y. X., and Lu, G. Q. M. (2008). Chemoselective catalytic conversion of glycerol as a biorenewable source to valuable commodity chemicals. Chem. Soc. Rev. 37, 527-549. doi: $10.1039 /$ B $707343 \mathrm{G}$

Zhou, J. C., Yang, X. F., Wang, Y. Q., and Chen, W. J. (2014). An efficient oxidation of cyclohexane over $\mathrm{Au} @ \mathrm{TiO}_{2} / \mathrm{MCM}-41$ catalyst prepared by photocatalytic reduction method using molecular oxygen as oxidant. Catal. Commun. 46, 228-233. doi: 10.1016/..catcom.2013.12.026

Zhu, J., Carabineiro, S. a. C., Shan, D., Faria, J. L., Zhu, Y., and Figueiredo, J. L. (2010). Oxygen activation sites in gold and iron catalysts supported on carbon nitride and activated carbon. J. Catal. 274, 207-214 doi: $10.1016 /$ j.jcat.2010.06.018

Zhu, K. K., Hu, J. C., and Richards, R. (2005). Aerobic oxidation of cyclohexane by gold nanoparticles immobilized upon mesoporous silica. Catal. Lett. 100, 195-199. doi: 10.1007/s10562-004-3454-5

Zope, B. N., Hibbitts, D. D., Neurock, M., and Davis, R. J. (2010). Reactivity of the gold/water interface during selective oxidation catalysis. Science 330, 74-78. doi: 10.1126/science. 1195055

Conflict of Interest: The author declares that the research was conducted in the absence of any commercial or financial relationships that could be construed as a potential conflict of interest.

Copyright (๑) 2019 Carabineiro. This is an open-access article distributed under the terms of the Creative Commons Attribution License (CC BY). The use, distribution or reproduction in other forums is permitted, provided the original author $(s)$ and the copyright owner(s) are credited and that the original publication in this journal is cited, in accordance with accepted academic practice. No use, distribution or reproduction is permitted which does not comply with these terms. 